\title{
A Study of the Effects of Altitude on Thermal Ice Protection System Performance
}

\author{
Harold E. Addy, Jr. ${ }^{1}$ and Andy P. Broeren ${ }^{2}$ \\ NASA Glenn Research Center, Cleveland, Ohio 44135 \\ Myron Oleskiw ${ }^{3}$ and David Orchard ${ }^{4}$ \\ National Research Council Canada, Ottawa, Ontario, Canada
}

\begin{abstract}
A study of the effects of altitude on an aircraft thermal ice protection system (IPS) performance was conducted. The study included tests of an airfoil model, with a heated-air IPS installed, in an altitude icing wind tunnel at altitude and at ground level conditions. An altitude scaling method was used to simulate the altitude icing conditions at ground level. The study allowed thermal and mass transfer phenomena to be examined. Three different flight scenarios were tested: Descent, Cold Hold, and Warm Hold. The test results showed that heat transfer was accurately simulated using the scaling method. Results of the mass transfer, in terms of amount of ice accreted, were less conclusive, but indicated that mass transfer was not as well matched.
\end{abstract}

\section{Nomenclature}

c $\quad=$ model chord

$d \quad=$ twice the model leading edge radius

IPS $=$ ice protection system

$\mathrm{K} \quad=$ inertia parameter

$\mathrm{K}_{0} \quad=$ modified inertia parameter

LWC = liquid water content

$\mathrm{M} \quad=$ Mach number

MVD = median volumetric diameter

$\mathrm{M}_{\mathrm{w}} \quad=$ water loading

$\operatorname{Pr} \quad=$ Prandtl number

qdot $=$ power density

$r \quad=$ recovery factor

$\operatorname{Re} \quad=$ Reynolds number

$\operatorname{Re}_{\mathrm{d}} \quad=$ Reynolds number based on droplet diameter

$\mathrm{s} \quad=$ surface distance

$\mathrm{T}_{\mathrm{r}} \quad=$ recovery temperature

$\mathrm{T}_{\text {st }} \quad=$ static temperature

$\mathrm{V}_{\text {tas }} \quad=$ true air speed

$\gamma \quad=$ ratio of specific heats for air

$\mu_{\text {air }} \quad=$ air viscosity

$\rho_{\text {air }} \quad=$ air density

$\rho_{\mathrm{w}} \quad=$ water density

$\beta_{0} \quad=$ collection efficiency at stagnation

$\lambda / \lambda_{\text {stokes }}=$ droplet range parameter

$\delta \quad=$ droplet median volumetric diameter

${ }_{1}^{1}$ Aerospace Engineer, Icing Branch, 21000 Brookpark Rd., MS 11-2, AIAA Associate Fellow.

2 Aerospace Engineer, Icing Branch, 21000 Brookpark Rd., MS 11-2, AIAA Associate Fellow.

${ }^{3}$ Senior Research Officer, NRC Aerospace, 1200 Montreal Rd., Bldg. M-2, Ottawa, Ontario, Canada.

${ }^{4}$ Senior Research Officer, NRC Aerospace, 1200 Montreal Rd., Bldg. M-2, Ottawa, Ontario, Canada. 


\section{Background}

$\mathrm{T}_{\mathrm{f}}$ HERMAL IPSs use heat energy to prevent the buildup of potentially dangerous ice accretions on aircraft when flying in icing conditions. That heat energy must be supplied by the aircraft. As new aircraft are being designed for higher efficiencies, all energy-using systems on the aircraft are being re-examined with an eye toward reducing their energy needs, including thermal IPSs. A thermal anti-icing IPS is designed to evaporate all water impinging on critical exposed surfaces of an aircraft during flight in even the most extreme conditions. This mode of operation is, however, quite energy-intensive. One way in which energy requirements can be greatly reduced is if, under the more severe icing conditions, a thermal IPS is designed to warm the impinging water only enough to allow it to run completely off the aircraft or back to a noncritical area before freezing. Such operation, however, requires that energy requirements be more accurately calculated and evaluated. These energy requirements must account for the many aspects of the aircraft icing process including air temperature, air speed, cloud water content, as well as aircraft altitude. While the effects of altitude, in particular reduced air density and pressure, have always been taken into account in the design of thermal IPSs, a better understanding of these effects is needed so as to enable more exact design, testing, and evaluation of these systems.

Current methods to calculate the heat energy and mass transfer involved with thermal IPS operation are based on empirical relations. Heat transfer coefficients are typically derived from experiments designed to measure heat transfer from flat plates or cylinders. By similarity, the mass transfer coefficient is then assumed to be a function of the heat transfer coefficient. While these approximations have been adequate in the past, a more rigorous validation is needed if accuracy is to be increased, particularly when scaling is applied to account for the effects of altitude.

For these reasons, the National Aeronautics and Space Administration (NASA) and the National Research Council Canada (NRCC) have undertaken an investigation of thermal IPS operation. This study is the first conducted specifically to better understand the effects of altitude on the heat and mass transfer processes occurring during operation of a thermal IPS in flight icing conditions. NRCC provided test time in the Altitude Icing Wind Tunnel (AIWT) in Ottawa, Canada. This facility provided aircraft inflight icing conditions over a range of air speeds, temperatures, and pressure altitudes as well as inflight icing cloud liquid water contents and droplet size spectra. NASA provided a NACA airfoil model equipped with a piccolo tube heated-air IPS. The model was instrumented such that heated-air flow rates and temperatures could be measured and inner surface temperatures of the model's leading edge could be monitored.

\section{A. Prior Research}

Although no studies directly comparing the performance of a thermal IPS operating at altitude with its performance at ground level conditions have been reported, various aircraft icing research efforts have been conducted in the past that are of interest to the current study. These include the development of scaling methods for icing of unprotected surfaces, heat transfer studies, and ground level tests of thermal IPSs.

Aircraft icing scaling methods for unprotected surfaces have been in development for a number of years. These methods include both geometric scaling for icing tests of subscale models and icing condition scaling for icing wind tunnel tests where a particular test point or points do not fall within the icing envelope that can be produced by the tunnel. Anderson, ${ }^{1}$ Kind and Oleskiw, ${ }^{2}$ and Bartlett ${ }^{3}$ provide descriptions and evaluations of these methods. While the addition of a relatively large source of heat by a thermal IPS to the icing processes is a major difference, these methods developed for unprotected surfaces can be used as a basis for similar research directed toward surfaces with a thermal IPS. The scaling method employed in this study used select parameters from these methods and are noted in the background section below.

Heat transfer is an important aspect of aircraft icing and has been the focus of a number of studies. In particular, air turbulence level and the transition from laminar to turbulent flow dramatically affect icing, particularly at nearfreezing temperatures. This is of particular concern when testing in icing wind tunnels where turbulence levels are typically well above those observed in flight. Research conducted by Newton, et al., ${ }^{4}$ provided important information on heat transfer in flight. That research was further extended to an icing tunnel by Poinsatte, et al. ${ }^{5}$ Important conclusions from this research were that, while the turbulence levels measured in the icing tunnel were 5 to 7 or more times as high as that in flight, there was good agreement in heat transfer between flight and tunnel tests at the lower Reynolds number conditions and only a slight increase in heat transfer at the higher Reynolds number conditions. Moreover, the increase in icing tunnel turbulence due to the addition of spray bar air did not change heat transfer over the tunnel operating without spray bar air. A later study by Bragg, et al. ${ }^{6}$ concluded that the addition of water to the spray did not appreciably change tunnel turbulence over that with the spray bar air only. These studies indicate that icing tunnel turbulence should not be a major factor in the current study. 
Miller, Wright, and Al-Khali1 ${ }^{7-9}$ conducted tests in the NASA Icing Research Tunnel using an electro-thermal IPS directed toward validating NASA thermal IPS simulation codes. This effort found that the codes were fairly accurate in predicting airfoil surface temperatures when operating an airfoil model with IPS in icing conditions. It was noted that water evaporation and its effect on surface heat and mass transfer is important, as it is in this study, and warranted further research.

\section{B. Facility Description}

The AIWT is a specialized closed-loop low to moderate speed wind tunnel used to simulate in-flight atmospheric icing conditions (see plan view in Fig. 1). It is employed for internal research, for collaboration with other research organizations, and to assist commercial clients with:

- Development, testing or calibration of aircraft or cloud physics instrumentation;

- Development and testing of de- and anti-icing systems;

- Evaluation of ice accretion on non-protected aircraft components;

- Validation of numerical ice accretion codes;

- Studies on basic physical processes leading to ice accretion.

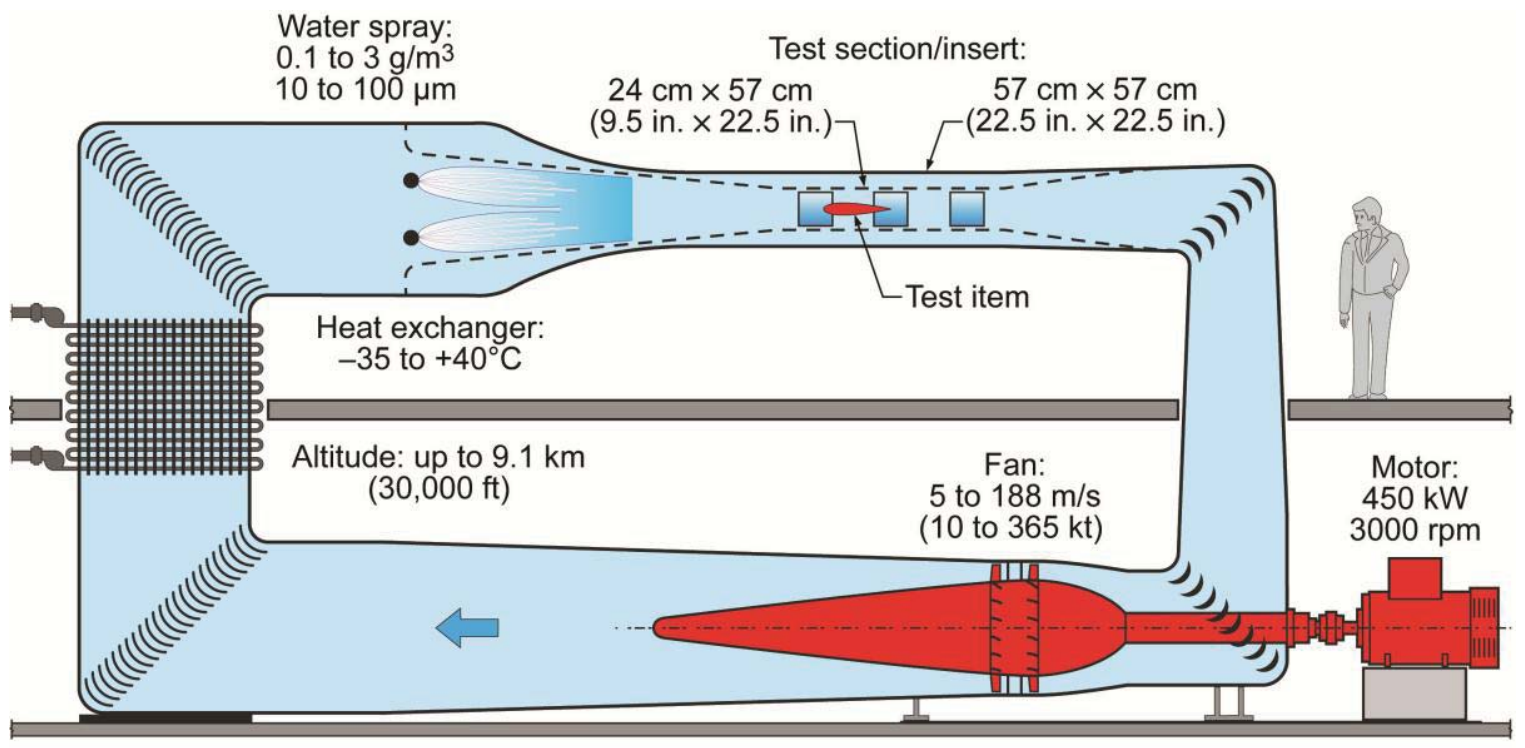
Figure 1. A cross-sectional view of the National Research Council Canada (NRCC) Altitude Icing Wind
Tunnel (AIWT).

The tunnel's standard test section is 22.5 inches square and $6 \mathrm{ft}$ long. The airspeed in this test section can vary from about 10 to $195 \mathrm{kts}$. Two inserts are available to reduce the height of the test section and thus increase the airspeed. The first insert reduces the height to 12 inches and leads to a maximum speed of $320 \mathrm{kts}$. The second insert further reduces the height to 10 inches with a corresponding maximum airspeed of $365 \mathrm{kts}$. Access panels in the tunnel walls, floor and ceiling provide rapid access to test articles as well as flexibility in their mounting in the test section. Plexiglas windows are commonly installed in the test section to enable photographic or video recording of ice formation and growth. Airspeed in the tunnel is computer-controlled using a variable frequency drive which provides power to the fan's $600 \mathrm{hp}$ motor. Test section flow uniformity and a relatively low turbulence level are enhanced through the use of a honeycomb structure and screen at the entry of the settling chamber. Figure 2 shows a view of the AIWT test section with the operator's console.

A heat exchanger located upstream of the tunnel's settling chamber permits rapid changes of air temperature within the test section. The use of a three-way valve to control the flow of chilled trichloroethylene through the heat exchanger permits a high level of temporal stability of air temperature in the tunnel. The closed cell insulation surrounding the tunnel shell assists in the ability to obtain static air temperatures as low as $-30{ }^{\circ} \mathrm{F}\left(-34.4{ }^{\circ} \mathrm{C}\right)$. A thick steel tunnel shell combined with the operation of vacuum pumps permits partial evacuation of the air from the tunnel to simulate flight at altitudes as high as $30,000 \mathrm{ft}$. 


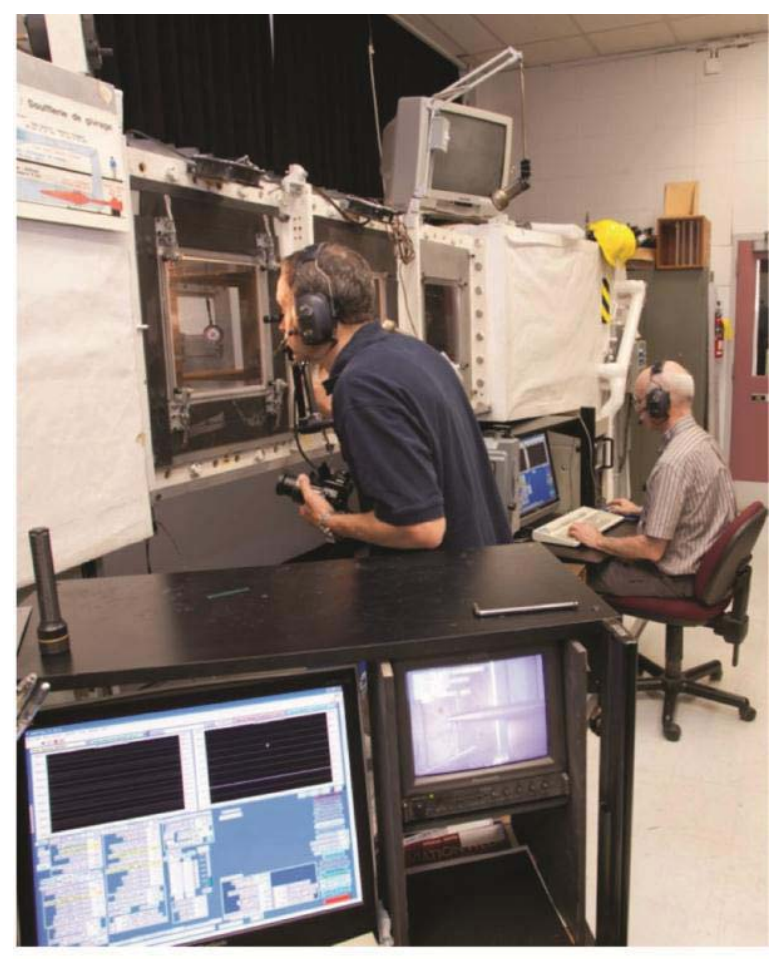

Figure 2. The AIWT test section with the operator's console in the foreground.

Six spray bars are located at the entry to the settling chamber, just downstream of the turbulence-reduction screens. Up to 5 of 7 spray nozzles in each spray bar may be selected at any one time in various patterns to ensure adequate spray coverage across the test section. By varying the flow rate of distilled water to the external-mix spray nozzles, the liquid water content (LWC) in the test section may be varied between 0.1 and $3.0 \mathrm{~g} / \mathrm{m}^{3}$. Controlling the spray air pressure permits the median volumetric diameter (MVD) of the spray droplet size distribution to vary between 10 and $100 \mu \mathrm{m}$. Additional details regarding the tunnel are provided in Oleskiw, et al. ${ }^{10}$

\section{Model Description}

The airfoil model used for this study was an 18-inch chord NACA-0018. A symmetric airfoil was selected for this fundamental study primarily because it reduces the number of complicating factors in the test. A NACA-0012 airfoil was originally considered, largely because it has been extensively and successfully used in many previous fundamental studies of aircraft icing physics. The size of the AIWT test section, however, limits the size of the model to about 18 inches in chord length. For a NACA-0012, an 18-inch chord results in a leading edge that is too narrow to allow installation of both a thermal IPS and measurement instruments. A hybrid airfoil was considered which would have incorporated a 36-inch chord NACA-0012 leading edge and truncated aft body to result in airfoil with an 18-inch chord. Such a hybrid airfoil, however, results in aerodynamics over the aft portion which might affect ice formed by water running aft along the airfoil surface, known as runback ice. This was undesirable for this study, so the hybrid design was not used. Instead, a NACA-0018 airfoil was chosen. It is a symmetric airfoil with a wider leading edge, allowing more space for installation of a thermal IPS and measurement instruments. Its leading edge also closely matches that of a 36-inch chord NACA-0012, as shown in Fig. 3.

The 2D, straight wing model spanned the 22.5 inch wide AIWT from wall to wall. It was constructed of a 0.063 inch thick 7075-T6 aluminum skin on a 0.625 inch thick, 7075 aluminum rib and spar frame. There were two ribs, one at each end, and two spars, near airfoil maximum thickness, as shown in Fig. 4. The trailing edge was also machined from 7075 aluminum. 
Figure 3. 18-inch chord NACA-0018 airfoil compared with a 36-inch chord NACA-0012 airfoil.

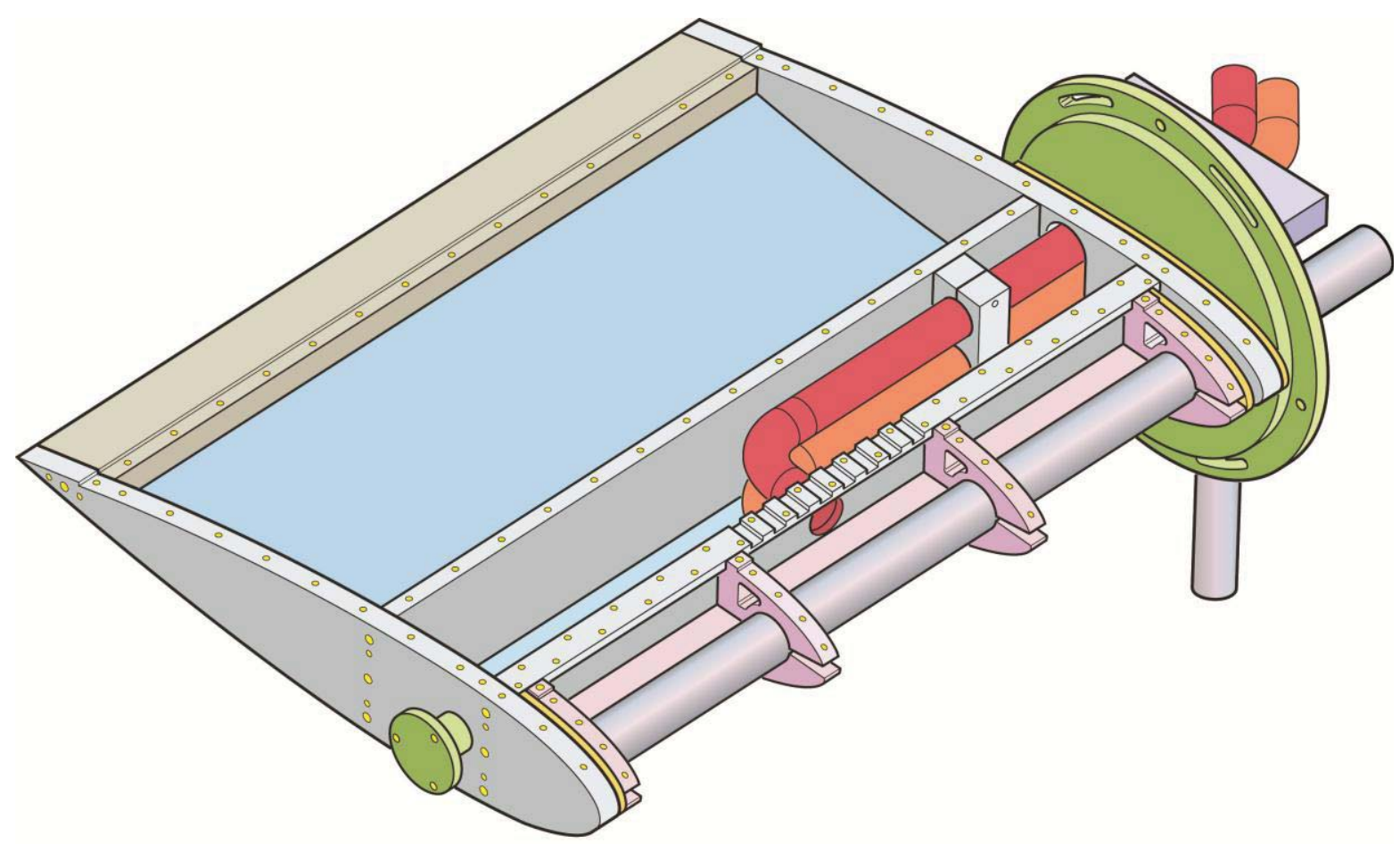

Figure 4. Model rib and spar layout with piccolo tube ice protection system (IPS) shown.

A heated-air piccolo tube IPS was designed for the model. The primary objective of the design was to provide a 2D heating system with minimal span-wise variation in the temperature and heat transfer profiles during testing. This would simplify modeling and analysis of the measurements. For these reasons, the forward edge of the fullspan piccolo tube was located 1.25 inches from the inside of the leading edge and had a single, straight row of 42 , 0.032-inch diameter holes spaced 31/64 inches apart. A steel diffuser was designed to direct the heated airflow to and around the inside of the leading edge. Four aluminum ribs were used to maintain the diffuser shape. A cross section of the leading edge of the airfoil showing the IPS design is shown in Fig. 5.

Heated air was supplied to one end of the piccolo tube where it was directed to the inner surface of the leading edge via small holes. The heated air was then directed along the inner surface of the leading edge by a symmetric diffuser. The heated air exited the model through exhaust pipes mounted to a spar at the aft of the leading edge. The heated exhaust air flowing from the upper surface was kept separate from that flowing from the lower surface by a horizontal wall extending from the aft of the piccolo tube to the spar. Each of these two exhaust flows were measured by a Coriolis flow meter located in the respective exhaust pipe. Manual valves situated downstream of the flow meters were adjusted to ensure proper flow rates maintained equal heating to both the upper and lower surfaces of the leading edge.

Thermocouples were used to measure model surface and heated air temperatures. A total of 25 thin film (0.0005 inch thick), T-type thermocouples were installed on the inner surface of the leading edge using a thin layer (approximately 0.002 inches thick) of thermally-conductive epoxy (M-Bond). The layout of the thermocouples on the leading edge is shown in Fig. 6. 


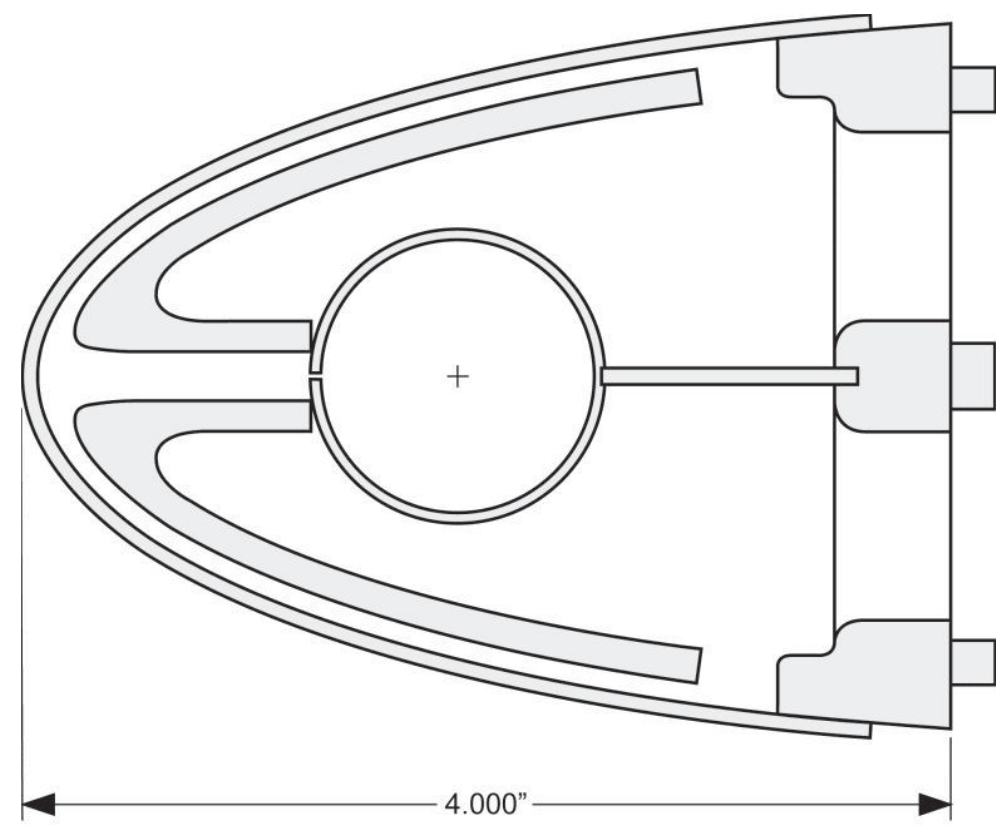

Figure 5. Model leading edge cross section.

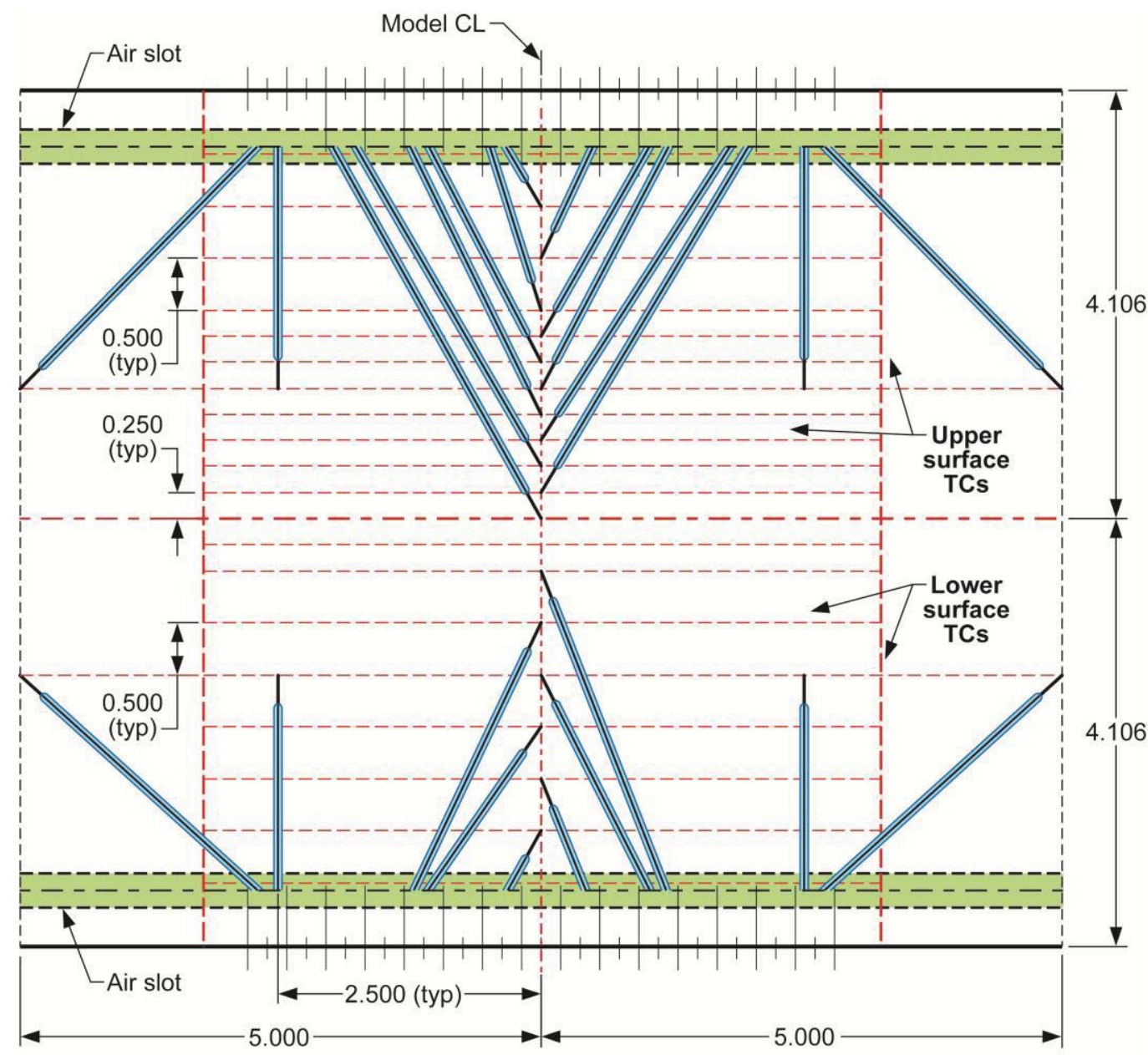

Figure 6. Leading edge inner surface thermocouple locations.

American Institute of Aeronautics and Astronautics 


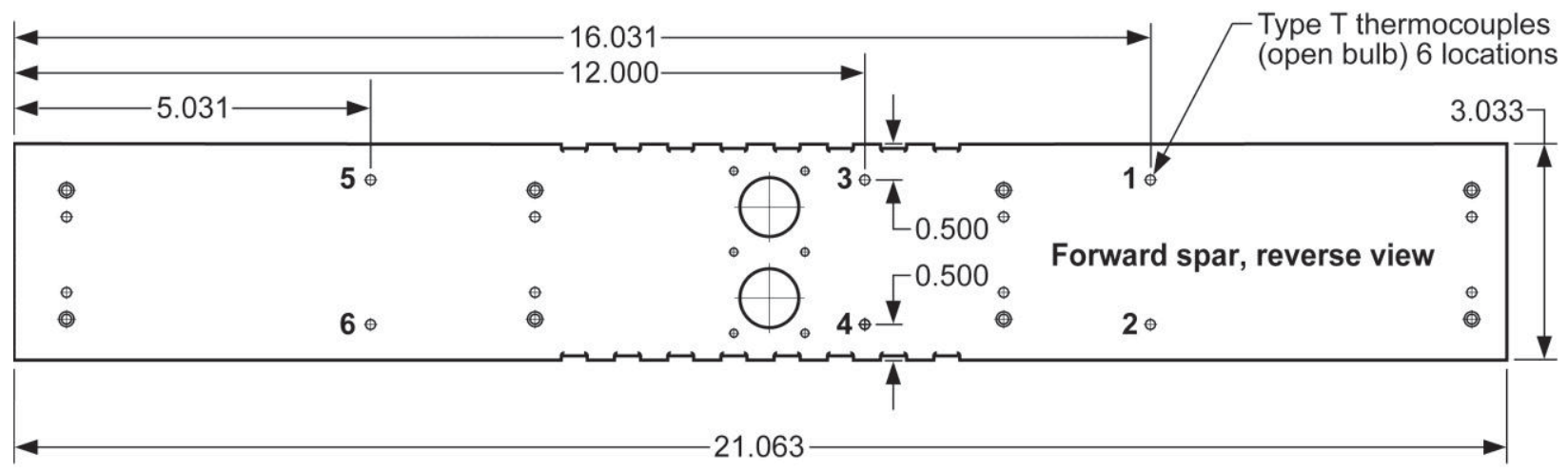

Figure 7. Heated air exhaust thermocouple locations.

Three T-type thermocouples were used to monitor the temperature of the heated air flowing into the model. One was at the entrance to the piccolo tube while two were spaced axially along the center of the tube using a rod device that was inserted into the end of the piccolo tube. Heated air exhaust temperatures were measured using six T-type thermocouples mounted through the front spar as shown in Fig. 7.

\section{Approach}

\section{A. Test Plan}

Icing conditions were selected to approximate three different aircraft icing scenarios at altitude: an aircraft hold at relatively low icing air temperature (Cold Hold), a hold at relatively warm icing temperature (Warm Hold), and a descent at intermediate icing temperature (Descent). These conditions are given in Table 1 and will be referred to as reference conditions throughout the remainder of this report. IPS heated air flow rates and temperatures were set to provide a 'running wet' mode of operation for the ice protection. In this mode, all the water impinging on the leading edge of the model is not evaporated. Some is allowed to flow aft before freezing in an area that is presumably less critical to the model's aerodynamics. For the purposes of this test, however, aerodynamic criticality was not a primary consideration. Instead, the heat and mass transfer phenomena involved in the accretion of ice in conjunction with a heat source (a thermal IPS), is the focus of this study.

The test plan also included runs without the IPS operating. These runs provided data in terms of unprotected ice accretion shapes and masses that could be used for post-test analysis and comparison purposes.

Table 1. Reference conditions.

\begin{tabular}{cccccccc}
\hline \hline Flight Phase & $\begin{array}{c}\text { Altitude, } \\
\mathbf{f t}\end{array}$ & $\begin{array}{c}\mathbf{V}_{\text {tas, }} \\
\mathbf{k t s}\end{array}$ & $\begin{array}{c}\mathbf{A O A}, \\
\mathbf{d e g}\end{array}$ & $\begin{array}{c}\mathbf{T}_{\text {static, }}, \\
{ }^{\circ} \mathbf{F}\end{array}$ & $\begin{array}{c}\mathbf{T}_{\text {total, }}, \\
{ }^{\circ} \mathbf{F}\end{array}$ & $\begin{array}{c}\mathbf{L W C}, \\
\mathbf{g} / \mathbf{m}^{\mathbf{3}}\end{array}$ & $\begin{array}{c}\text { MVD, } \\
\boldsymbol{\mu m}\end{array}$ \\
\hline Descent & 10000 & 180 & 0 & -4.0 & 3.7 & 0.15 & 20 \\
Cold Hold & 15000 & 180 & 0 & -22.0 & -14.3 & 0.15 & 20 \\
Warm Hold & 15000 & 180 & 0 & 16.5 & 24.2 & 0.50 & 20 \\
\hline \hline
\end{tabular}

\section{B. Scaling Method}

In addition to the three aircraft icing scenarios at altitude, three corresponding icing conditions at ground level were selected for the test. Because the heat and mass transfer associated with the icing process in the presence of a thermal IPS are known to be affected by air density and pressure, a method to scale for these effects was employed. This method matched the following four parameters at altitude and ground level for each of the three scenarios in the test:

1. External Reynolds number

2. Water loading

3. Modified droplet inertia parameter

4. Recovery temperature 
Empirical analysis has most often found that the heat transfer coefficient is typically a function of the external Reynolds number. Since, by similarity, the mass transfer coefficient is a function of the heat transfer coefficient; both coefficients are dependent on Reynolds number. It follows then, that to obtain similar results at altitude and ground level, the external Reynolds number must be the same for both reference and scale cases. For this study, the following expression for Reynolds number was used: ${ }^{1}$

$$
\operatorname{Re}=\frac{\rho_{\mathrm{air}} \cdot V_{\mathrm{tas}} \cdot d}{\mu_{\mathrm{air}}}
$$

The amount of water impinging on the leading edge of a model in icing conditions also has a major effect on the ice that forms. Therefore, it is important to maintain the amount of water impinging on the model at the same level for both the altitude and ground level cases. The following expression for water loading was used: ${ }^{1}$

$$
M_{\mathrm{w}}=\mathrm{LWC} \cdot V_{\mathrm{tas}} \cdot \beta_{0}
$$

The area of coverage of the impinging water should also be the same between altitude and ground level. This was achieved by matching the modified droplet inertia parameter: ${ }^{1}$

$$
K_{0}=\frac{1}{8}+\frac{\lambda}{\lambda_{\text {Stokes }}}\left(K-\frac{1}{8}\right)
$$

where

$$
K=\frac{\rho_{w} \cdot \delta^{2} \cdot V_{\mathrm{tas}}}{18 d \mu_{\mathrm{air}}}
$$

air

$$
\frac{\lambda}{\lambda_{\text {Stokes }}}=\frac{1}{0.8388+0.001483 \operatorname{Re}_{\delta}+0.1847 \sqrt{\operatorname{Re}_{\delta}}}
$$

Air temperature also plays a major role in ice formation. Because matching external Reynolds number between altitude and ground level conditions results in a very different airspeed for the two, it then follows that both total air temperature and static air temperature cannot be matched. For unprotected surfaces, total air temperature is a driving factor, with static air temperature playing a lesser role. In a running wet situation, where the ice forms further aft on the airfoil, static air temperature may play a greater role. Therefore, for this test, it was decided to match recovery temperature, which is between total and static air temperature, but is closer to total.

$$
T_{r}=T_{s t}\left(1+r\left(\frac{\gamma-1}{2}\right) M^{2}\right)
$$

where

$$
r=\sqrt{P r}
$$

The scaled conditions for each of the three flight scenarios along with the corresponding conditions at altitude (reference) are given in Table 2 and will be referred to as scale conditions throughout the remainder of this report.

The reason for this approach was twofold: a) it permitted a close examination of the heat and mass transfer as well as the associated assumptions involved and b) it will aid in the development of altitude scaling methods for icing tests where altitude simulation is not available. 
Table 2. Reference and corresponding scale conditions.

\begin{tabular}{|c|c|c|c|c|c|c|c|c|c|c|c|}
\hline Flight Phase & $\begin{array}{c}\text { Alt., } \\
\text { ft }\end{array}$ & $\begin{array}{l}\mathrm{V}, \\
\text { kts }\end{array}$ & $\begin{array}{c}\text { AOA, } \\
\text { deg }\end{array}$ & $\begin{array}{c}\mathbf{T}_{\text {static }}, \\
{ }^{\circ} \mathbf{F}\end{array}$ & $\begin{array}{c}\mathbf{T}_{\text {total, }} \\
{ }^{\circ} \mathbf{F}\end{array}$ & $\begin{array}{c}\mathbf{L W C}, \\
\mathrm{g} / \mathrm{m}^{3}\end{array}$ & $\begin{array}{c}\text { MVD, } \\
\mu \mathrm{m}\end{array}$ & $\begin{array}{l}\mathbf{R e}_{\mathrm{d}} \\
\times 10^{6}\end{array}$ & $\begin{array}{c}M_{w} \\
g / m^{2}-s\end{array}$ & $\bar{~} \mathbf{K}_{0}$ & $\begin{array}{l}\mathbf{T}_{\mathrm{r}}, \\
{ }^{\circ} \mathbf{F}\end{array}$ \\
\hline \multirow{2}{*}{$\begin{array}{c}\text { Descent(ref) } \\
(\mathrm{sc})\end{array}$} & \multirow{2}{*}{10000} & 180 & 0 & -4.0 & 3.7 & 0.15 & 20.0 & 1.64 & 8.81 & 1.41 & 2.5 \\
\hline & & 130 & 0 & -0.9 & 3.1 & 0.21 & 24.5 & 1.64 & 8.81 & 1.41 & 2.5 \\
\hline \multirow{2}{*}{$\begin{array}{l}\text { Cld Hld(ref) } \\
\text { (sc) }\end{array}$} & \multirow[t]{2}{*}{15000} & 180 & 0 & -22.0 & -14.3 & 0.15 & 20.0 & 1.40 & 9.02 & 1.52 & -15.5 \\
\hline & & 106 & 0 & -17.8 & -15.1 & 0.25 & 27.8 & 1.40 & 9.02 & 1.52 & -15.5 \\
\hline \multirow{2}{*}{$\begin{array}{l}\text { Wm Hld(ref) } \\
\text { (sc) }\end{array}$} & \multirow[t]{2}{*}{15000} & 180 & 0 & 16.5 & 24.2 & 0.50 & 20.0 & 1.29 & 30.0 & 1.50 & 23.0 \\
\hline & & 105 & 0 & 20.8 & 23.4 & 0.85 & 27.8 & 1.29 & 30.0 & 1.50 & 23.0 \\
\hline
\end{tabular}

\section{Test Procedure}

Estimates for the thermal IPS's heated air temperature and flow rate were made using past test experience and LEWICE predictions. These values were then adjusted slightly during checkout runs at the reference conditions to obtain runback ice shapes that were judged to be desirable for both recording and computational modeling purposes. The desired ice shape was a runback ridge of ice running continuously across the span of the leading edge of the airfoil. This ice shape can be predicted by 2D ice accretion codes such as LEWICE2D and can be traced on a template fit over the leading edge of the model in the tunnel. The IPS settings determined during checkout runs at the reference conditions were then also used for the scaled conditions.

For each test run, the AIWT was first brought to the desired airspeed and air temperature. For the reference runs, AIWT pressure was set to obtain the desired altitude value. The model IPS operating conditions were also set at the predetermined settings. Once the tunnel and the model had reached steady-state operating conditions, the tunnel's water spray system was activated, exposing the model to icing conditions for a predetermined period of time.

At the conclusion of each test run, photographs were taken of the accreted ice and ice tracings were made to record the shape and location of the ice on the airfoil. Ice depth measurements were also made and then the ice was removed from the model and weighed. Three ice tracings were typically made for each ice accretion; one at the midspan of the model and one each at 5.25 inches on either side of mid-span. This covered an area of relatively uniform LWC for most clouds used in these tests. Since the ice was cut at these locations, the ice mass values reported, unless otherwise noted, are for the ice accreted over the center 10.5 inches of the model. Results of the tests will be discussed in terms of these measurements as well as the model leading edge temperatures and heated air flow rates and temperatures.

Model and heated air thermocouples were calibrated before and after the tests and were found to be within $\pm 1{ }^{\circ} \mathrm{C}$. The heated air flow meters were recalibrated after the tests and were found to be accurate to $\pm 1 \%$. A rootmean-squared error analysis of the heated-air power density calculations yields less than two percent error. The error in ice depth and mass measurements can only be approximated as the techniques used were highly manual. Repeat measurements of ice accreted without the IPS operating indicated that they were likely to be within $\pm 10 \%$.

\section{Pre-test LEWICE Study}

Prior to running the tests at the AIWT, the LEWICE ${ }^{11}$ ice accretion code was used to predict the resulting ice shapes using the test conditions to help ensure that the approach and methods employed were sound. Figures 8-10 show the LEWICE results from the Descent, Cold Hold, and Warm Hold cases, respectively, for both the altitude and ground level conditions. The close agreement indicates that the scaling method is promising. It should be noted that results from this code using the thermal IPS simulation capability are highly dependent upon how the surface grid and boundary conditions are set up. 
Final ice shape, thermal/altitude test, NACA0018 -...- Airfoil

180.0 kts, $0^{\circ} \mathrm{AOA}, 20.0 \mathrm{MVD}, 0.15 \mathrm{LWC}, 3.7^{\circ} \mathrm{F}$

$130.0 \mathrm{kts}, 0^{\circ} \mathrm{AOA}, 24.5 \mathrm{MVD}, 0.21 \mathrm{LWC},-0.9^{\circ} \mathrm{F}$

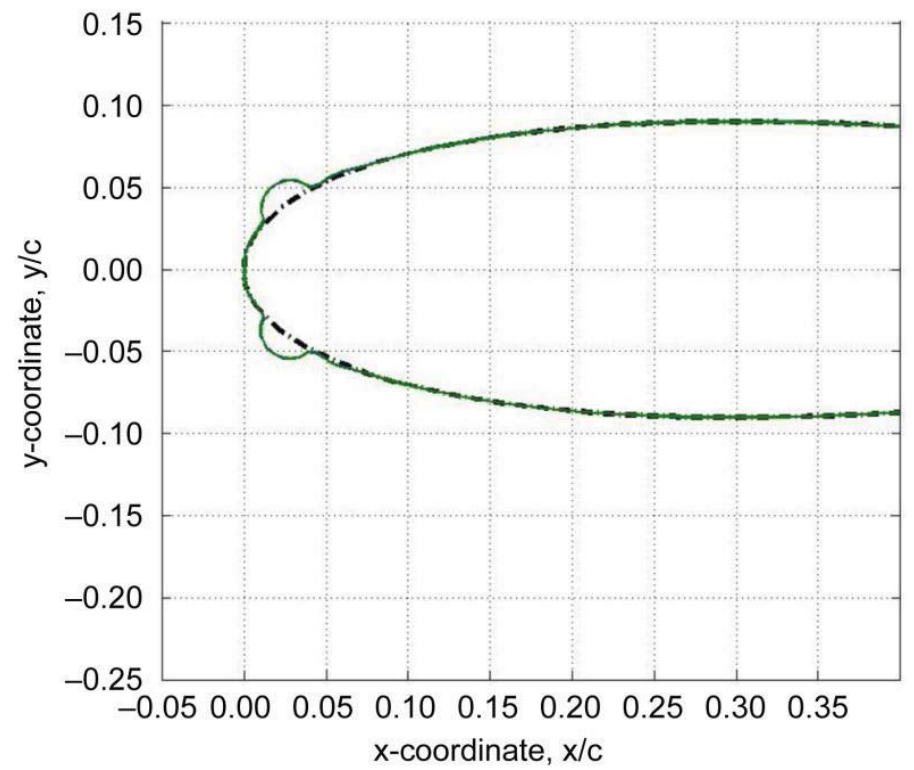

Figure 8. LEWICE results for Descent; both reference and scale conditions.

Final ice shape, thermal/altitude test, NACA0018 -...- Airfoil

$180.0 \mathrm{kts}, 0^{\circ} \mathrm{AOA}, 20.0 \mathrm{MVD}, 0.15 \mathrm{LWC},-22.0^{\circ} \mathrm{F}$

- 105.9 kts, $0^{\circ} \mathrm{AOA}, 27.8 \mathrm{MVD}, 0.25 \mathrm{LWC},-17.8^{\circ} \mathrm{F}$

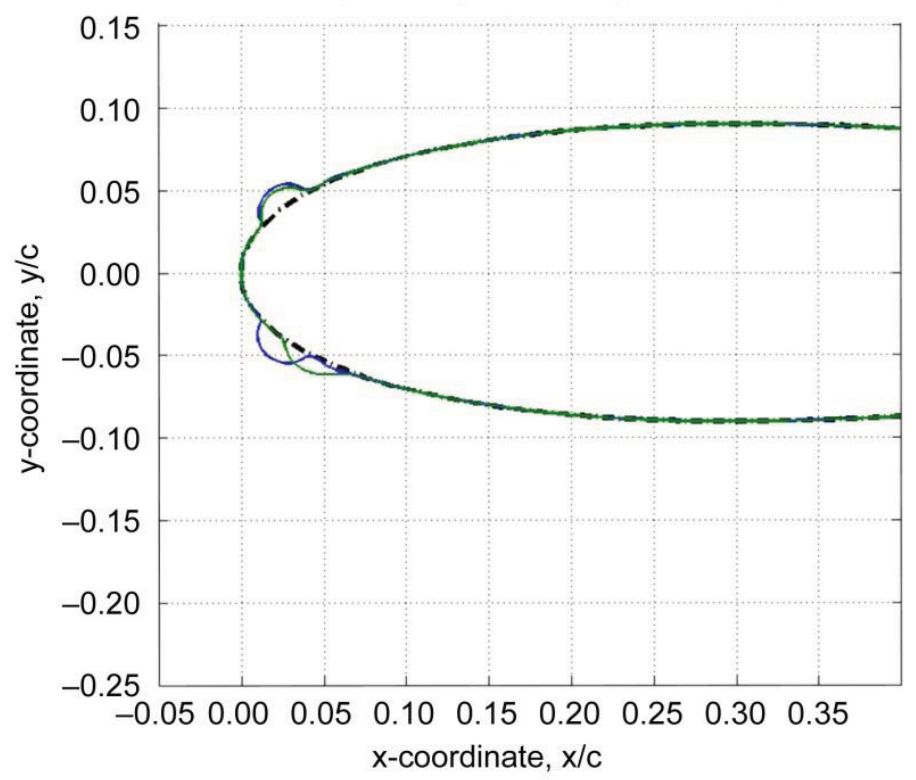

Figure 9. LEWICE results for Cold Hold; both reference and scale conditions. 


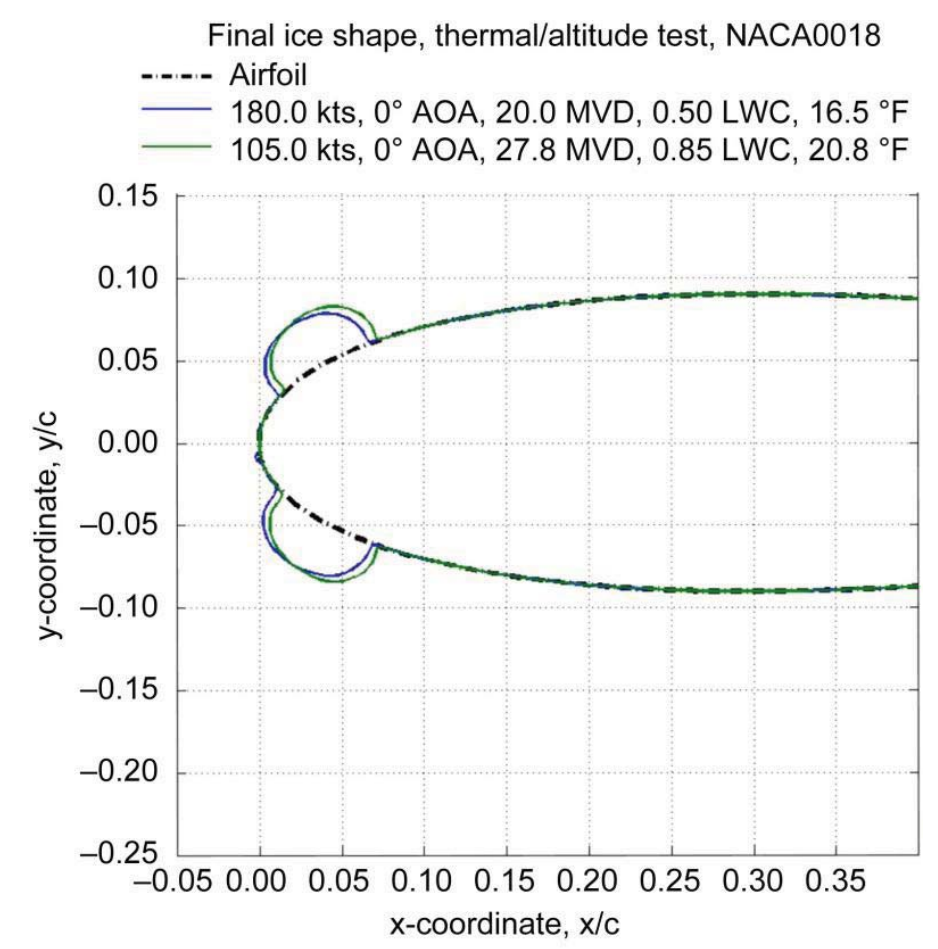

Figure 10. LEWICE results for Warm Hold; both reference and scale conditions.

\section{Results}

\section{A. Post Test Data Analysis}

During post-test calibration of the AIWT, it was found that the cloud operating settings produced droplet sizes that differed from those desired. The calibration found that the droplet sizes for the reference conditions in each case were smaller than intended and they were larger than intended for the scaled cases. This affected two of the four parameters that were to be matched in the scaling method. The actual values for modified inertia parameter, $\mathrm{K}_{0}$, and water loading, $M_{w}$, were no longer matched between their respective reference and scale values. Both the intended and actual test conditions and resulting scale parameters are given in Table 3.

Table 3. Intended and actual (shown in blue italic) conditions.

\begin{tabular}{|c|c|c|c|c|c|c|c|c|c|c|c|}
\hline Flight Phase & $\begin{array}{c}\text { Alt., } \\
\text { ft }\end{array}$ & $\begin{array}{l}V_{\text {tas, }}, \\
\text { kts }\end{array}$ & $\begin{array}{c}\text { AOA, } \\
\text { deg }\end{array}$ & $\begin{array}{c}\mathbf{T}_{\text {static, }} \\
\quad{ }^{\circ} \mathbf{F}\end{array}$ & $\begin{array}{c}\mathbf{T}_{\text {total, }} \\
{ }^{\circ} \mathbf{F}\end{array}$ & $\begin{array}{c}\text { LWC, } \\
\mathrm{g} / \mathrm{m}^{3}\end{array}$ & $\begin{array}{c}\text { MVD, } \\
\mu \mathrm{m}\end{array}$ & $\begin{array}{r}\mathbf{R e}_{\mathrm{d}} \\
\times 10^{6} \\
\end{array}$ & $\begin{array}{c}M_{w} \\
g / m^{2}-s\end{array}$ & $\mathbf{K}_{\mathbf{0}}$ & $\begin{array}{l}\mathbf{T}_{\mathbf{r}}, \\
{ }^{\circ} \mathbf{F}\end{array}$ \\
\hline \multirow[t]{4}{*}{ Descent(ref) } & 10000 & 180 & 0 & -4.0 & 3.7 & 0.15 & 20.0 & 1.64 & 8.81 & 1.41 & 2.5 \\
\hline & 10000 & 180 & 0 & -4.0 & 3.7 & 0.14 & 17.9 & 1.63 & 7.74 & 1.19 & 2.5 \\
\hline & & 130 & 0 & -0.9 & 3.1 & 0.21 & 24.5 & 1.64 & 8.81 & 1.41 & 2.5 \\
\hline & & 130 & 0 & -0.9 & 3.1 & 0.22 & 28.1 & 1.59 & 9.98 & 1.75 & 2.4 \\
\hline \multirow[t]{4}{*}{ Cld Hld(ref) } & 15000 & 180 & 0 & -22.0 & -14.3 & 0.15 & 20.0 & 1.40 & 9.02 & 1.52 & -15.5 \\
\hline & 15000 & 180 & 0 & -22.0 & -14.3 & 0.15 & 16.2 & 1.39 & 8.03 & 1.10 & -15.5 \\
\hline & & 106 & 0 & -17.8 & -15.1 & 0.25 & 27.8 & 1.40 & 9.02 & 1.52 & -15.5 \\
\hline & & 106 & 0 & -17.8 & -15.1 & 0.26 & 32.6 & 1.36 & 9.91 & 1.95 & -15.5 \\
\hline \multirow[t]{2}{*}{ Wm Hld(ref) } & 15000 & 180 & 0 & 16.5 & 24.2 & 0.50 & 20.0 & 1.29 & 30.0 & 1.50 & 23.0 \\
\hline & 15000 & 180 & 0 & 16.3 & 24.0 & 0.48 & 16.3 & 1.29 & 25.6 & 1.09 & 22.8 \\
\hline \multirow[t]{2}{*}{ (sc) } & & 105 & 0 & 20.8 & 23.4 & 0.85 & 27.8 & 1.29 & 30.0 & 1.50 & 23.0 \\
\hline & & 105 & 0 & 20.8 & 23.4 & 0.87 & 29.8 & 1.27 & 31.4 & 1.67 & 23.0 \\
\hline
\end{tabular}


The values for $\mathrm{K}_{0}$ were most affected with the scale values being greater than the corresponding reference values. For the Descent case, the $\mathrm{K}_{0}$ scale value was $42.8 \%$ greater than the reference value; for the Cold Hold case, it was $77.3 \%$ greater; and the Warm Hold case, it was $50.0 \%$ higher. The scale values for $\mathrm{M}_{\mathrm{w}}$ were also greater than there corresponding reference values. In the Descent case, it was $28.9 \%$ higher; in the Cold Hold case, it was $23.4 \%$ higher; and in the Warm Hold case, the $\mathrm{M}_{\mathrm{w}}$ scale value was $21.6 \%$ higher than the reference value.

Of these two parameters, $\mathrm{K}_{0}$ and $\mathrm{M}_{\mathrm{w}}, \mathrm{M}_{\mathrm{w}}$ is likely to have a greater influence on the results. $\mathrm{K}_{0}$ affects the droplet impingement limits and the collection efficiency, but $\mathrm{M}_{\mathrm{w}}$ drives the rate of ice buildup or, in the instance of an IPS, the amount of power required to prevent or dramatically reduce ice buildup.

The results of this study, therefore, are less clear than they would have been otherwise. Nonetheless, this test, being the first of this particular nature, is of interest and, moreover, conclusions can still be drawn, albeit with slightly less certainty.

\section{B. Descent Case}

Figures 11(a) and (b) show photographs of the ice accreted on the model for both the reference and scale conditions for the Descent case. Qualitatively, the ice shapes are similar. This similarity is reflected in the mid-span ice tracings shown in Fig. 12. The tracings do, however, show that more ice was accreted at the scale conditions and that it froze slightly further aft on the model. The measured masses of ice and the height of the ice on both the upper and lower surfaces for both reference and scale conditions are given in Table 4.
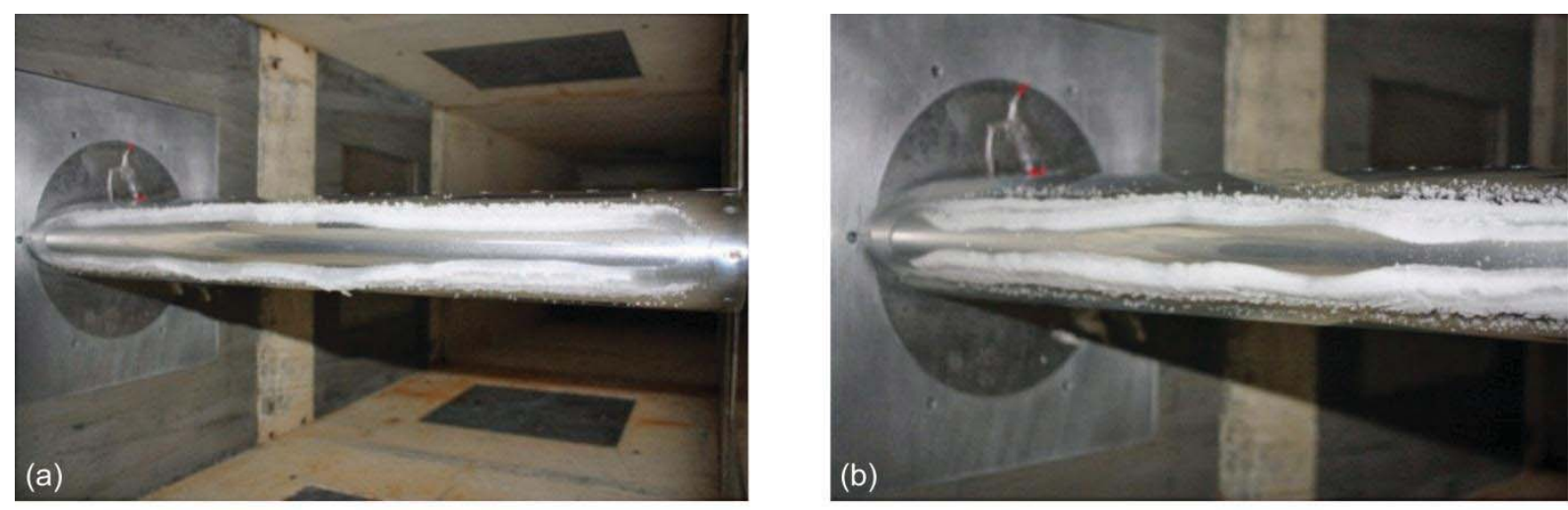

Figure 11. Descent ice accretion photographs for (a) reference and (b) scale conditions.

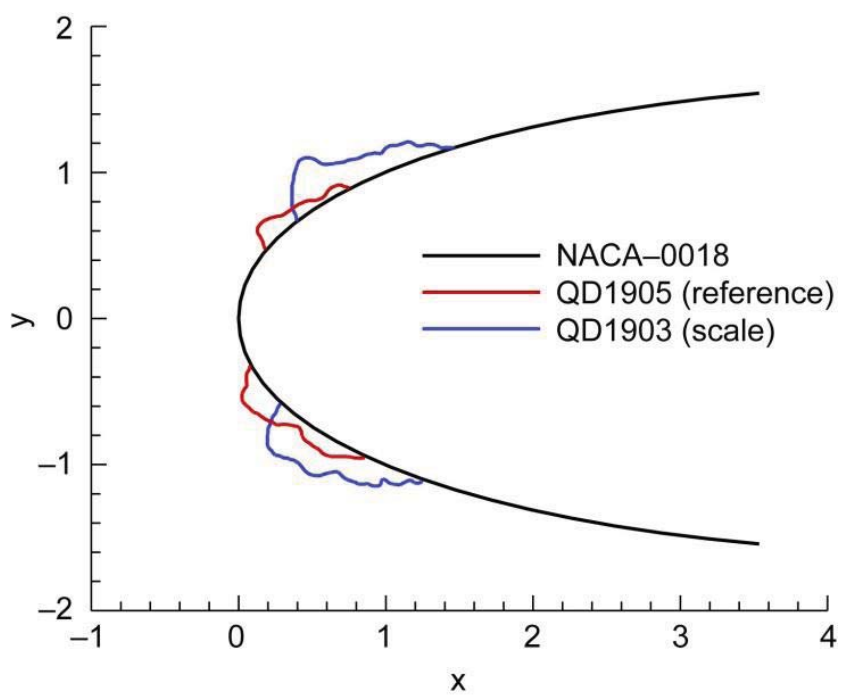

Figure 12. Descent ice tracings at model mid-span for the reference and scale conditions. 
Table 4. Descent case results.

\begin{tabular}{|c|c|c|c|c|c|c|c|c|c|c|c|}
\hline $\begin{array}{l}\text { Flight } \\
\text { Phase }\end{array}$ & $\begin{array}{c}\text { Alt., } \\
\text { ft }\end{array}$ & $\begin{array}{c}V_{\text {tas, }}, \\
\text { kts }\end{array}$ & $\begin{array}{c}\text { deg } \\
\text { deg }\end{array}$ & $\begin{array}{c}\mathbf{T}_{\text {static }}, \\
\quad{ }^{\circ} \mathbf{F}\end{array}$ & $\begin{array}{c}\mathbf{T}_{\text {total }}, \\
{ }^{\circ} \mathbf{F}\end{array}$ & $\begin{array}{c}\mathbf{L W C}, \\
\mathrm{g} / \mathrm{m}^{3}\end{array}$ & $\begin{array}{c}\text { MVD, } \\
\mu \mathrm{m}\end{array}$ & $\begin{array}{c}\text { Tau, } \\
\text { s }\end{array}$ & $\begin{array}{l}\text { Up } \\
\text { Ice, } \\
\text { in. }\end{array}$ & $\begin{array}{l}\text { Lo } \\
\text { Ice, } \\
\text { in. }\end{array}$ & $\begin{array}{c}\text { Ice } \\
\text { Mass, } \\
\text { g }\end{array}$ \\
\hline Descent(ref) & 10000 & 180 & 0 & -4.0 & 3.7 & 0.14 & 17.9 & 600 & 0.14 & 0.18 & 29 \\
\hline Descent(sc) & & 130 & 0 & -0.9 & 3.1 & 0.22 & 28.1 & 600 & 0.18 & 0.22 & 54 \\
\hline
\end{tabular}

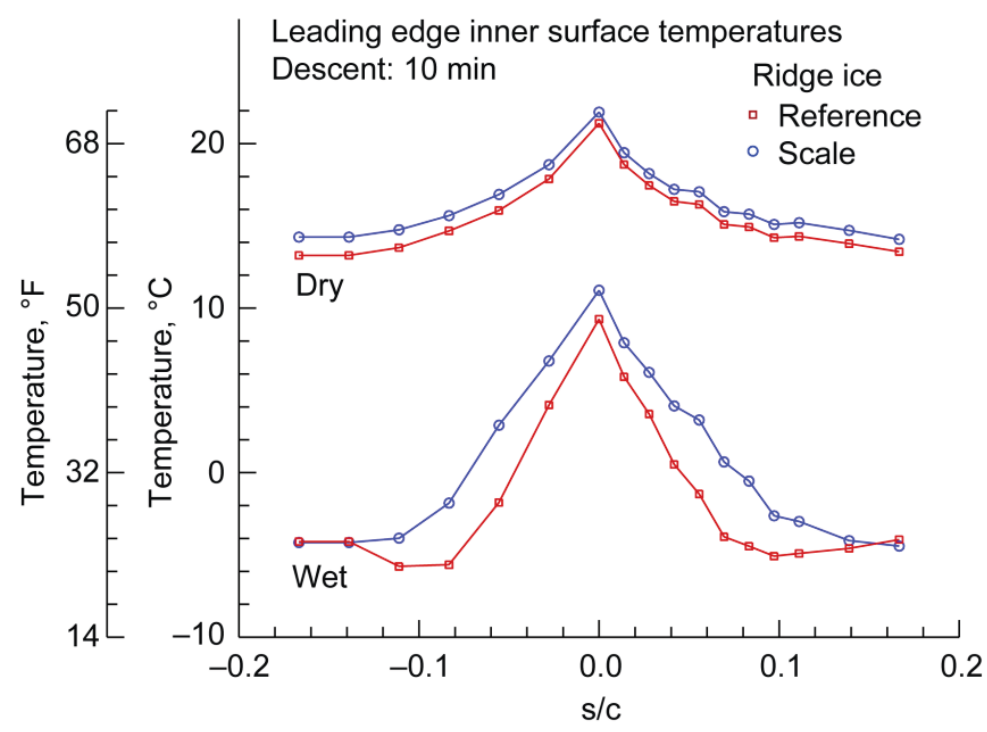

Figure 13. Descent surface temperatures before and during exposure to icing cloud.

Figure 13 shows the model surface temperatures during the run both before exposing the model to the cloud (dry) and again during exposure to the cloud (wet). The close agreement between the reference and scale in the dry conditions indicate the degree to which matching Reynolds number matches heat transfer between the two. There is more of a difference between the surface temperatures in the wet conditions. Here, the confounding effects of differing $\mathrm{M}_{\mathrm{w}}$ and $\mathrm{K}_{0}$ make it difficult to ascertain the cause. It is expected that the increased loading of supercooled water in the scale conditions would result in lower surface temperatures, but this is not the case. Instead, increased surface cooling was observed during the wet reference conditions. Increased evaporative cooling is expected at the reference conditions due to the lower tunnel air pressure. Mathematical models to calculate the amount of evaporative cooling in this situation, however, are approximate and have not been validated.

The measured reference and scale IPS heated air inlet and outlet temperatures for both the dry and wet conditions for this case are shown in Fig. 14(a). Similarly, the heat energy used by the IPS is shown in Fig. 14(b). The close agreement between reference and scale values for these parameters even though $\mathrm{M}_{\mathrm{w}}$ was $28.9 \%$ higher and $\mathrm{K}_{0}$ was $42.8 \%$ higher in the scale conditions shows that this IPS is not greatly affected by such changes in external icing conditions.

During pre-test analysis, calculations indicated that the water evaporation rate would be slightly higher for the reference conditions than in the scale conditions. Further calculations showed that the evaporation rate for the scale conditions could be raised by slightly increasing the surface temperatures of the model by increasing the heated air temperature supplied to the model IPS. A test run was, therefore, made with the surface temperatures increased by $2.8^{\circ} \mathrm{C}\left(5.0^{\circ} \mathrm{F}\right)$. Results of this test run are shown in the photograph in Fig. 15 and the ice tracings in Fig. 16. The resulting scale ice accretion was reduced slightly in size and mass, but is still different from the reference ice accretion. The ice was also accreted further aft on the model than in the initial scale run. The desired scale-condition ice accretion is one that matches the reference ice accreted in size, shape, and location. As expected, the surface temperature profiles, shown in Fig. 17, as well as the heated air inlet and outlet temperatures and heat energy plots, shown in Fig. 18, reflect the increased heated air supply temperature. 

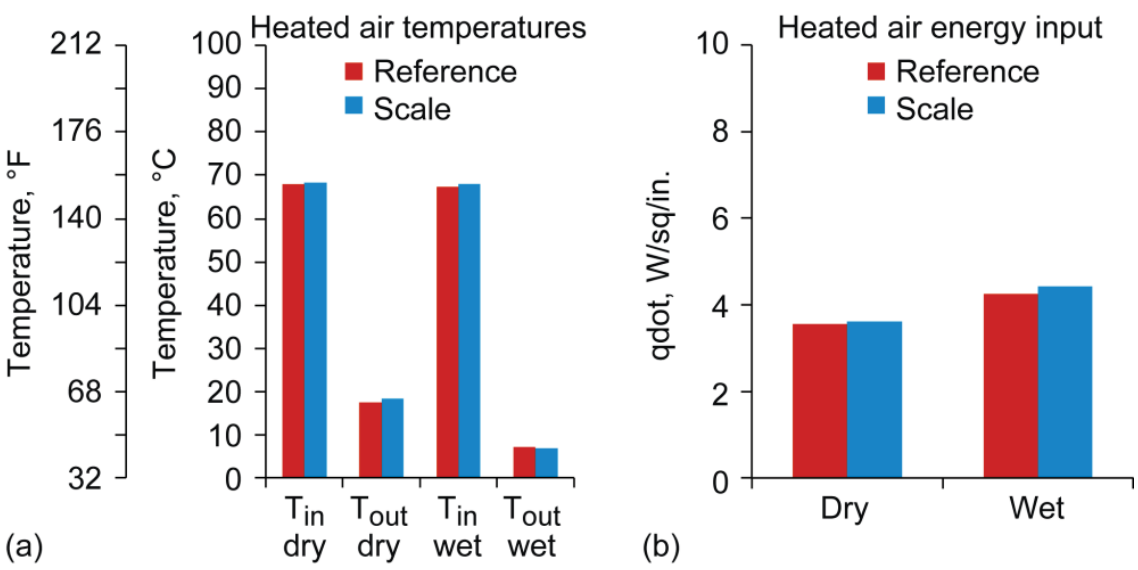

Figure 14. Descent (a) heated air temperatures and (b) heated air energy input before and during exposure to icing cloud.

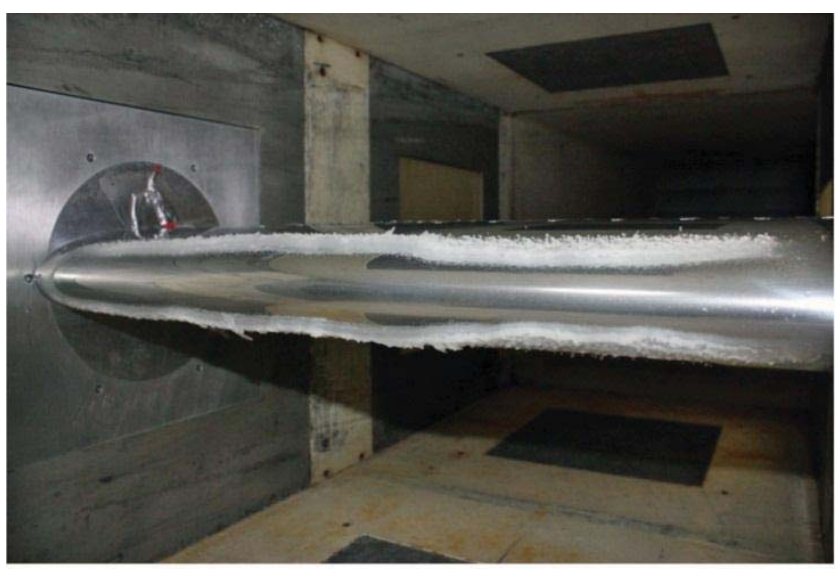

Figure 15. Descent for scaled conditions with model surface temperature increased $2.8^{\circ} \mathrm{C}\left(5.0^{\circ} \mathrm{F}\right)$.

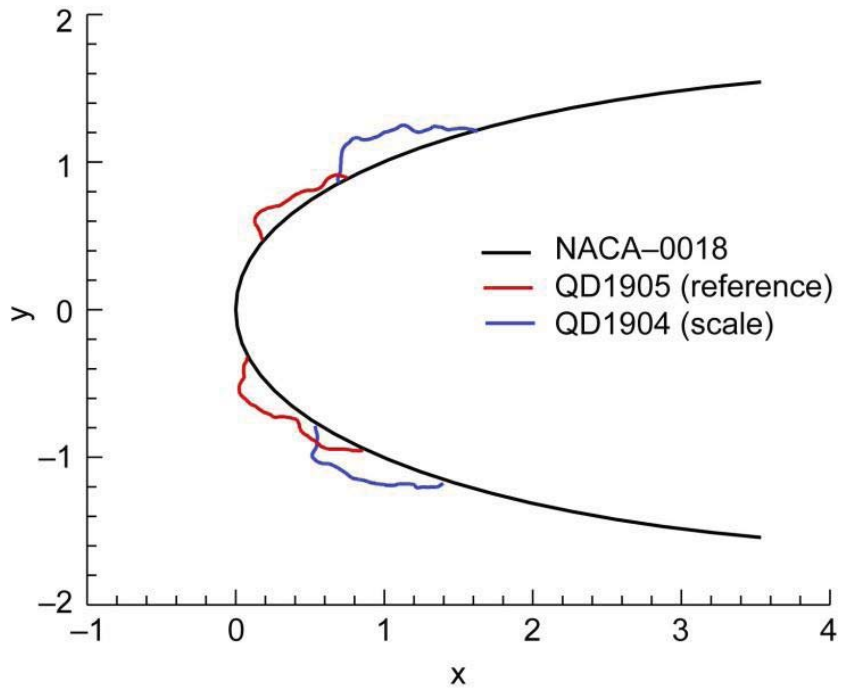

Figure 16. Descent ice tracing for scaled conditions with increased surface temperature compared with reference ice tracing. 


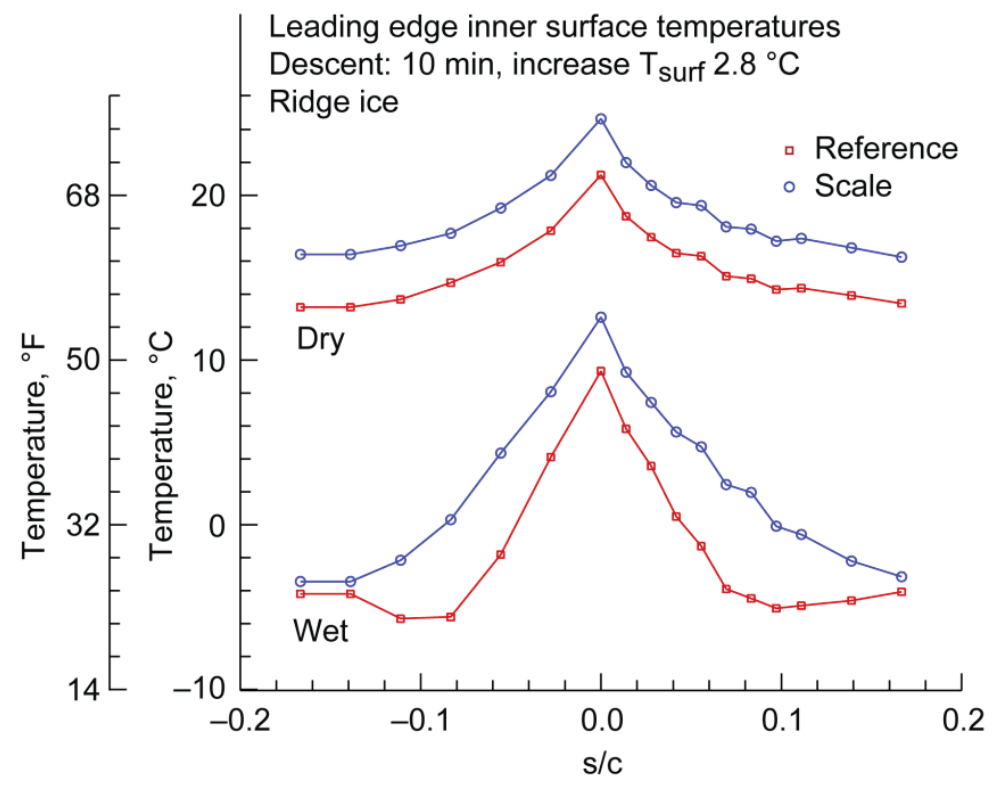

Figure 17. Surface temperatures for Descent for scaled conditions with increased surface temperatures compare with reference surface temperatures.
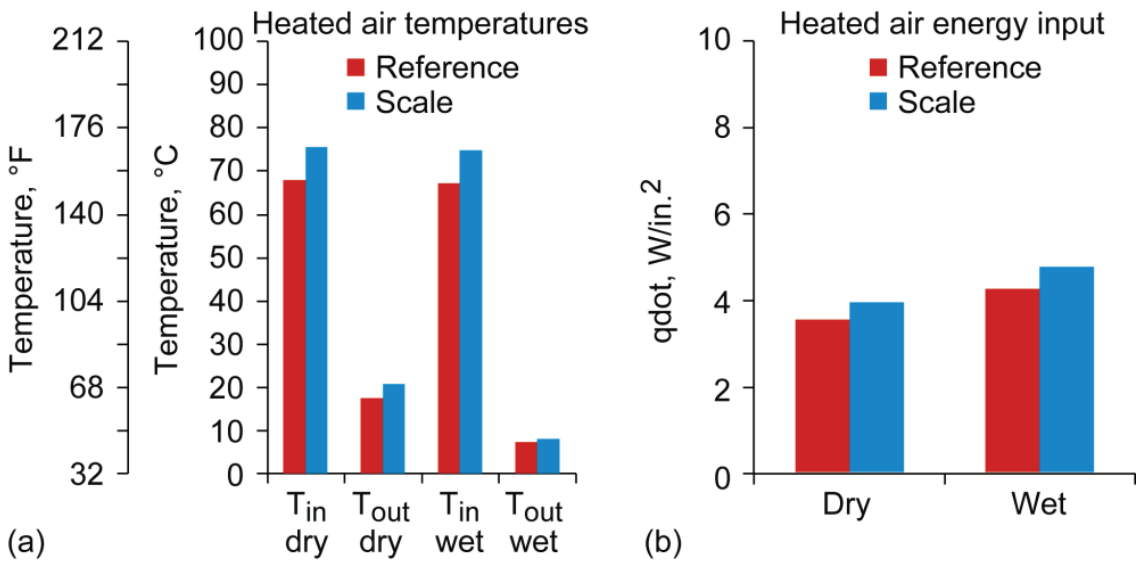

Figure 18. (a) Heated air inlet and outlet temperatures and (b) heated air energy input for Descent at scale conditions with increased model surface temperatures compared with reference case.

\section{Cold Hold Case}

For tunnel operation purposes, the scale conditions were run first for this Cold Hold case only. No checkout run was performed for the reference conditions, therefore, the reference ice accretion was not the result of adjusting the IPS settings to obtain a more desirable accretion. The case was not repeated due to time and priority considerations.

Photographs of the ice accreted for the reference and scale conditions of the Cold Hold case are shown in Fig. 19. The mid-span ice tracings are shown in Fig. 20. Unfortunately, a relatively large piece of ice shed from the upper surface of the model during the run at reference conditions. The shed ice prevents a quantitative comparison of the upper surface ice thickness, and overall mass. The ice on the lower surface was fairly similar, however, and it is not unreasonable to assume the upper ice accretions would also have been similar had the piece of ice not been shed. It will be noted that the ice accretion formed more forward in these runs. The measured ice height and mass data for this case are given in Table 5. 

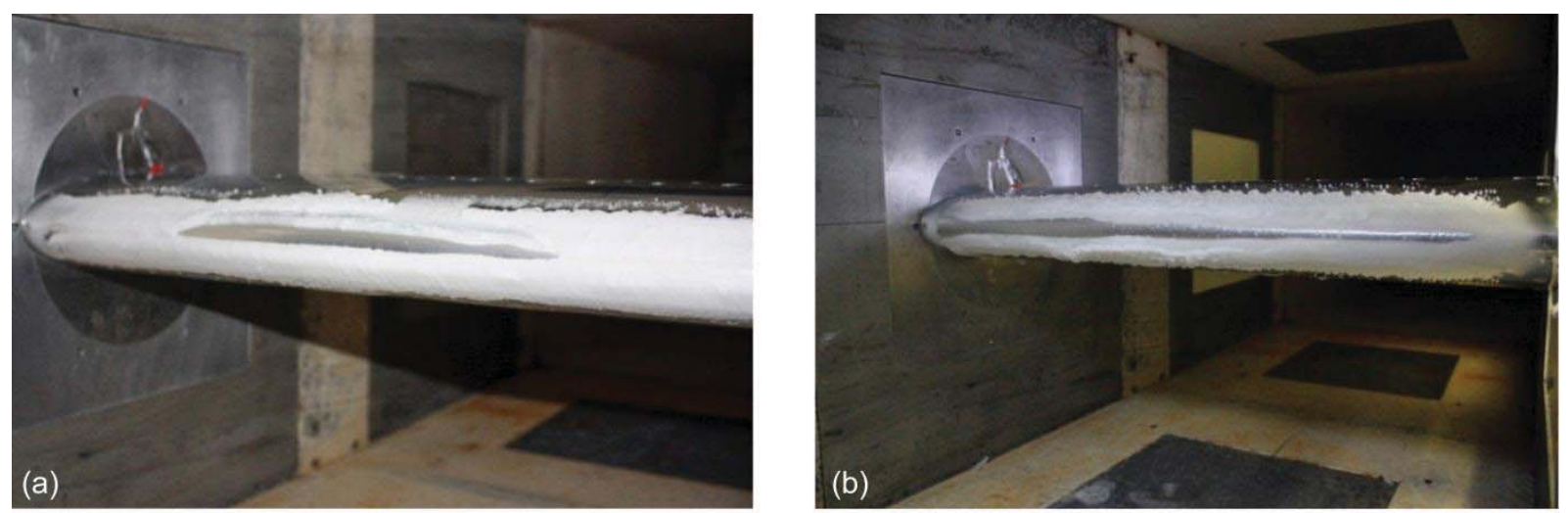

Figure 19. Cold Hold ice accretions for (a) reference and (b) scale conditions.

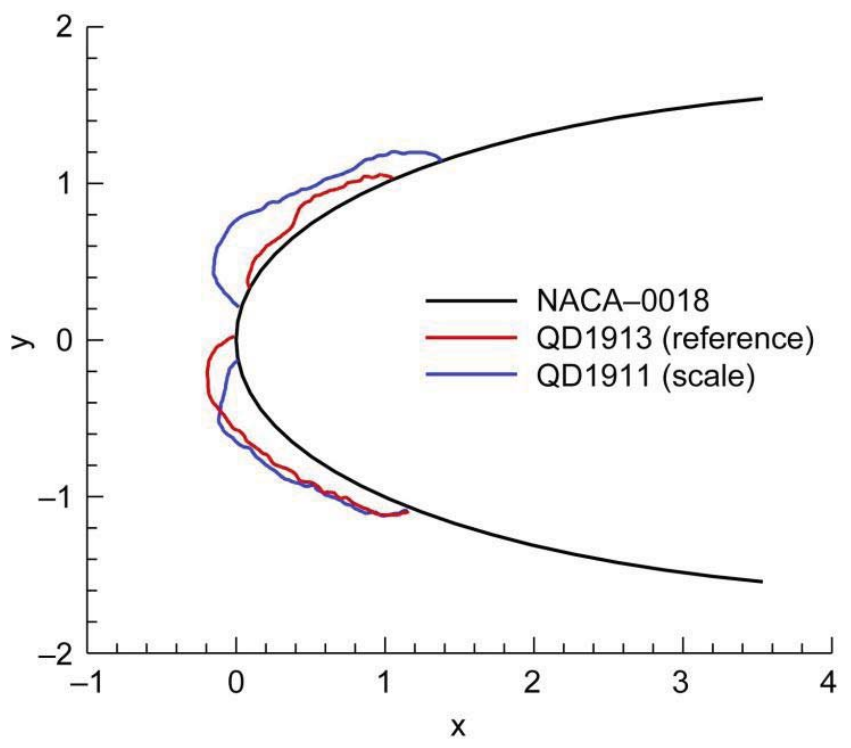

Figure 20. Cold Hold ice tracings.

Table 5. Cold Hold case results.

\begin{tabular}{lccccccccccc}
\hline \hline Flight Phase & $\begin{array}{c}\text { Alt., } \\
\mathbf{f t}\end{array}$ & $\begin{array}{c}\mathbf{V}_{\text {tas, }} \\
\mathbf{k t s}\end{array}$ & $\begin{array}{c}\mathbf{A O A}, \\
\mathbf{d e g}\end{array}$ & $\begin{array}{c}\mathbf{T}_{\text {static, }}{ }^{\circ} \mathbf{F} \\
\end{array}$ & $\begin{array}{c}{ }^{\circ} \mathbf{F} \\
\text { total, }\end{array}$ & $\begin{array}{c}\mathbf{L W C}, \\
\mathbf{g} / \mathbf{m}^{3}\end{array}$ & $\begin{array}{c}\text { MVD, } \\
\boldsymbol{\mu m}\end{array}$ & $\begin{array}{c}\text { Tau, } \\
\mathbf{s}\end{array}$ & $\begin{array}{c}\text { Up } \\
\text { Ice, } \\
\text { in. }\end{array}$ & $\begin{array}{c}\text { Lo } \\
\text { Ice, } \\
\text { in. }\end{array}$ & $\begin{array}{c}\text { Ice } \\
\mathbf{M a s s}, \\
\mathbf{g}\end{array}$ \\
\hline Cld Hld(ref) & 15000 & 180 & 0 & -22.0 & -14.3 & 0.15 & 16.2 & 600 & 0.12 & 0.20 & 25 \\
Cld Hld(sc) & & 106 & 0 & -17.8 & -15.1 & 0.26 & 32.6 & 600 & 0.20 & 0.23 & 56 \\
\hline \hline
\end{tabular}

Model surface temperatures for this case are shown in Fig. 21. The dry model temperature profiles are nearly the same for the reference and scale icing conditions, again indicating similarity in heat transfer. For icing cloud on, wet surface conditions, the reference surface temperature profile, as in the Descent case, is lower than the profile for the scale conditions. Here, $\mathrm{M}_{\mathrm{w}}$ is $23.4 \%$ higher and $\mathrm{K}_{0}$ is $77.3 \%$ higher in the scale conditions. Figure 22 shows the heated air temperatures and heat energy used by the IPS. Once again, IPS operating parameters are not greatly affected by such deviations from the target icing condition parameters, $\mathrm{M}_{\mathrm{w}}$ and $\mathrm{K}_{0}$. 


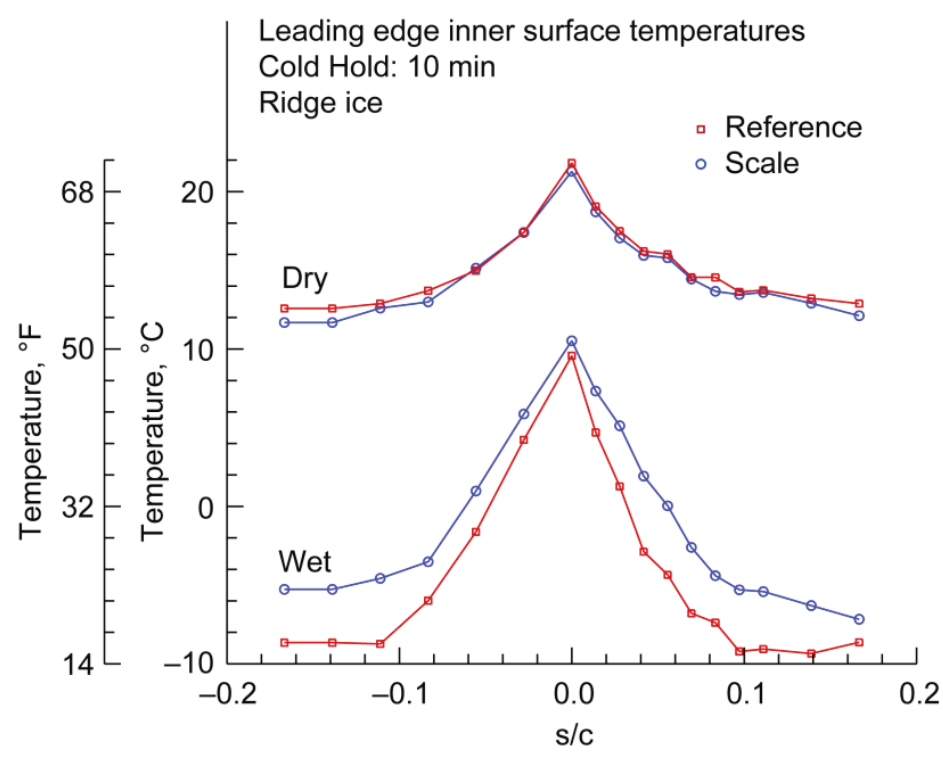

Figure 21. Cold Hold surface temperatures before and during exposure to icing cloud.
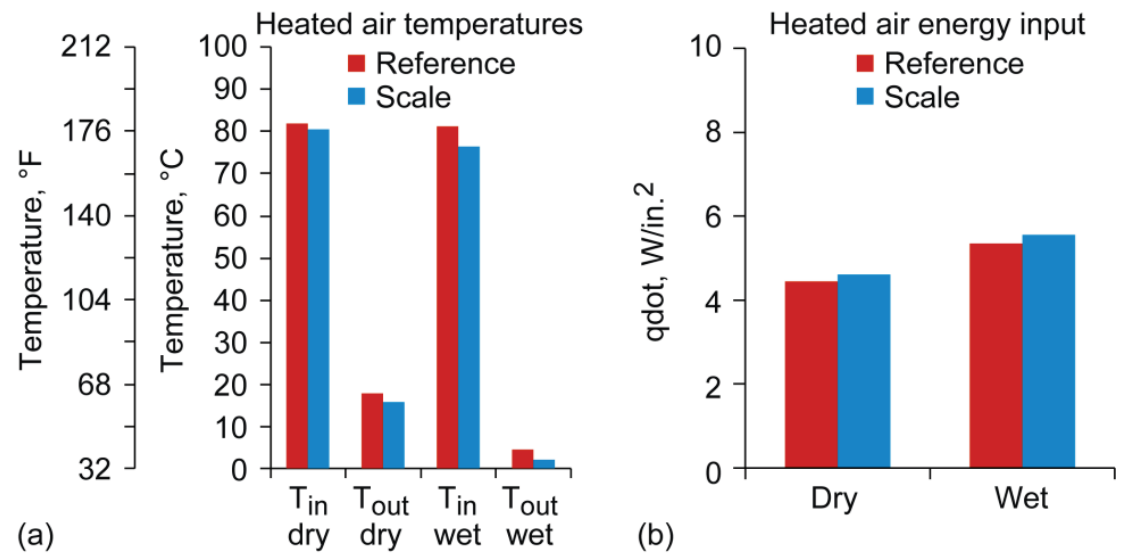

Figure 22. Cold Hold (a) heated air temperatures and (b) heated air energy input before and during exposure to icing cloud.

\section{Warm Hold Case}

Warmer ambient air temperatures typically result in ice accretions of less structural strength while higher water loading conditions usually result in larger ice accretions. The combination of these two factors made the Warm Hold case the most challenging for which to obtain measurable runback ice. Several initial runs at the reference conditions were made during which large portions of ice were shed before reaching the end of the designated $10 \mathrm{~min}$ icing exposure period. The exposure time was then reduced to seven minutes and a run at reference conditions was completed without ice shedding. A photograph of the ice accreted at the reference conditions, along with the centerline ice tracing, are shown in Figs. 23(a) and (b), respectively. When the scale conditions were run, however, the runback ice did not form a ridge. It instead froze in the form of rivulets further aft on the airfoil. Photographs of this ice are shown in Fig. 24(a) and (b). This frozen rivulet ice did not lend itself to the tracing method used for the runback ridge ice. The tracing templates did not extend far enough aft in the chordwise direction to capture this ice. Moreover, frozen rivulet ice is oriented primarily in the chordwise direction, with relatively large spaces between the rivulets in the spanwise direction. Because the tracing templates were not designed to trace this type of ice, no tracings were made. The thickness of the frozen rivulets was, however, measured using a depth gage in the forward part of the rivulet. The ice was removed from the model and weighed, similar to the instances where ridge ice formed; however, all of the rivulet ice was removed and weighed, instead of weighing only the ice from the center section 10.5 inch section of the airfoil. The ice depth and mass data for this case are shown in Table 6. 

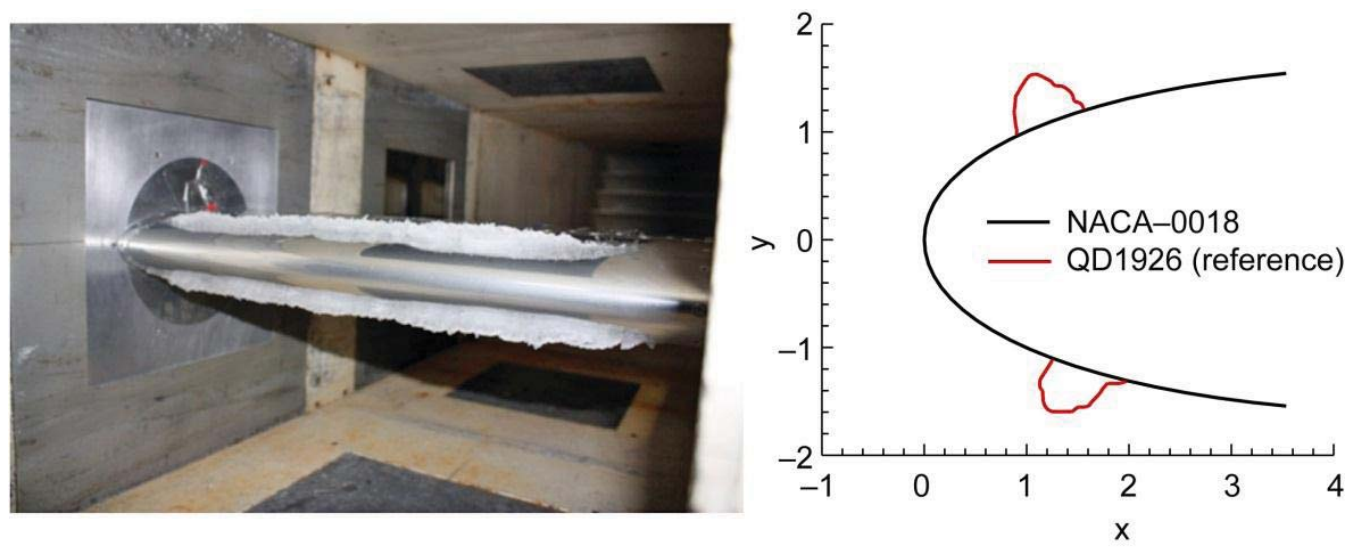

Figure 23. (a) Warm Hold ice accretion and (b) mid-span ice tracing for reference conditions.
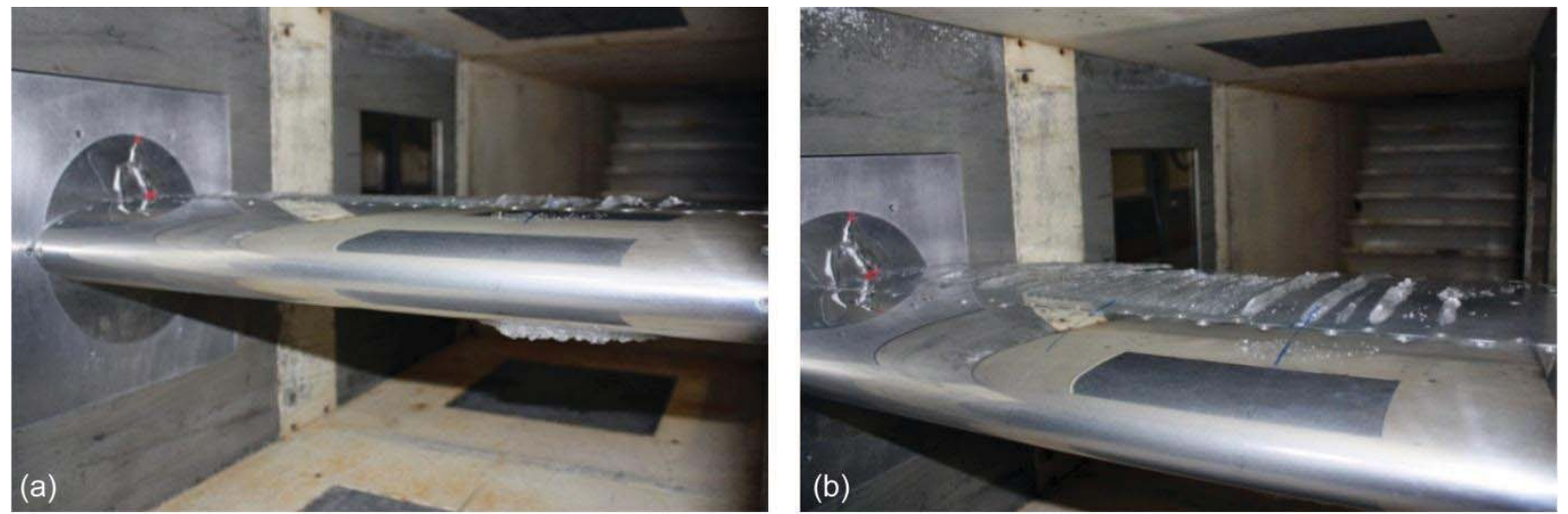

Figure 24. (a) Warm Hold ice accretion for scale conditions and (b) view of frozen rivulets formed.

Table 6. Warm Hold case-ridge ice results.

\begin{tabular}{|c|c|c|c|c|c|c|c|c|c|c|c|}
\hline Flight Phase & $\begin{array}{c}\text { Alt., } \\
\text { ft }\end{array}$ & $\begin{array}{c}V_{\text {tas, }}, \\
\text { kts }\end{array}$ & $\begin{array}{c}\text { AOA, } \\
\text { deg }\end{array}$ & $\begin{array}{c}\mathbf{T}_{\text {static, }} \\
{ }^{\circ} \mathbf{F}\end{array}$ & $\begin{array}{c}\mathbf{T}_{\text {total, }} \\
{ }^{\circ} \mathbf{F}\end{array}$ & $\begin{array}{c}\mathrm{LWC}, \\
\mathrm{g} / \mathrm{m}^{3}\end{array}$ & $\begin{array}{c}\text { MVD, } \\
\mu \mathrm{m}\end{array}$ & $\begin{array}{c}\text { Tau, } \\
\text { s }\end{array}$ & $\begin{array}{l}\text { Up } \\
\text { Ice, } \\
\text { in. }\end{array}$ & $\begin{array}{c}\text { Lo } \\
\text { Ice, } \\
\text { in. }\end{array}$ & $\begin{array}{c}\text { Ice } \\
\text { Mass, } \\
\text { g } \\
\end{array}$ \\
\hline $\mathrm{Wm}$ & 15000 & 18 & 0 & 16 & $\overline{24.2}$ & 0. & & $\overline{42}$ & 0.48 & 0.51 & 53 \\
\hline Wm Hld(sc) & & 105 & 0 & 20.8 & 23.4 & 0.87 & 29.9 & 420 & ---- & --- & ---- \\
\hline
\end{tabular}

For this case, the post-test tunnel cloud calibration yielded an $\mathrm{M}_{\mathrm{w}}$ that was $21.6 \%$ higher and a $\mathrm{K}_{0}$ that was $50.0 \%$ higher for the scale conditions. It appears likely that these deviations in cloud conditions resulted in dramatically different ice accretions. Although verification of this observation is warranted, it would illustrate the highly non-linear nature of icing at near-freezing temperatures.

The airfoil surface temperature data are given in Fig. 25. As in the other cases, surface temperature profiles are the same for the dry conditions and close for the wet conditions with the reference-run temperatures slightly lower $\left(1{ }^{\circ} \mathrm{C}\right.$ or less). Heated air inlet and outlet temperatures as well as the heat energy input for the reference and scale conditions are nearly identical, as shown in Fig. 26.

The difficulties associated with successfully accreting and recording runback ridge ice accretions became a major obstacle to obtaining results for use in the study. Therefore, the test plan was changed to instead accrete and record runback rivulet ice accretions as the reference for the Warm Hold case. This was done by raising the heated air inlet temperature by $20^{\circ} \mathrm{F}\left(11.1^{\circ} \mathrm{C}\right)$. While this eliminated ice tracings as a means of recording and comparing test results, the height of the frozen rivulets could still be measured and the ice could still be removed and weighed for comparison purposes. 


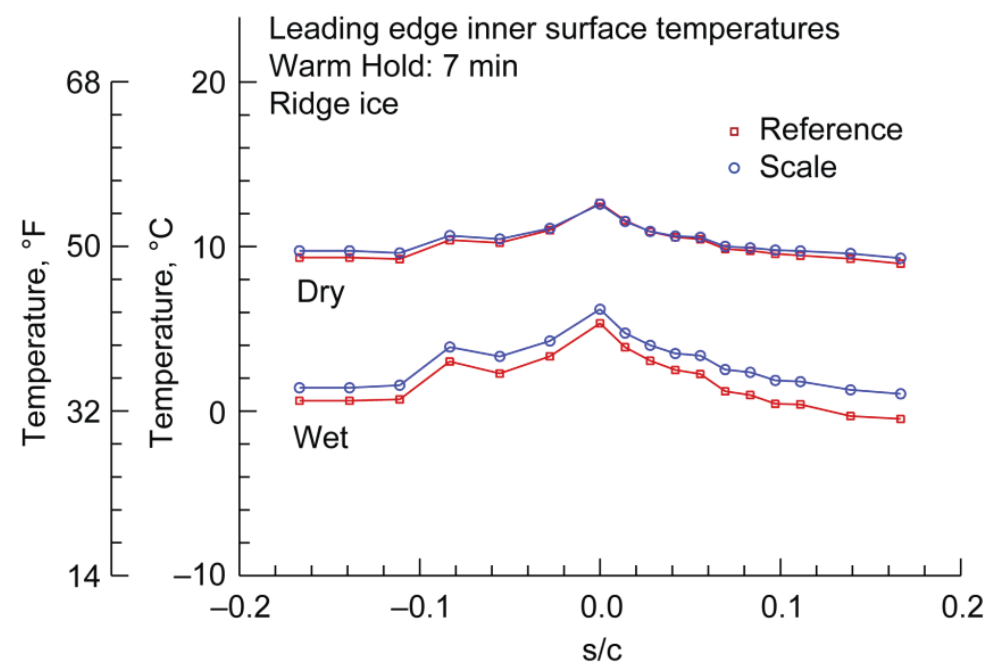

Figure 25. Warm Hold surface temperatures before and during exposure to icing cloud.
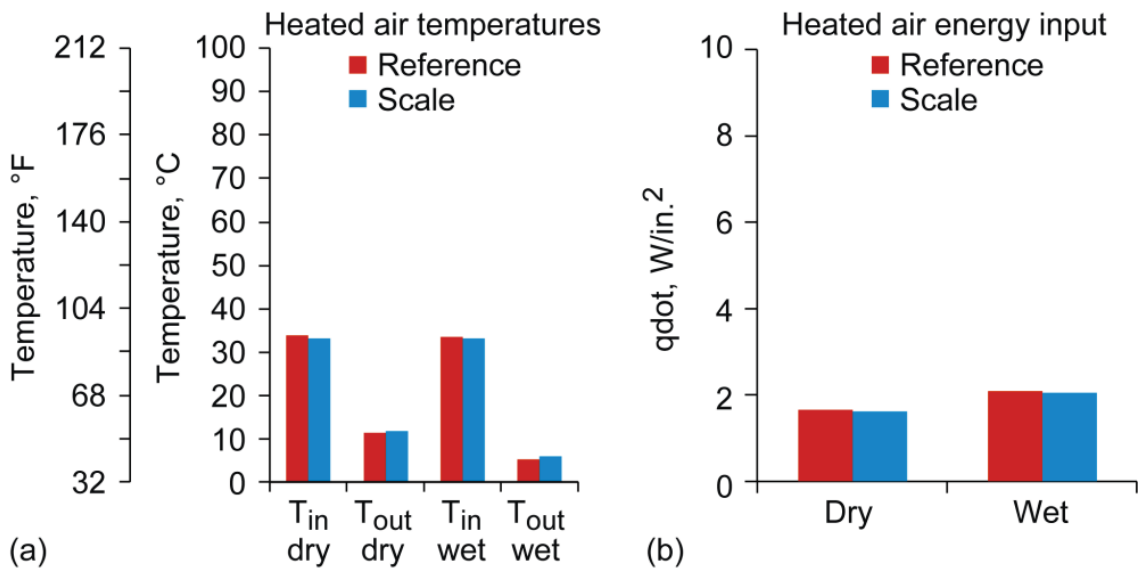

Figure 26. Warm Hold (a) heated air temperatures and (b) heated air energy input before and during exposure to icing cloud.

Photographs of the resulting ice from the test runs at the Warm Hold conditions with runback rivulet ice accretions are shown in Fig. 27. An examination of the frozen rivulets formed shows that, similar to the cases run with runback ridge ice, more ice accreted at the scale conditions than at the reference conditions. This increase in accreted ice is reflected in the measured ice heights and masses given in Table 7. During close observation of the formation of the frozen rivulets, beads of water were seen running aft along the length of the rivulets and then disappearing. It is suspected that these relatively large beads of water were being re-entrained into the airstream, rather than freezing and adding to the ice mass on the airfoil.

Figure 28 shows the model surface temperatures for this case. They are again close between the reference and scale runs, indicating a close matching of heat transfer between the two. Figures 29(a) and (b) show the heated air data for this case. The close matching between reference and scale conditions also substantiate a matching of heat transfer as well as a reduced level of sensitivity of the IPS operation to deviations in cloud parameters. 

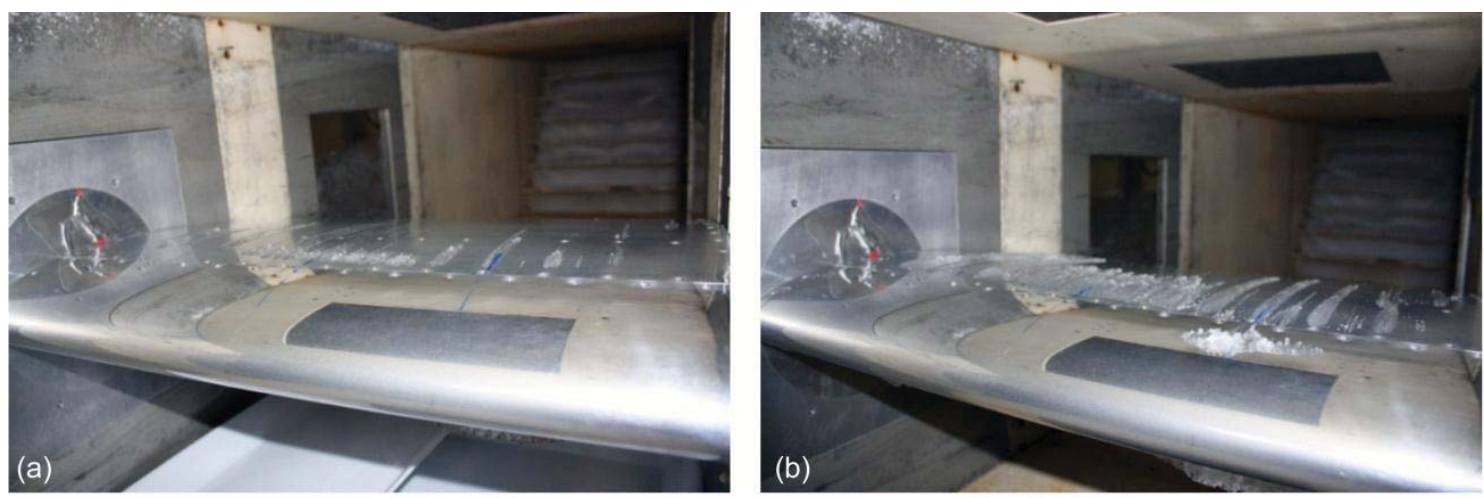

Figure 27. Warm Hold frozen rivulets for (a) reference and (b) scale conditions.

Table 7. Warm Hold case-frozen rivulet ice results.

\begin{tabular}{|c|c|c|c|c|c|c|c|c|c|c|c|}
\hline Flight Phase & $\begin{array}{c}\text { Alt., } \\
\text { ft }\end{array}$ & $\begin{array}{c}\mathrm{V}_{\text {tas }}, \\
\text { kts }\end{array}$ & $\begin{array}{c}\text { AOA, } \\
\operatorname{deg}\end{array}$ & $\begin{array}{c}\mathbf{T}_{\text {static }}, \\
{ }^{\circ} \mathbf{F}\end{array}$ & $\begin{array}{c}\mathbf{T}_{\text {total }}, \\
{ }^{\circ} \mathbf{F}\end{array}$ & $\begin{array}{c}\text { LWC, } \\
\mathbf{g} / \mathbf{m}^{3}\end{array}$ & $\begin{array}{c}\text { MVD, } \\
\mu \mathrm{m}\end{array}$ & $\begin{array}{c}\text { Tau, } \\
\text { s }\end{array}$ & $\begin{array}{l}\text { Up } \\
\text { Ice, } \\
\text { in. }\end{array}$ & $\begin{array}{l}\text { Lo } \\
\text { Ice, } \\
\text { in. }\end{array}$ & $\begin{array}{c}\text { Ice } \\
\text { Mass, } \\
\mathbf{g} \\
\end{array}$ \\
\hline Wm Hld(ref) & 15000 & 180 & 0 & 16.5 & 24.2 & 0.48 & 16.3 & 420 & 0.08 & 0.09 & 15 \\
\hline Wm Hld(sc) & & 105 & 0 & 20.8 & 23.4 & 0.87 & 29.8 & 420 & 0.13 & 0.12 & 83 \\
\hline
\end{tabular}

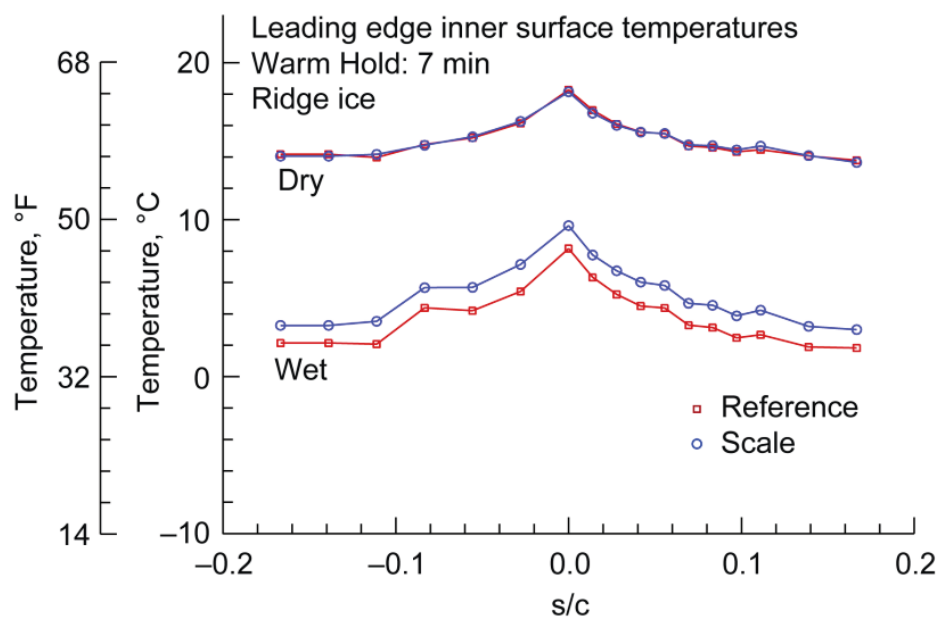

Figure 28. Warm Hold surface temperatures before and during exposure to icing cloud; frozen rivulet ice.
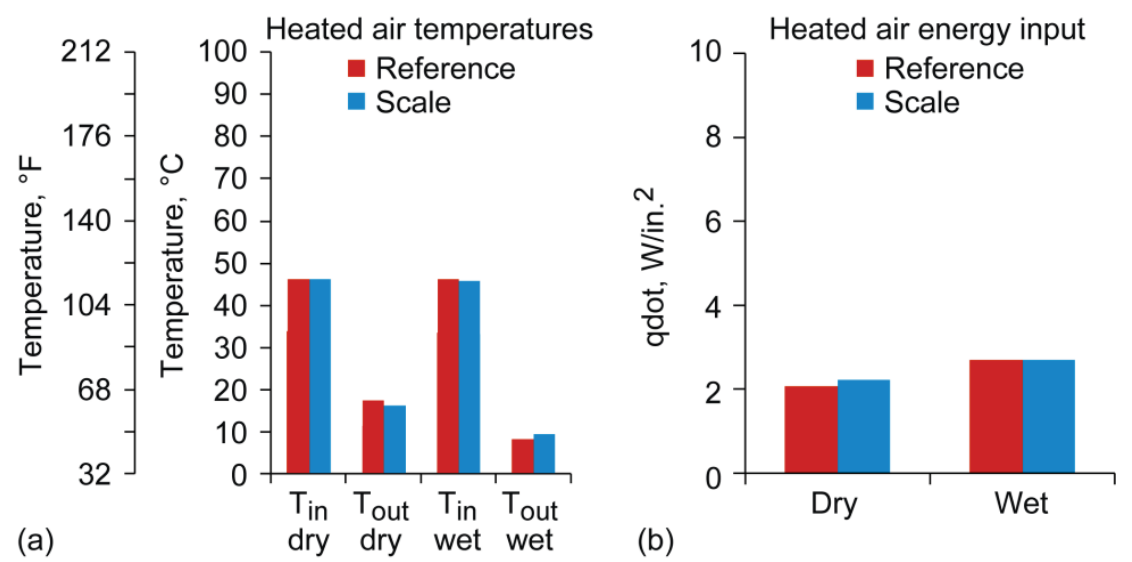

Figure 29. Warm Hold (a) heated air temperatures and (b) heat energy used. 


\section{E. Discussion}

For all cases, the close matching of the surface temperatures and heated air temperatures and energy use rates between the reference and scale conditions showed that the scaling method works well in matching the heat transfer between altitude and ground level conditions. The fact that there was consistently less ice accreted for the reference conditions than for the corresponding scale conditions, however, suggested that the scaling method does not match mass transfer between altitude and scale conditions. Confounding this observation is the post-test calibration finding that $\mathrm{M}_{\mathrm{w}}$ was $21.6-28.9 \%$ higher for the scale conditions in each flight-scenario case. In general, the mass of the accreted ice was roughly $80-500 \%$ higher for the scale conditions in each case. The additional ice accreted in the scale conditions cannot be due to the increase in $\mathrm{M}_{\mathrm{w}}$ unless the ice accretion rate in each case was highly nonlinear, a distinct possibility.

The one exception to mass transfer scaling mismatch is the Cold Hold case. Here ice which shed from the upper surface of the reference conditions precluded a direct comparison of the ice masses between reference and scale. Inspection of the ice tracings, however, indicated that the masses may have been similar had the ice not shed. The additional ice accreted due to the increased $\mathrm{M}_{\mathrm{w}}$ in the scale conditions would still have placed the ice masses within the margin of error estimated for these measurements. It should further be noted that the ice accreted for this case nearly covered the entire leading edge, thereby reducing the area for evaporation as well as reducing the length of runback for the water. The case rightfully should have been rerun with a higher heated air energy input such that the IPS operated more effectively. As was mentioned earlier, tunnel test time and run priorities prevented a repeat run of this case. One should be cautioned against drawing conclusions from this single case.

All of the Descent and Warm Hold cases with the IPS operating resulted in less ice accreted during runs with the reference conditions than during the runs with scale conditions. This was evident even though ice shedding was a problem for the Descent cases and the Warm Hold cases where runback ridge ice was formed. To further illustrate the ice accretion differences between reference and scale conditions, normalized icing rates for the Descent and Warm Hold conditions are plotted in Figs. 30 and 31, respectively. Icing rates, in terms of grams of ice per unit area per unit time, were calculated from the ice mass measurements, the pertinent impingement area of the airfoil, and the icing exposure time. The normalized values were obtained by dividing the icing rates for the runs with the IPS operating by the rates for the corresponding unprotected runs. Figure 31 shows multiple Warm Hold runs for both reference and scale conditions because the frozen rivulet results proved to be more repeatable than the runback ridge ice results where shedding ice was a frequent occurrence. For both cases, the increase in accreted ice for the scale conditions was greater than the unintended increase in $\mathrm{M}_{\mathrm{w}}$.

The difference between the reference and scale ice accretions is more pronounced for the Warm Hold case than for the Descent case. It is strongly suspected that a reason for at least part of difference between the Warm Hold and Descent cases is the observation of the runback water droplets on the frozen rivulets which appeared to be reentrained into the airstream. This phenomenon was not readily noticeable during the Descent cases where only runback ridge ice was formed.

The unintended increase in $\mathrm{M}_{\mathrm{w}}$ and $\mathrm{K}_{0}$ for the scale conditions tested in this study added uncertainty to the results. Those results, nonetheless, strongly suggested that, in order to faithfully simulate the amount of runback ice formed where a running wet IPS is being tested at ground level, another scaling parameter may well need to be considered or an appropriate correction method be employed. Methods used to calculate water evaporation rates should also be examined more closely. The evaporation rates used during prediction of ice accretion on unprotected

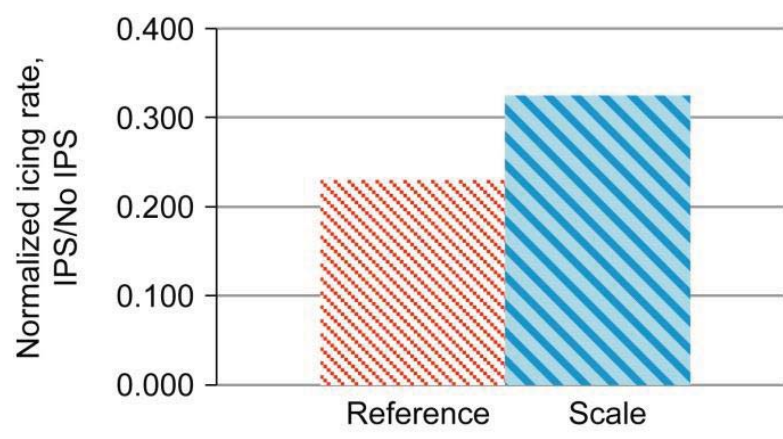

Figure 30. Normalized icing rates for Descent.

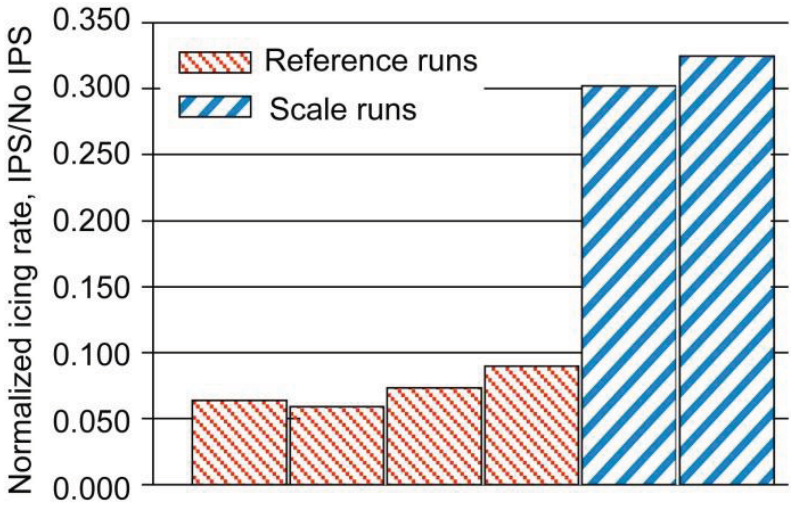

Figure 31. Normalized icing rates for Warm Hold. 
surfaces are relatively low in comparison to the incoming water, so errors in the evaporation rate calculation are not critical. This is not the case for a thermal IPS that is operating effectively. Here a relatively large portion of the incoming water is evaporating, and thus accurate calculation is more important when determining the amount of runback ice that accumulates.

In cases of aircraft icing where flow of water is known to occur, such as during the accretion of glaze ice on an unprotected surface, the Weber number can be an important factor in scaling icing conditions to obtain ice shape similarity. The flow of water is obviously present in the instance of frozen rivulet icing. Therefore, the inclusion of the Weber number should be considered in future research.

\section{Closing Remarks}

This study was the first documented effort directed specifically toward better understanding the effects of altitude on the heat and mass transfer processes occurring during operation of a thermal IPS. The tests described should be considered an initial step toward providing technology that is essential to the enhancement of aircraft thermal IPSs and, thereby, aviation safety. Further steps in the study of the effects of altitude on IPS performance should include testing in an altitude icing wind tunnel to:

1. Verify initial findings,

2. More firmly establish the existence of water droplet re-entrainment, and investigate methods to quantify it, and

3. Establish methods to determine water evaporation rates.

\section{Acknowledgements}

The authors would like to thank Gislain Chevrette and Steve Totolo of NRCC for setting up and operating the test rig and AIWT. We also would like to thank Bill Magas, Paul Butterfield, Pat Murphy, and Terry Mathes of NASA Glenn for assisting with model checkout. NASA's Aviation Safety Program as well as NRCC's Reduction of Aviation Icing Risk Program supported this research.

\section{References}

${ }^{1}$ Anderson, D.N., "Manual of Scaling Methods," NASA/CR-2004-212875, 2004.

${ }^{2}$ Kind, R.J. and Oleskiw, M.M., "Recent Developments in Scaling Methods for Icing Wind Tunnel Testing at Reduced Scale," ICAS 2002 Congress, 2002.

${ }^{3}$ Bartlett, C.S., "An Analytical Study of Icing Similitude for Aircraft Engine Testing,” DOT/FAA/CT-86/35; AEDC-TR-8626, 1986.

${ }^{4}$ Newton, J.E., VanFossen, G.J., Poinsatte, P.E., and DeWitt, K.J., "Measurement of Local Convective Heat Transfer Coefficients From a Smooth and Roughened NACA-0012 Airfoil; Flight Test Data," AIAA-88-0287, NASA TM-100284, 1988.

${ }^{5}$ Poinsatte, P.E., VanFossen, G.J., and DeWitt, K.J., "Convective Heat Transfer Measurements From a NACA 0012 Airfoil in Flight and in the NASA Lewis Icing Research Tunnel," AIAA-90-0199, NASA TM-102448, 1990.

${ }^{6}$ Bragg, M.B., Lee, S., and Henze, C.M., "Heat-Transfer and Freestream Turbulence Measurements for Improvement of the Ice Accretion Physical Model," AIAA-97-0053, 1997.

${ }^{7}$ Miller, D., Bond, T., Sheldon, D., Wright, W., Langhals, T., Al-Khalil, K., and Broughton, H., "Validation of NASA Thermal Ice Protection Computer Codes Part 1-Program Overview,” AIAA-97-0049, NASA TM-107397, 1997.

${ }^{8}$ Wright, W.B., Al-Khalil, K.M., and Miller, D.R., "Validation of NASA Thermal Ice Protection Computer Codes: Part 2 The Validation of LEWICE/Thermal," AIAA-97-0050, 1997.

${ }^{9}$ Al-Khalil, K.M., Horvath, C., Wright, and W.B., Miller, D.R., "Validation of NASA Thermal Ice Protection Computer Codes: Part 3 - The Validation of ANTICE," AIAA-97-0051, 1997.

${ }^{10}$ Oleskiw, M.M., Hyde, F.H., and Penna, P.J., "In-Flight Icing Simulation Capabilities of NRC's Altitude Icing Wind Tunnel," AIAA-2001-0094, 2001.

${ }^{11}$ Wright, W., “User's Manual for LEWICE Version 3.2,” NASA/CR-2008-214255, 2008. 
NASA/TM-2013-216559

\section{A Study of the Effects of Altitude on Thermal Ice Protection System Performance}

Harold E. Addy, Jr.

Glenn Research Center, Cleveland, Ohio

Myron Oleskiw

National Research Council Canada, Ottawa, Ontario, Canada

Andy P. Broeren

Glenn Research Center, Cleveland, Ohio

David Orchard

National Research Council Canada, Ottawa, Ontario, Canada 


\section{NASA STI Program . . . in Profile}

Since its founding, NASA has been dedicated to the advancement of aeronautics and space science. The NASA Scientific and Technical Information (STI) program plays a key part in helping NASA maintain this important role.

The NASA STI Program operates under the auspices of the Agency Chief Information Officer. It collects, organizes, provides for archiving, and disseminates NASA's STI. The NASA STI program provides access to the NASA Aeronautics and Space Database and its public interface, the NASA Technical Reports Server, thus providing one of the largest collections of aeronautical and space science STI in the world. Results are published in both non-NASA channels and by NASA in the NASA STI Report Series, which includes the following report types:

- TECHNICAL PUBLICATION. Reports of completed research or a major significant phase of research that present the results of NASA programs and include extensive data or theoretical analysis. Includes compilations of significant scientific and technical data and information deemed to be of continuing reference value. NASA counterpart of peer-reviewed formal professional papers but has less stringent limitations on manuscript length and extent of graphic presentations.

- TECHNICAL MEMORANDUM. Scientific and technical findings that are preliminary or of specialized interest, e.g., quick release reports, working papers, and bibliographies that contain minimal annotation. Does not contain extensive analysis.

- CONTRACTOR REPORT. Scientific and technical findings by NASA-sponsored contractors and grantees.
- CONFERENCE PUBLICATION. Collected papers from scientific and technical conferences, symposia, seminars, or other meetings sponsored or cosponsored by NASA.

- SPECIAL PUBLICATION. Scientific, technical, or historical information from NASA programs, projects, and missions, often concerned with subjects having substantial public interest.

- TECHNICAL TRANSLATION. Englishlanguage translations of foreign scientific and technical material pertinent to NASA's mission.

Specialized services also include creating custom thesauri, building customized databases, organizing and publishing research results.

For more information about the NASA STI program, see the following:

- Access the NASA STI program home page at http://www.sti.nasa.gov

- E-mail your question to help@sti.nasa.gov

- Fax your question to the NASA STI Information Desk at 443-757-5803

- Phone the NASA STI Information Desk at 443-757-5802

- Write to: STI Information Desk NASA Center for AeroSpace Information 7115 Standard Drive Hanover, MD 21076-1320 
NASA/TM-2013-216559

AIAA-2013-2934

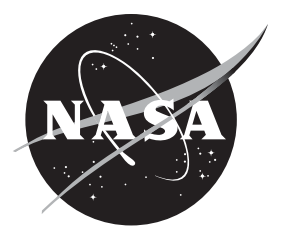

\section{A Study of the Effects of Altitude on Thermal Ice Protection System Performance}

Harold E. Addy, Jr.

Glenn Research Center, Cleveland, Ohio

Myron Oleskiw

National Research Council Canada, Ottawa, Ontario, Canada

Andy P. Broeren

Glenn Research Center, Cleveland, Ohio

David Orchard

National Research Council Canada, Ottawa, Ontario, Canada

Prepared for the

5th Atmospheric and Space Environments Conference

sponsored by the American Institute of Aeronautics and Astronautics

San Diego, California, June 24-27, 2013

National Aeronautics and

Space Administration

Glenn Research Center

Cleveland, Ohio 44135 


\section{Acknowledgments}

The authors would like to thank Gislain Chevrette and Steve Totolo of NRCC for setting up and operating the test rig and AIWT. We also would like to thank Bill Magas, Paul Butterfield, Pat Murphy, and Terry Mathes of NASA Glenn for assisting with model checkout. NASA's Aviation Safety Program as well as NRCC's Reduction of Aviation Icing Risk Program supported this research.

This report contains preliminary findings, subject to revision as analysis proceeds.

Level of Review: This material has been technically reviewed by technical management.

Available from

NASA Center for Aerospace Information 7115 Standard Drive

Hanover, MD 21076-1320
National Technical Information Service 5301 Shawnee Road Alexandria, VA 22312

Available electronically at http://www.sti.nasa.gov 


\title{
A Study of the Effects of Altitude on Thermal Ice Protection System Performance
}

\author{
Harold E. Addy, Jr. \\ National Aeronautics and Space Administration \\ Glenn Research Center \\ Cleveland, Ohio 44135 \\ Myron Oleskiw \\ National Research Council Canada \\ Ottawa, Ontario, Canada K1A 0R6 \\ Andy P. Broeren \\ National Aeronautics and Space Administration \\ Glenn Research Center \\ Cleveland, Ohio 44135 \\ David Orchard \\ National Research Council Canada \\ Ottawa, Ontario, Canada K1A 0R6
}

\begin{abstract}
A study of the effects of altitude on an aircraft thermal ice protection system (IPS) performance was conducted. The study included tests of an airfoil model, with a heated-air IPS installed, in an altitude icing wind tunnel at altitude and at ground level conditions. An altitude scaling method was used to simulate the altitude icing conditions at ground level. The study allowed thermal and mass transfer phenomena to be examined. Three different flight scenarios were tested: Descent, Cold Hold, and Warm Hold. The test results showed that heat transfer was accurately simulated using the scaling method. Results of the mass transfer, in terms of amount of ice accreted, were less conclusive, but indicated that mass transfer was not as well matched.
\end{abstract}

\section{Nomenclature}

$\begin{array}{ll}c & \text { model chord } \\ d & \text { twice the model leading edge radius } \\ \text { qdot } & \text { power density } \\ r & \text { recovery factor } \\ s & \text { surface distance } \\ \text { IPS } & \text { ice protection system } \\ K & \text { inertia parameter } \\ K_{0} & \text { modified inertia parameter } \\ \mathrm{LWC} & \text { liquid water content } \\ \mathrm{M} & \text { Mach number } \\ \mathrm{MVD} & \text { median volumetric diameter } \\ M_{w} & \text { water loading } \\ \mathrm{Pr} & \text { Prandtl number } \\ \mathrm{Re} & \text { Reynolds number } \\ \mathrm{Re} & \text { Reynolds number based on droplet diameter } \\ T_{r} & \text { recovery temperature }\end{array}$




$\begin{array}{ll}T_{s t} & \text { static temperature } \\ V_{\text {tas }} & \text { true air speed } \\ \beta_{0} & \text { collection efficiency at stagnation } \\ \delta & \text { droplet median volumetric diameter } \\ \gamma & \text { ratio of specific heats for air } \\ \lambda / \lambda_{\text {Stokes }} & \text { droplet range parameter } \\ \mu_{\text {air }} & \text { air viscosity } \\ \rho_{\text {air }} & \text { air density } \\ \rho_{w} & \text { water density }\end{array}$

\subsection{Background}

Thermal IPSs use heat energy to prevent the buildup of potentially dangerous ice accretions on aircraft when flying in icing conditions. That heat energy must be supplied by the aircraft. As new aircraft are being designed for higher efficiencies, all energy-using systems on the aircraft are being re-examined with an eye toward reducing their energy needs, including thermal IPSs. A thermal anti-icing IPS is designed to evaporate all water impinging on critical exposed surfaces of an aircraft during flight in even the most extreme conditions. This mode of operation is, however, quite energy-intensive. One way in which energy requirements can be greatly reduced is if, under the more severe icing conditions, a thermal IPS is designed to warm the impinging water only enough to allow it to run completely off the aircraft or back to a noncritical area before freezing. Such operation, however, requires that energy requirements be more accurately calculated and evaluated. These energy requirements must account for the many aspects of the aircraft icing process including air temperature, air speed, cloud water content, as well as aircraft altitude. While the effects of altitude, in particular reduced air density and pressure, have always been taken into account in the design of thermal IPSs, a better understanding of these effects is needed so as to enable more exact design, testing, and evaluation of these systems.

Current methods to calculate the heat energy and mass transfer involved with thermal IPS operation are based on empirical relations. Heat transfer coefficients are typically derived from experiments designed to measure heat transfer from flat plates or cylinders. By similarity, the mass transfer coefficient is then assumed to be a function of the heat transfer coefficient. While these approximations have been adequate in the past, a more rigorous validation is needed if accuracy is to be increased, particularly when scaling is applied to account for the effects of altitude.

For these reasons, the National Aeronautics and Space Administration (NASA) and the National Research Council Canada (NRCC) have undertaken an investigation of thermal IPS operation. This study is the first conducted specifically to better understand the effects of altitude on the heat and mass transfer processes occurring during operation of a thermal IPS in flight icing conditions. NRCC provided test time in the Altitude Icing Wind Tunnel (AIWT) in Ottawa, Canada. This facility provided aircraft inflight icing conditions over a range of air speeds, temperatures, and pressure altitudes as well as inflight icing cloud liquid water contents and droplet size spectra. NASA provided a NACA airfoil model equipped with a piccolo tube heated-air IPS. The model was instrumented such that heated-air flow rates and temperatures could be measured and inner surface temperatures of the model's leading edge could be monitored.

\subsection{Prior Research}

Although no studies directly comparing the performance of a thermal IPS operating at altitude with its performance at ground level conditions have been reported, various aircraft icing research efforts have been conducted in the past that are of interest to the current study. These include the development of scaling methods for icing of unprotected surfaces, heat transfer studies, and ground level tests of thermal IPSs. 
Aircraft icing scaling methods for unprotected surfaces have been in development for a number of years. These methods include both geometric scaling for icing tests of subscale models and icing condition scaling for icing wind tunnel tests where a particular test point or points do not fall within the icing envelope that can be produced by the tunnel. Anderson (Ref. 1), Kind and Oleskiw (Ref. 2), and Bartlett (Ref. 3) provide descriptions and evaluations of these methods. While the addition of a relatively large source of heat by a thermal IPS to the icing processes is a major difference, these methods developed for unprotected surfaces can be used as a basis for similar research directed toward surfaces with a thermal IPS. The scaling method employed in this study used select parameters from these methods and are noted in the background section below.

Heat transfer is an important aspect of aircraft icing and has been the focus of a number of studies. In particular, air turbulence level and the transition from laminar to turbulent flow dramatically affect icing, particularly at near-freezing temperatures. This is of particular concern when testing in icing wind tunnels where turbulence levels are typically well above those observed in flight. Research conducted by Newton, et al. (Ref. 4), provided important information on heat transfer in flight. That research was further extended to an icing tunnel by Poinsatte, et al. (Ref. 5) Important conclusions from this research were that, while the turbulence levels measured in the icing tunnel were 5 to 7 or more times as high as that in flight, there was good agreement in heat transfer between flight and tunnel tests at the lower Reynolds number conditions and only a slight increase in heat transfer at the higher Reynolds number conditions. Moreover, the increase in icing tunnel turbulence due to the addition of spray bar air did not change heat transfer over the tunnel operating without spray bar air. A later study by Bragg, et al. (Ref. 6) concluded that the addition of water to the spray did not appreciably change tunnel turbulence over that with the spray bar air only. These studies indicate that icing tunnel turbulence should not be a major factor in the current study.

Miller, Wright, and Al-Khalil (Refs. 7 to 9) conducted tests in the NASA Icing Research Tunnel using an electro-thermal IPS directed toward validating NASA thermal IPS simulation codes. This effort found that the codes were fairly accurate in predicting airfoil surface temperatures when operating an airfoil model with IPS in icing conditions. It was noted that water evaporation and its effect on surface heat and mass transfer is important, as it is in this study, and warranted further research.

\subsection{Facility Description}

The AIWT is a specialized closed-loop low to moderate speed wind tunnel used to simulate in-flight atmospheric icing conditions (see plan view in Fig. 1). It is employed for internal research, for collaboration with other research organizations, and to assist commercial clients with:

- Development, testing or calibration of aircraft or cloud physics instrumentation;

- Development and testing of de- and anti-icing systems;

- Evaluation of ice accretion on non-protected aircraft components;

- Validation of numerical ice accretion codes;

- Studies on basic physical processes leading to ice accretion.

The tunnel's standard test section is $22.5 \mathrm{in}$. square and $6 \mathrm{ft}$ long. The airspeed in this test section can vary from about 10 to $195 \mathrm{kn}$. Two inserts are available to reduce the height of the test section and thus increase the airspeed. The first insert reduces the height to $12 \mathrm{in}$. and leads to a maximum speed of $320 \mathrm{kn}$. The second insert further reduces the height to $10 \mathrm{in}$. with a corresponding maximum airspeed of $365 \mathrm{kn}$. Access panels in the tunnel walls, floor and ceiling provide rapid access to test articles as well as flexibility in their mounting in the test section. Plexiglas windows are commonly installed in the test section to enable photographic or video recording of ice formation and growth. Airspeed in the tunnel is computer-controlled using a variable frequency drive which provides power to the fan's $600 \mathrm{hp}$ motor. Test section flow uniformity and a relatively low turbulence level are enhanced through the use of a honeycomb structure and screen at the entry of the settling chamber. Figure 2 shows a view of the AIWT test section with the operator's console. 


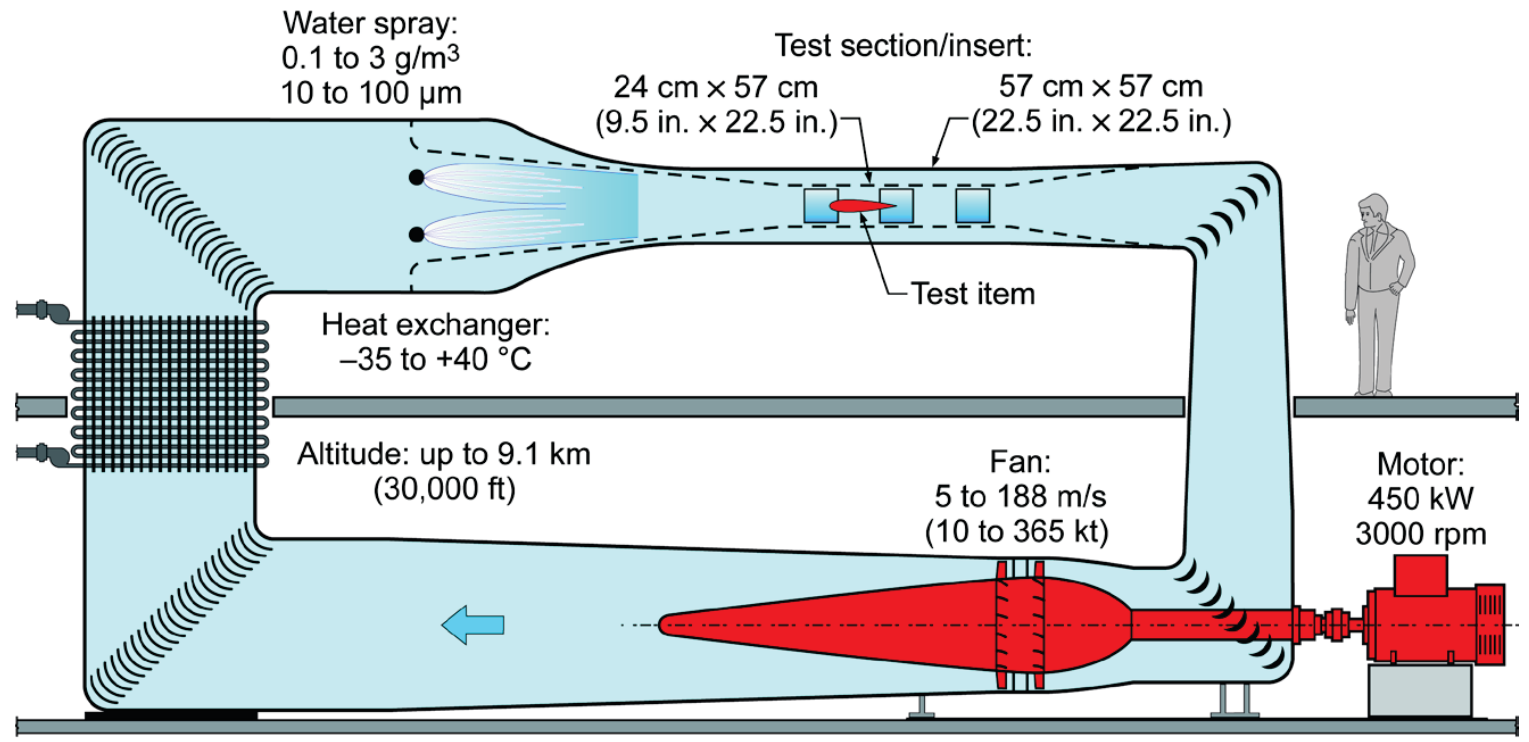

Figure 1.-A cross-sectional view of the National Research Council Canada (NRCC) Altitude Icing Wind Tunnel (AIWT).

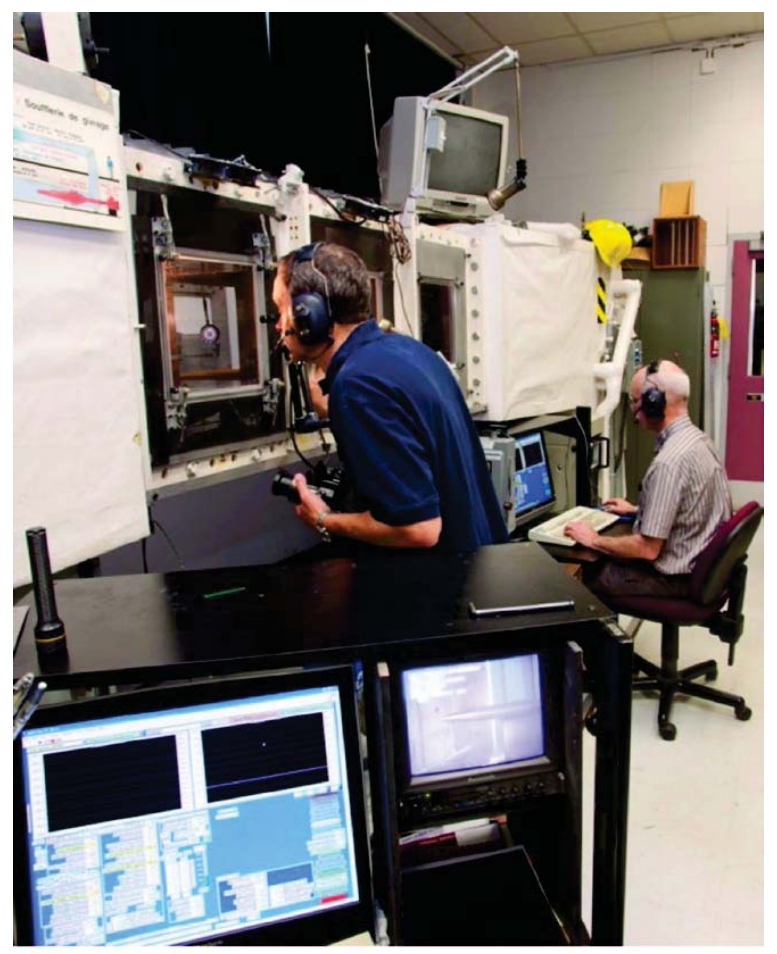

Figure 2.-The AIWT test section with the operator's console in the foreground. 
A heat exchanger located upstream of the tunnel's settling chamber permits rapid changes of air temperature within the test section. The use of a three-way valve to control the flow of chilled trichloroethylene through the heat exchanger permits a high level of temporal stability of air temperature in the tunnel. The closed cell insulation surrounding the tunnel shell assists in the ability to obtain static air temperatures as low as $-30{ }^{\circ} \mathrm{F}\left(-34.4^{\circ} \mathrm{C}\right)$. A thick steel tunnel shell combined with the operation of vacuum pumps permits partial evacuation of the air from the tunnel to simulate flight at altitudes as high as $30,000 \mathrm{ft}$.

Six spray bars are located at the entry to the settling chamber, just downstream of the turbulencereduction screens. Up to 5 of 7 spray nozzles in each spray bar may be selected at any one time in various patterns to ensure adequate spray coverage across the test section. By varying the flow rate of distilled water to the external-mix spray nozzles, the liquid water content (LWC) in the test section may be varied between 0.1 and $3.0 \mathrm{~g} / \mathrm{m}^{3}$. Controlling the spray air pressure permits the median volumetric diameter (MVD) of the spray droplet size distribution to vary between 10 and $100 \mu \mathrm{m}$. Additional details regarding the tunnel are provided in Oleskiw, et al. (Ref. 10).

\subsection{Model Description}

The airfoil model used for this study was an 18-in. chord NACA-0018. A symmetric airfoil was selected for this fundamental study primarily because it reduces the number of complicating factors in the test. A NACA-0012 airfoil was originally considered, largely because it has been extensively and successfully used in many previous fundamental studies of aircraft icing physics. The size of the AIWT test section, however, limits the size of the model to about 18 in. in chord length. For a NACA-0012, an 18 -in. chord results in a leading edge that is too narrow to allow installation of both a thermal IPS and measurement instruments. A hybrid airfoil was considered which would have incorporated a 36-in. chord NACA-0012 leading edge and truncated aft body to result in airfoil with an 18-in. chord. Such a hybrid airfoil, however, results in aerodynamics over the aft portion which might affect ice formed by water running aft along the airfoil surface, known as runback ice. This was undesirable for this study, so the hybrid design was not used. Instead, a NACA-0018 airfoil was chosen. It is a symmetric airfoil with a wider leading edge, allowing more space for installation of a thermal IPS and measurement instruments. Its leading edge also closely matches that of a 36-in. chord NACA-0012, as shown in Figure 3.

The 2D, straight wing model spanned the 22.5 in. wide AIWT from wall to wall. It was constructed of a 0.063 in. thick 7075-T6 aluminum skin on a 0.625 in. thick, 7075 aluminum rib and spar frame. There were two ribs, one at each end, and two spars, near airfoil maximum thickness, as shown in Figure 4 . The trailing edge was also machined from 7075 aluminum.

A heated-air piccolo tube IPS was designed for the model. The primary objective of the design was to provide a $2 \mathrm{D}$ heating system with minimal span-wise variation in the temperature and heat transfer profiles during testing. This would simplify modeling and analysis of the measurements. For these reasons, the forward edge of the full-span piccolo tube was located $1.25 \mathrm{in}$. from the inside of the leading edge and had a single, straight row of 42, 0.032-in. diameter holes spaced 31/64 in. apart. A steel diffuser was designed to direct the heated airflow to and around the inside of the leading edge. Four aluminum ribs were used to maintain the diffuser shape. A cross section of the leading edge of the airfoil showing the IPS design is shown in Figure 5.

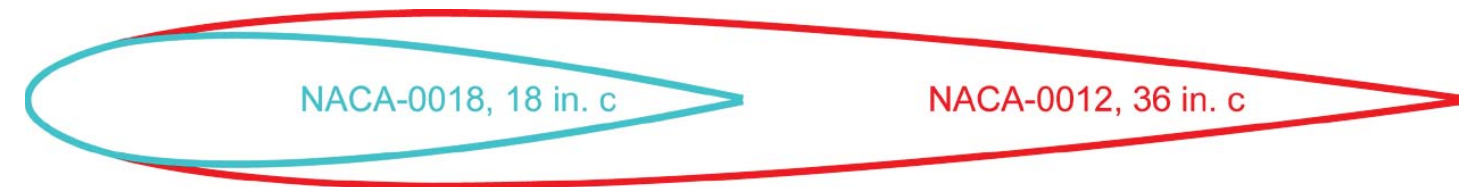

Figure 3.-The 18-inch chord NACA-0018 airfoil compared with a 36-inch chord NACA-0012 airfoil. 


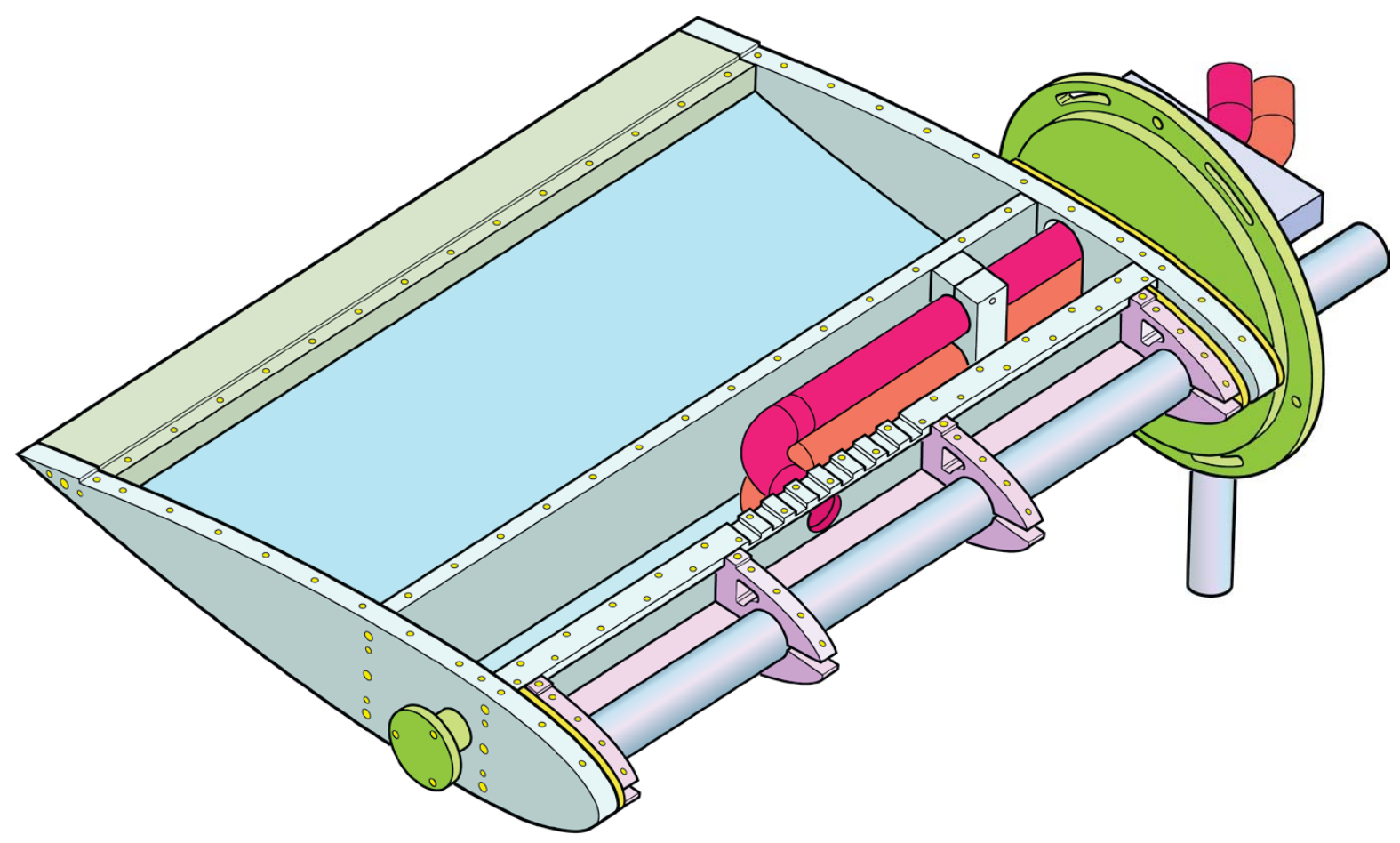

Figure 4.-Model rib and spar layout with piccolo tube ice protection system (IPS) shown.

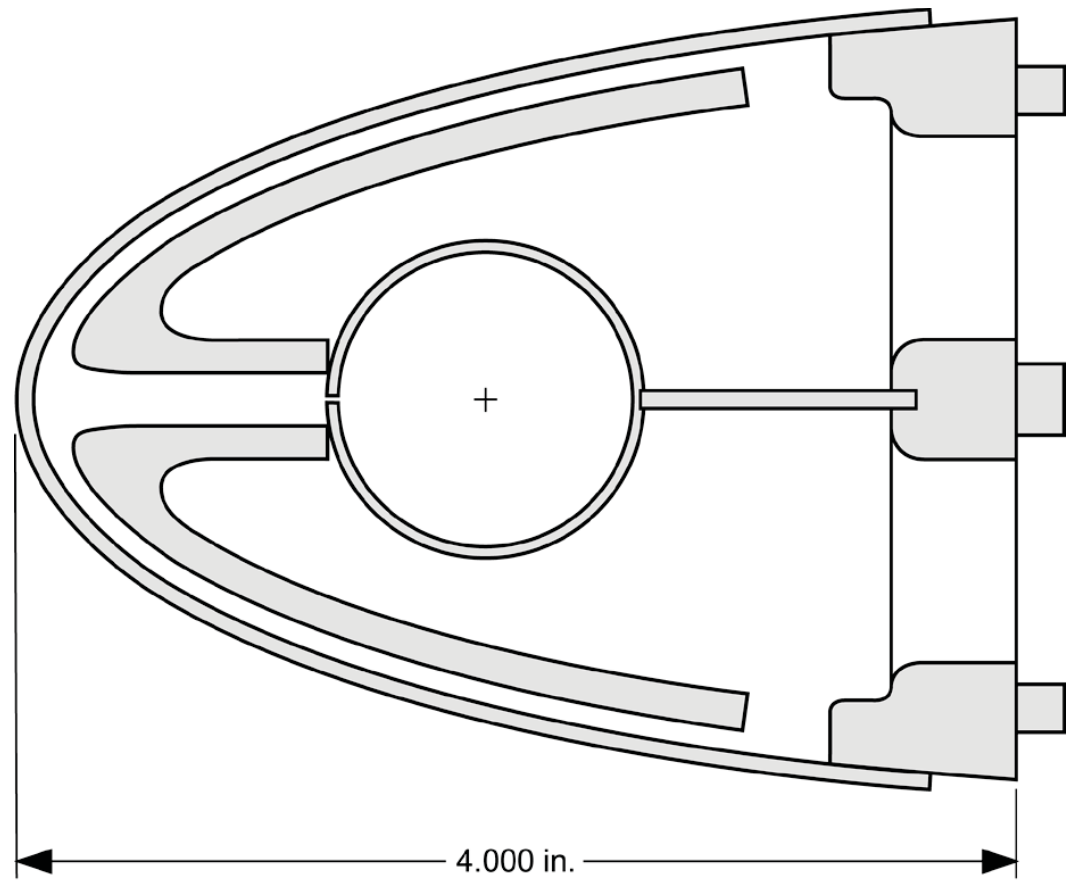

Figure 5.-Model leading edge cross section. 
Heated air was supplied to one end of the piccolo tube where it was directed to the inner surface of the leading edge via small holes. The heated air was then directed along the inner surface of the leading edge by a symmetric diffuser. The heated air exited the model through exhaust pipes mounted to a spar at the aft of the leading edge. The heated exhaust air flowing from the upper surface was kept separate from that flowing from the lower surface by a horizontal wall extending from the aft of the piccolo tube to the spar. Each of these two exhaust flows were measured by a Coriolis flow meter located in the respective exhaust pipe. Manual valves situated downstream of the flow meters were adjusted to ensure proper flow rates maintained equal heating to both the upper and lower surfaces of the leading edge.

Thermocouples were used to measure model surface and heated air temperatures. A total of 25 thin film (0.0005 in. thick), T-type thermocouples were installed on the inner surface of the leading edge using a thin layer (approximately 0.002 in. thick) of thermally-conductive epoxy (M-Bond). The layout of the thermocouples on the leading edge is shown in Figure 6.

Three T-type thermocouples were used to monitor the temperature of the heated air flowing into the model. One was at the entrance to the piccolo tube while two were spaced axially along the center of the tube using a rod device that was inserted into the end of the piccolo tube. Heated air exhaust temperatures were measured using six T-type thermocouples mounted through the front spar as shown in Figure 7.

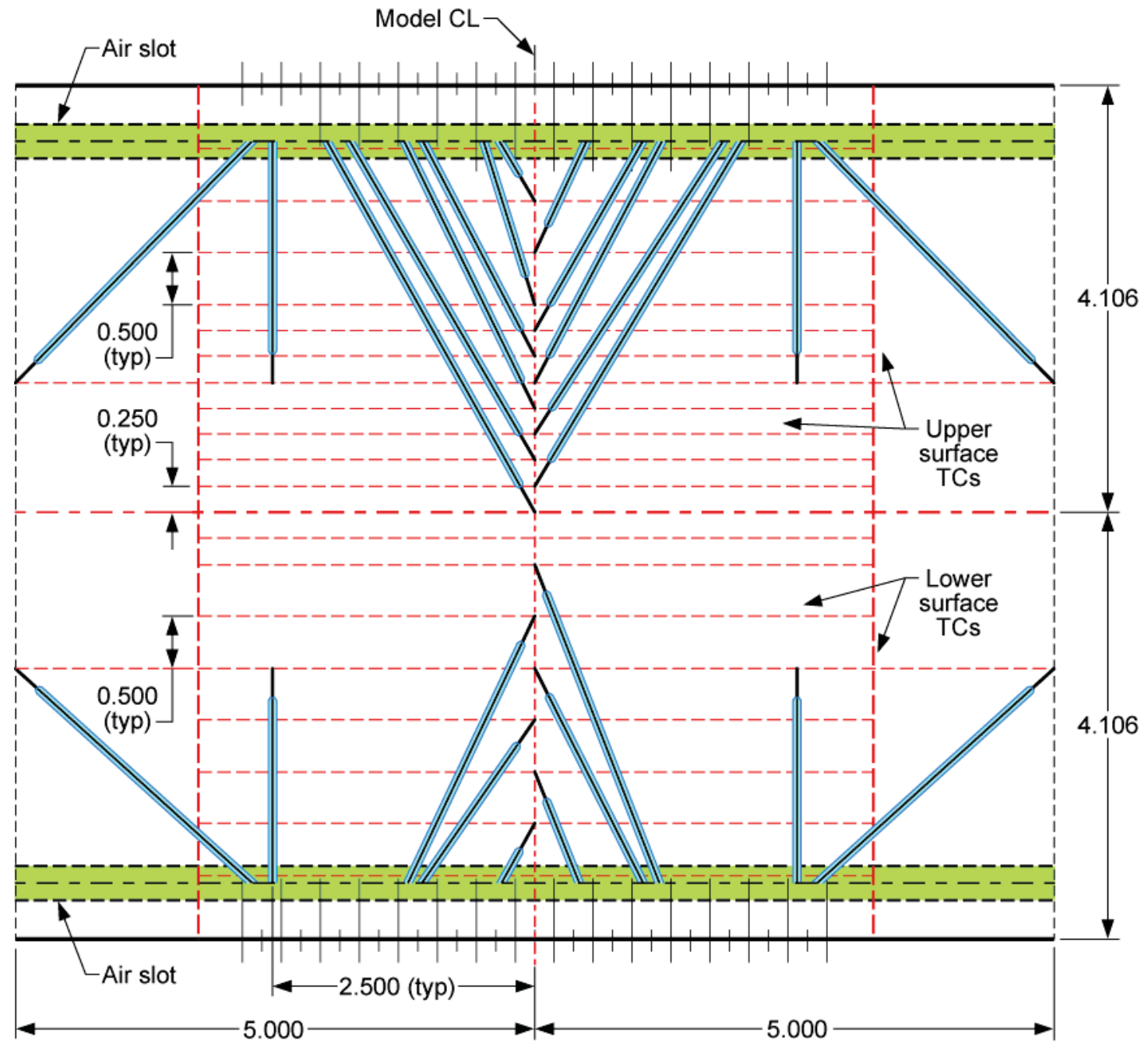

Figure 6.-Leading edge inner surface thermocouple locations. 


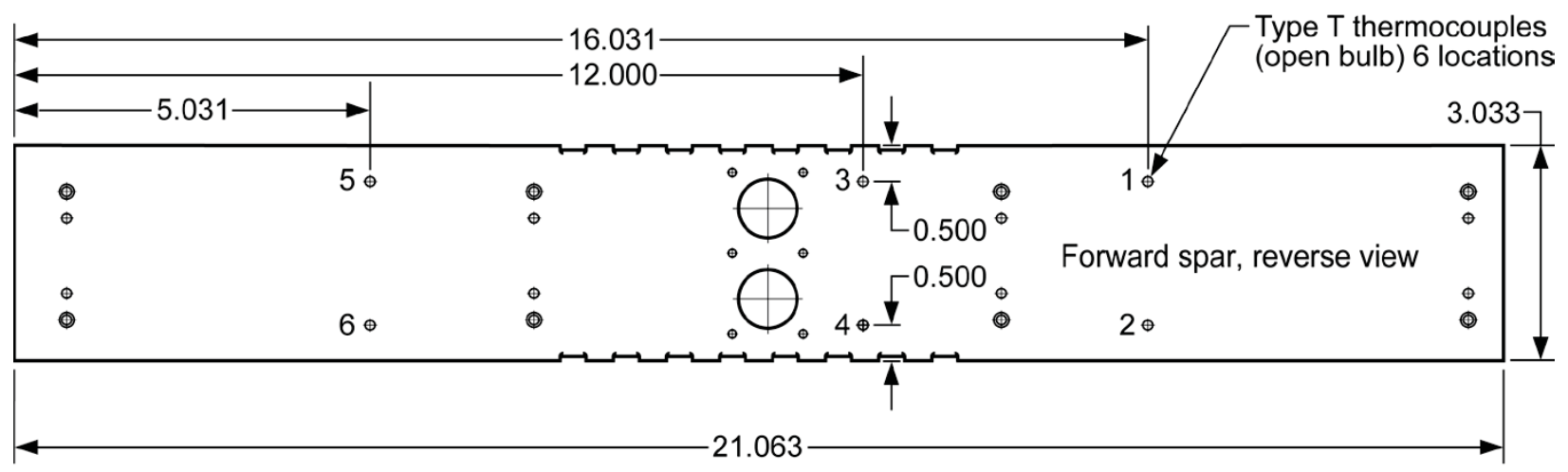

Figure 7.-Heated air exhaust thermocouple locations.

\subsection{Approach}

\subsection{Test Plan}

Icing conditions were selected to approximate three different aircraft icing scenarios at altitude: an aircraft hold at relatively low icing air temperature (Cold Hold), a hold at relatively warm icing temperature (Warm Hold), and a descent at intermediate icing temperature (Descent). These conditions are given in Table 1 and will be referred to as reference conditions throughout the remainder of this report. IPS heated air flow rates and temperatures were set to provide a 'running wet' mode of operation for the ice protection. In this mode, all the water impinging on the leading edge of the model is not evaporated. Some is allowed to flow aft before freezing in an area that is presumably less critical to the model's aerodynamics. For the purposes of this test, however, aerodynamic criticality was not a primary consideration. Instead, the heat and mass transfer phenomena involved in the accretion of ice in conjunction with a heat source (a thermal IPS), is the focus of this study.

The test plan also included runs without the IPS operating. These runs provided data in terms of unprotected ice accretion shapes and masses that could be used for post-test analysis and comparison purposes.

TABLE 1.-REFERENCE CONDITIONS

\begin{tabular}{|c|c|c|c|c|c|c|c|}
\hline Flight phase & $\begin{array}{l}\text { Altitude, } \\
\mathrm{ft}\end{array}$ & $\begin{array}{c}V_{\mathrm{tas}}, \\
\mathrm{kn}\end{array}$ & $\begin{array}{c}\mathrm{AOA}, \\
\operatorname{deg}\end{array}$ & $\begin{array}{c}T_{\text {static }}, \\
{ }^{\circ} \mathrm{F}\end{array}$ & $\begin{array}{c}T_{\text {total, }}, \\
{ }^{\circ} \mathrm{F}\end{array}$ & $\begin{array}{c}\text { LWC, } \\
\mathrm{g} / \mathrm{m}^{3}\end{array}$ & $\begin{array}{c}\text { MVD, } \\
\mu \mathrm{m}\end{array}$ \\
\hline Descent & 10,000 & 180 & 0 & -4.0 & 3.7 & 0.15 & 20 \\
\hline Cold Hold & 15,000 & 180 & 0 & -22.0 & -14.3 & 0.15 & 20 \\
\hline Warm Hold & 15,000 & 180 & 0 & 16.5 & 24.2 & 0.50 & 20 \\
\hline
\end{tabular}

\subsection{Scaling Method}

In addition to the three aircraft icing scenarios at altitude, three corresponding icing conditions at ground level were selected for the test. Because the heat and mass transfer associated with the icing process in the presence of a thermal IPS are known to be affected by air density and pressure, a method to scale for these effects was employed. This method matched the following four parameters at altitude and ground level for each of the three scenarios in the test:

1. External Reynolds number

2. Water loading

3. Modified droplet inertia parameter

4. Recovery temperature 
Empirical analysis has most often found that the heat transfer coefficient is typically a function of the external Reynolds number. Since, by similarity, the mass transfer coefficient is a function of the heat transfer coefficient; both coefficients are dependent on Reynolds number. It follows then, that to obtain similar results at altitude and ground level, the external Reynolds number must be the same for both reference and scale cases. For this study, the following expression for Reynolds number was used (Ref. 1):

$$
\operatorname{Re}=\frac{\rho_{\text {air }} \cdot V_{\text {tas }} \cdot d}{\mu_{\text {air }}}
$$

The amount of water impinging on the leading edge of a model in icing conditions also has a major effect on the ice that forms. Therefore, it is important to maintain the amount of water impinging on the model at the same level for both the altitude and ground level cases. The following expression for water loading was used (Ref. 1):

$$
M_{w}=\mathrm{LWC} \cdot V_{\operatorname{tas}} \cdot \beta_{0}
$$

The area of coverage of the impinging water should also be the same between altitude and ground level. This was achieved by matching the modified droplet inertia parameter (Ref. 1):

$$
K_{0}=\frac{1}{8}+\frac{\lambda}{\lambda_{\text {Stokes }}}\left(K-\frac{1}{8}\right)
$$

where

air

$$
K=\frac{\rho_{w} \cdot \delta^{2} \cdot V_{\mathrm{tas}}}{18 d \mu_{\mathrm{air}}}
$$

$$
\frac{\lambda}{\lambda_{\text {Stokes }}}=\frac{1}{0.8388+0.001483 \operatorname{Re}_{\delta}+0.1847 \sqrt{\operatorname{Re}_{\delta}}}
$$

Air temperature also plays a major role in ice formation. Because matching external Reynolds number between altitude and ground level conditions results in a very different airspeed for the two, it then follows that both total air temperature and static air temperature cannot be matched. For unprotected surfaces, total air temperature is a driving factor, with static air temperature playing a lesser role. In a running wet situation, where the ice forms further aft on the airfoil, static air temperature may play a greater role. Therefore, for this test, it was decided to match recovery temperature, which is between total and static air temperature, but is closer to total.

$$
T_{r}=T_{s t}\left(1+r\left(\frac{\gamma-1}{2}\right) M^{2}\right)
$$

where

$$
r=\sqrt{\operatorname{Pr}}
$$

The scaled conditions for each of the three flight scenarios along with the corresponding conditions at altitude (reference) are given in Table 2 and will be referred to as scale conditions throughout the remainder of this report. 
TABLE 2.-REFERENCE AND CORRESPONDING SCALE CONDITIONS

\begin{tabular}{|c|c|c|c|c|c|c|c|c|c|c|c|}
\hline Flight phase & $\begin{array}{c}\text { Alt., } \\
\mathrm{ft}\end{array}$ & $\begin{array}{l}\mathrm{V}, \\
\mathrm{kn}\end{array}$ & $\begin{array}{c}\mathrm{AOA}, \\
\text { deg }\end{array}$ & $\begin{array}{c}T_{\text {static }}, \\
{ }^{\circ} \mathrm{F}\end{array}$ & $\begin{array}{c}T_{\text {total }}, \\
{ }^{\circ} \mathrm{F}\end{array}$ & $\begin{array}{l}\text { LWC, } \\
\mathrm{g} / \mathrm{m}^{3}\end{array}$ & $\begin{array}{c}\text { MVD, } \\
\mu \mathrm{m}\end{array}$ & $\begin{array}{l}\mathrm{Re}_{\mathrm{d}} \\
\times 10^{6}\end{array}$ & $\begin{array}{c}M_{w}, \\
\mathrm{~g} / \mathrm{m}^{2}-\mathrm{s}\end{array}$ & $K_{0}$ & $\begin{array}{l}T_{r}, \\
{ }^{\circ} \mathrm{F}\end{array}$ \\
\hline Descent(ref) & 10,000 & 180 & 0 & -4.0 & 3.7 & 0.15 & 20.0 & 1.64 & 8.81 & 1.41 & 2.5 \\
\hline (sc) & & 130 & 0 & -0.9 & 3.1 & 0.21 & 24.5 & 1.64 & 8.81 & 1.41 & 2.5 \\
\hline Cld Hld(ref) & 15,000 & 180 & 0 & -22.0 & -14.3 & 0.15 & 20.0 & 1.40 & 9.02 & 1.52 & -15.5 \\
\hline (sc) & & 106 & 0 & -17.8 & -15.1 & 0.25 & 27.8 & 1.40 & 9.02 & 1.52 & -15.5 \\
\hline Wm Hld(ref) & 15,000 & 180 & 0 & 16.5 & 24.2 & 0.50 & 20.0 & 1.29 & 30.0 & 1.50 & 23.0 \\
\hline (sc) & & 105 & 0 & 20.8 & 23.4 & 0.85 & 27.8 & 1.29 & 30.0 & 1.50 & 23.0 \\
\hline
\end{tabular}

The reason for this approach was twofold: a) it permitted a close examination of the heat and mass transfer as well as the associated assumptions involved and b) it will aid in the development of altitude scaling methods for icing tests where altitude simulation is not available.

\subsection{Test Procedure}

Estimates for the thermal IPS's heated air temperature and flow rate were made using past test experience and LEWICE predictions. These values were then adjusted slightly during checkout runs at the reference conditions to obtain runback ice shapes that were judged to be desirable for both recording and computational modeling purposes. The desired ice shape was a runback ridge of ice running continuously across the span of the leading edge of the airfoil. This ice shape can be predicted by 2D ice accretion codes such as LEWICE2D and can be traced on a template fit over the leading edge of the model in the tunnel. The IPS settings determined during checkout runs at the reference conditions were then also used for the scaled conditions.

For each test run, the AIWT was first brought to the desired airspeed and air temperature. For the reference runs, AIWT pressure was set to obtain the desired altitude value. The model IPS operating conditions were also set at the predetermined settings. Once the tunnel and the model had reached steadystate operating conditions, the tunnel's water spray system was activated, exposing the model to icing conditions for a predetermined period of time.

At the conclusion of each test run, photographs were taken of the accreted ice and ice tracings were made to record the shape and location of the ice on the airfoil. Ice depth measurements were also made and then the ice was removed from the model and weighed. Three ice tracings were typically made for each ice accretion; one at the mid-span of the model and one each at $5.25 \mathrm{in}$. on either side of mid-span. This covered an area of relatively uniform LWC for most clouds used in these tests. Since the ice was cut at these locations, the ice mass values reported, unless otherwise noted, are for the ice accreted over the center $10.5 \mathrm{in}$. of the model. Results of the tests will be discussed in terms of these measurements as well as the model leading edge temperatures and heated air flow rates and temperatures.

Model and heated air thermocouples were calibrated before and after the tests and were found to be within $\pm 1{ }^{\circ} \mathrm{C}$. The heated air flow meters were recalibrated after the tests and were found to be accurate to \pm 1 percent. A root-mean-squared error analysis of the heated-air power density calculations yields less than two percent error. The error in ice depth and mass measurements can only be approximated as the techniques used were highly manual. Repeat measurements of ice accreted without the IPS operating indicated that they were likely to be within \pm 10 percent.

\subsection{Pre-Test LEWICE Study}

Prior to running the tests at the AIWT, the LEWICE (Ref. 11) ice accretion code was used to predict the resulting ice shapes using the test conditions to help ensure that the approach and methods employed were sound. Figures 8 to 10 show the LEWICE results from the Descent, Cold Hold, and Warm Hold cases, respectively, for both the altitude and ground level conditions. The close agreement indicates that the scaling method is promising. It should be noted that results from this code using the thermal IPS simulation capability are highly dependent upon how the surface grid and boundary conditions are set up. 
Final ice shape, thermal/altitude test, NACA0018 -.-.- Airfoil

$180.0 \mathrm{kn}, 0^{\circ} \mathrm{AOA}, 20.0 \mathrm{MVD}, 0.15 \mathrm{LWC}, 3.7^{\circ} \mathrm{F}$

130.0 kn, $0^{\circ} \mathrm{AOA}, 24.5 \mathrm{MVD}, 0.21 \mathrm{LWC},-0.9^{\circ} \mathrm{F}$

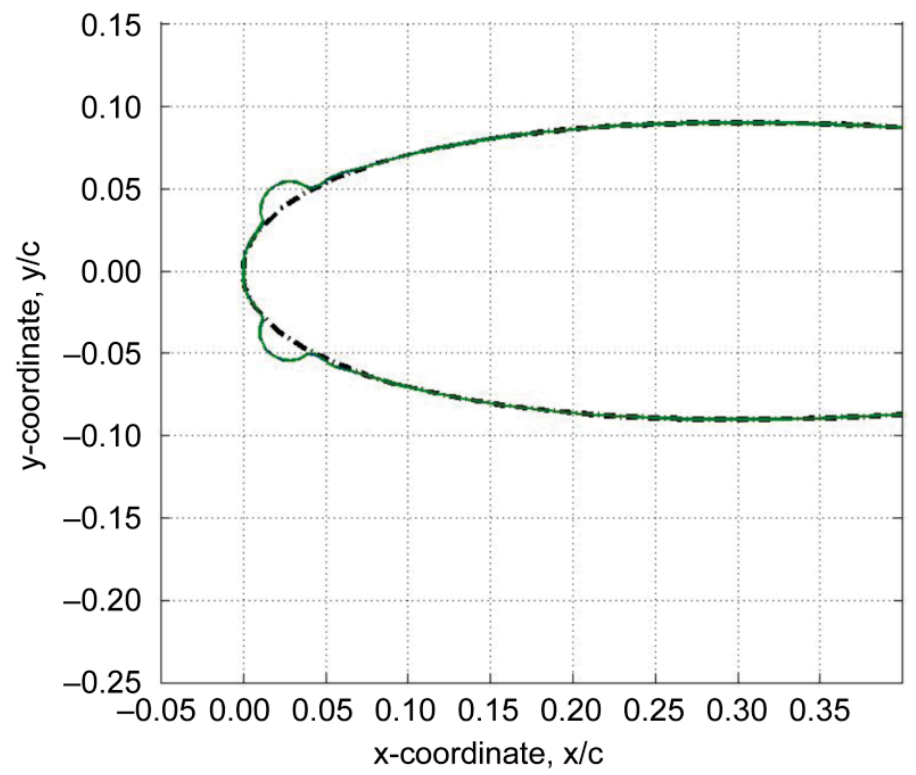

Figure 8.-LEWICE results for Descent; both reference and scale conditions.

Final ice shape, thermal/altitude test, NACA0018 -..-- Airfoil

- $180.0 \mathrm{kn}, 0^{\circ} \mathrm{AOA}, 20.0 \mathrm{MVD}, 0.15 \mathrm{LWC},-22.0^{\circ} \mathrm{F}$ 105.9 kn, $0^{\circ} \mathrm{AOA}, 27.8 \mathrm{MVD}, 0.25 \mathrm{LWC},-17.8^{\circ} \mathrm{F}$

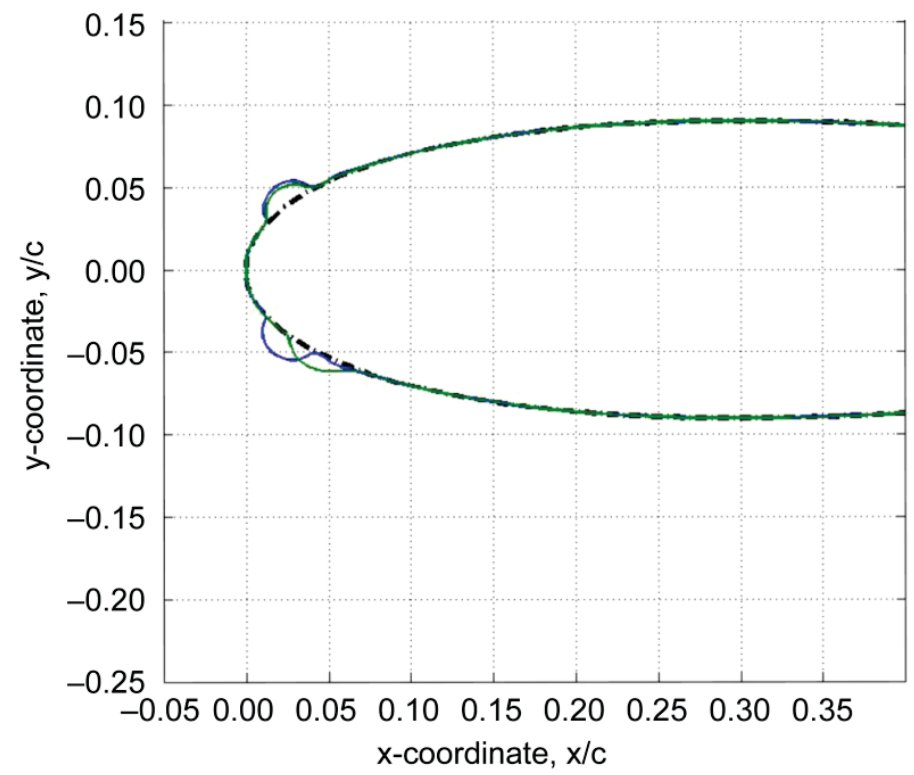

Figure 9._LEWICE results for Cold Hold; both reference and scale conditions. 


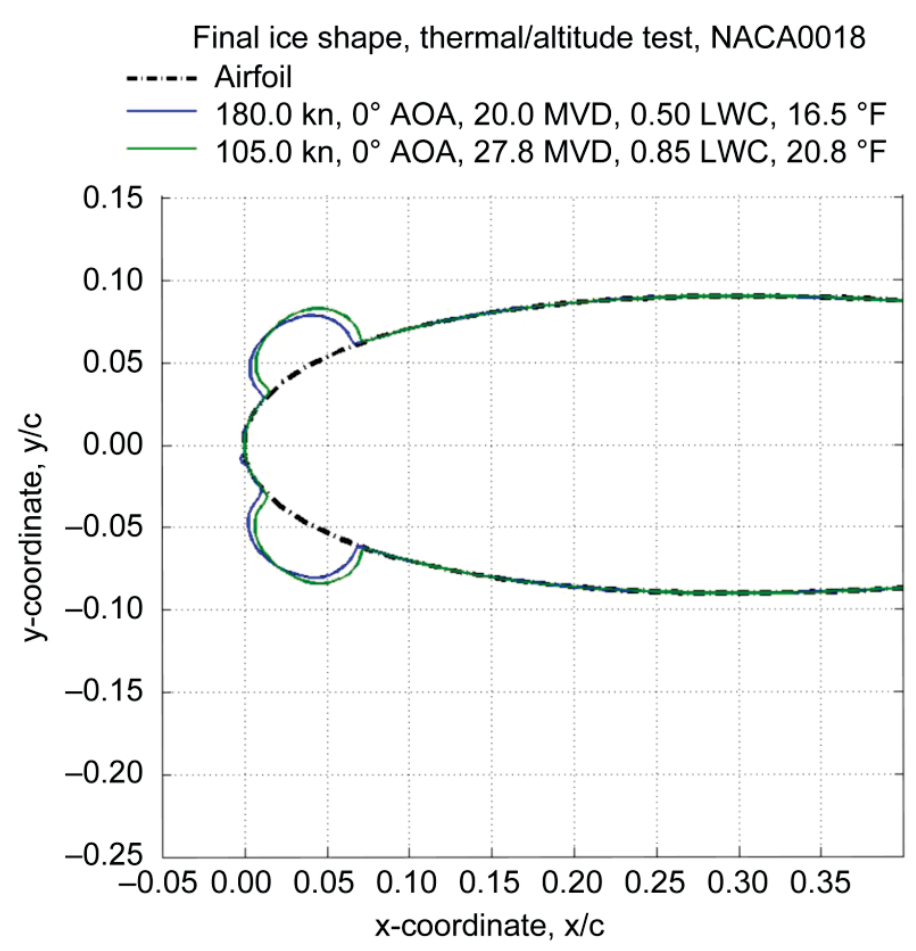

Figure 10.-LEWICE results for Warm Hold; both reference and scale conditions.

\subsection{Results}

\subsection{Post Test Data Analysis}

During post-test calibration of the AIWT, it was found that the cloud operating settings produced droplet sizes that differed from those desired. The calibration found that the droplet sizes for the reference conditions in each case were smaller than intended and they were larger than intended for the scaled cases. This affected two of the four parameters that were to be matched in the scaling method. The actual values for modified inertia parameter, $K_{0}$, and water loading, $M_{w}$, were no longer matched between their respective reference and scale values. Both the intended and actual test conditions and resulting scale parameters are given in Table 3.

TABLE 3.-INTENDED AND ACTUAL (SHOWN IN BOLD) CONDITIONS

\begin{tabular}{|c|c|c|c|c|c|c|c|c|c|c|c|}
\hline $\begin{array}{l}\text { Flight } \\
\text { phase }\end{array}$ & $\begin{array}{c}\text { Alt., } \\
\mathrm{ft}\end{array}$ & $\begin{array}{c}V_{\text {tas }}, \\
\mathrm{kn}\end{array}$ & $\begin{array}{c}\mathrm{AOA}, \\
\operatorname{deg}\end{array}$ & $\begin{array}{c}T_{\text {static }}, \\
{ }^{\circ} \mathrm{F}\end{array}$ & $\begin{array}{c}T_{\text {total }}, \\
{ }^{\circ} \mathrm{F}\end{array}$ & $\begin{array}{c}\text { LWC, } \\
\mathrm{g} / \mathrm{m}^{3}\end{array}$ & $\begin{array}{c}\text { MVD, } \\
\mu \mathrm{m}\end{array}$ & $\begin{array}{c}\mathrm{Re}_{d} \\
\times 10^{6}\end{array}$ & $\begin{array}{c}M_{w} \\
\mathrm{~g} / \mathrm{m}^{2}-\mathrm{s}\end{array}$ & $K_{0}$ & $\begin{array}{l}T_{r}, \\
{ }^{\circ} \mathrm{F}\end{array}$ \\
\hline \multirow[t]{2}{*}{ Descent(ref) } & 10,000 & 180 & 0 & -4.0 & 3.7 & 0.15 & 20.0 & 1.64 & 8.81 & 1.41 & 2.5 \\
\hline & 10,000 & 180 & $\mathbf{0}$ & -4.0 & 3.7 & 0.14 & 17.9 & 1.63 & 7.74 & 1.19 & 2.5 \\
\hline \multirow[t]{2}{*}{ (sc) } & & 130 & 0 & -0.9 & 3.1 & 0.21 & 24.5 & 1.64 & 8.81 & 1.41 & 2.5 \\
\hline & & 130 & $\mathbf{0}$ & -0.9 & 3.1 & 0.22 & 28.1 & 1.59 & 9.98 & 1.75 & 2.4 \\
\hline \multirow[t]{2}{*}{ Cld Hld(ref) } & 15,000 & 180 & 0 & -22.0 & -14.3 & 0.15 & 20.0 & 1.40 & 9.02 & 1.52 & -15.5 \\
\hline & 15,000 & 180 & $\mathbf{0}$ & -22.0 & -14.3 & 0.15 & 16.2 & 1.39 & 8.03 & 1.10 & -15.5 \\
\hline \multirow[t]{2}{*}{ (sc) } & & 106 & 0 & -17.8 & -15.1 & 0.25 & 27.8 & 1.40 & 9.02 & 1.52 & -15.5 \\
\hline & & 106 & $\mathbf{0}$ & -17.8 & -15.1 & 0.26 & 32.6 & 1.36 & 9.91 & 1.95 & -15.5 \\
\hline \multirow[t]{2}{*}{ Wm Hld(ref) } & 15,000 & 180 & 0 & 16.5 & 24.2 & 0.50 & 20.0 & 1.29 & 30.0 & 1.50 & 23.0 \\
\hline & 15,000 & 180 & $\mathbf{0}$ & 16.3 & 24.0 & 0.48 & 16.3 & 1.29 & 25.6 & 1.09 & 22.8 \\
\hline \multirow[t]{2}{*}{ (sc) } & & 105 & 0 & 20.8 & 23.4 & 0.85 & 27.8 & 1.29 & 30.0 & 1.50 & 23.0 \\
\hline & & 105 & $\mathbf{0}$ & 20.8 & 23.4 & 0.87 & 29.8 & 1.27 & 31.4 & 1.67 & 23.0 \\
\hline
\end{tabular}


The values for $K_{0}$ were most affected with the scale values being greater than the corresponding reference values. For the Descent case, the $K_{0}$ scale value was 42.8 percent greater than the reference value; for the Cold Hold case, it was 77.3 percent greater; and the Warm Hold case, it was 50.0 percent higher. The scale values for $M_{w}$ were also greater than there corresponding reference values. In the Descent case, it was 28.9 percent higher; in the Cold Hold case, it was 23.4 percent higher; and in the Warm Hold case, the $M_{w}$ scale value was 21.6 percent higher than the reference value.

Of these two parameters, $K_{0}$ and $M_{w}, M_{w}$ is likely to have a greater influence on the results. $K_{0}$ affects the droplet impingement limits and the collection efficiency, but $M_{w}$ drives the rate of ice buildup or, in the instance of an IPS, the amount of power required to prevent or dramatically reduce ice buildup.

The results of this study, therefore, are less clear than they would have been otherwise. Nonetheless, this test, being the first of this particular nature, is of interest and, moreover, conclusions can still be drawn, albeit with slightly less certainty.

\subsection{Descent Case}

Figures 11(a) and (b) show photographs of the ice accreted on the model for both the reference and scale conditions for the Descent case. Qualitatively, the ice shapes are similar. This similarity is reflected in the mid-span ice tracings shown in Figure 12. The tracings do, however, show that more ice was accreted at the scale conditions and that it froze slightly further aft on the model. The measured masses of ice and the height of the ice on both the upper and lower surfaces for both reference and scale conditions are given in Table 4.
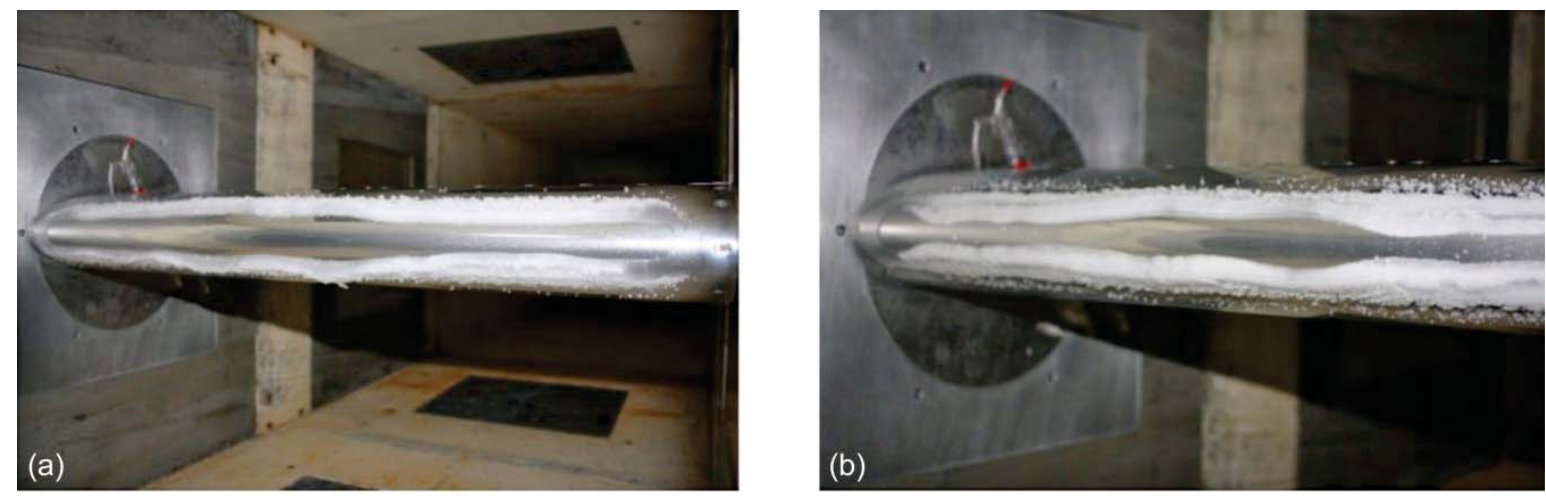

Figure 11.-Descent ice accretion photographs for (a) reference and (b) scale conditions.

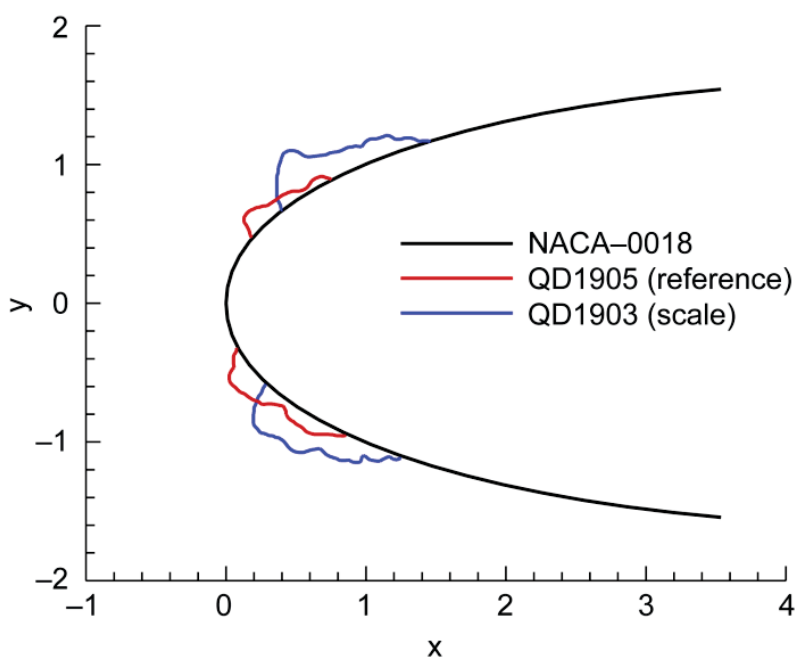

Figure 12.-Descent ice tracings at model mid-span for the reference and scale conditions. 
TABLE 4.-DESCENT CASE RESULTS

\begin{tabular}{|l|c|c|c|c|c|c|c|c|c|c|c|}
\hline Flight Phase & $\begin{array}{c}\text { Alt., } \\
\mathrm{ft}\end{array}$ & $\begin{array}{c}V_{\text {tas, }} \\
\mathrm{kn}\end{array}$ & $\begin{array}{c}\mathrm{AOA}, \\
\mathrm{deg}\end{array}$ & $\begin{array}{c}T_{\text {static, }}{ }^{\circ} \mathrm{F} \\
{ }\end{array}$ & $\begin{array}{c}T_{\text {total, }} \mathrm{F} \\
\mathrm{o}\end{array}$ & $\begin{array}{c}\mathrm{LWC}, \\
\mathrm{g} / \mathrm{m}^{3}\end{array}$ & $\begin{array}{c}\mathrm{MVD}, \\
\mu \mathrm{m}\end{array}$ & $\begin{array}{c}\tau, \\
\mathrm{s}\end{array}$ & $\begin{array}{c}\text { Up ice, } \\
\text { in. }\end{array}$ & $\begin{array}{c}\text { Lo ice, } \\
\text { in. }\end{array}$ & $\begin{array}{c}\text { Ice } \\
\text { mass, } \\
\mathrm{g}\end{array}$ \\
\hline Descent(ref) & 10,000 & 180 & 0 & -4.0 & 3.7 & $\mathbf{0 . 1 4}$ & $\mathbf{1 7 . 9}$ & 600 & 0.14 & 0.18 & 29 \\
Descent(sc) & & 130 & 0 & -0.9 & 3.1 & 0.22 & $\mathbf{2 8 . 1}$ & 600 & 0.18 & 0.22 & 54 \\
\hline
\end{tabular}

Figure 13 shows the model surface temperatures during the run both before exposing the model to the cloud (dry) and again during exposure to the cloud (wet). The close agreement between the reference and scale in the dry conditions indicate the degree to which matching Reynolds number matches heat transfer between the two. There is more of a difference between the surface temperatures in the wet conditions. Here, the confounding effects of differing $M_{w}$ and $K_{0}$ make it difficult to ascertain the cause. It is expected that the increased loading of supercooled water in the scale conditions would result in lower surface temperatures, but this is not the case. Instead, increased surface cooling was observed during the wet reference conditions. Increased evaporative cooling is expected at the reference conditions due to the lower tunnel air pressure. Mathematical models to calculate the amount of evaporative cooling in this situation, however, are approximate and have not been validated.

The measured reference and scale IPS heated air inlet and outlet temperatures for both the dry and wet conditions for this case are shown in Figure 14(a). Similarly, the heat energy used by the IPS is shown in Figure 14(b). The close agreement between reference and scale values for these parameters even though $M_{w}$ was 28.9 percent higher and $K_{0}$ was 42.8 percent higher in the scale conditions shows that this IPS is not greatly affected by such changes in external icing conditions.

During pre-test analysis, calculations indicated that the water evaporation rate would be slightly higher for the reference conditions than in the scale conditions. Further calculations showed that the evaporation rate for the scale conditions could be raised by slightly increasing the surface temperatures of the model by increasing the heated air temperature supplied to the model IPS. A test run was, therefore, made with the surface temperatures increased by $2.8^{\circ} \mathrm{C}\left(5.0^{\circ} \mathrm{F}\right)$. Results of this test run are shown in the photograph in Figure 15 and the ice tracings in Figure 16. The resulting scale ice accretion was reduced slightly in size and mass, but is still different from the reference ice accretion. The ice was also accreted further aft on the model than in the initial scale run. The desired scale-condition ice accretion is one that matches the reference ice accreted in size, shape, and location. As expected, the surface temperature profiles, shown in Figure 17, as well as the heated air inlet and outlet temperatures and heat energy plots, shown in Figure 18 , reflect the increased heated air supply temperature.

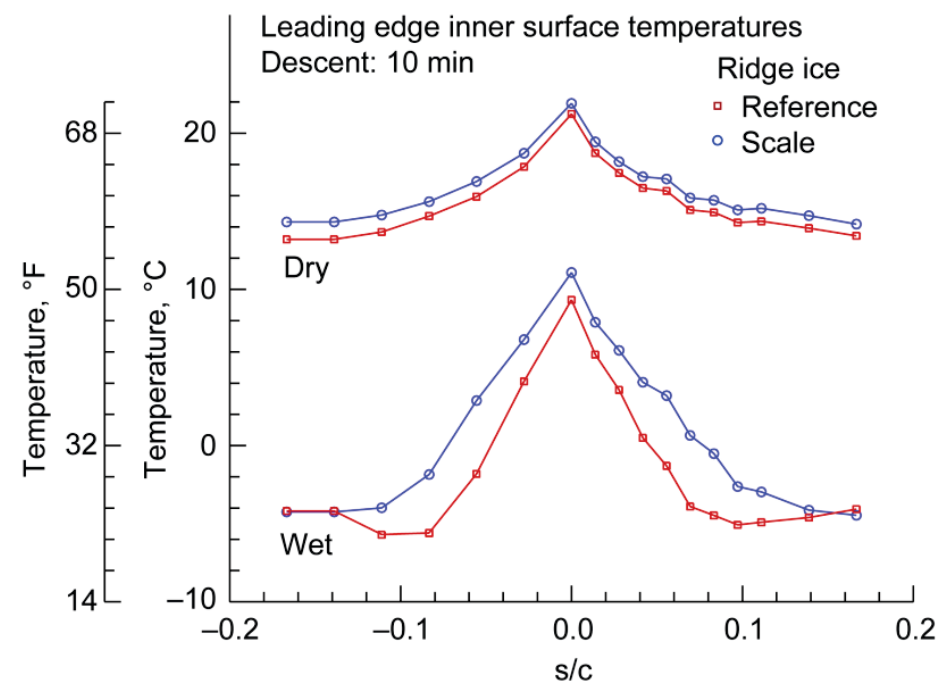

Figure 13.-Descent surface temperatures before and during exposure to icing cloud. 

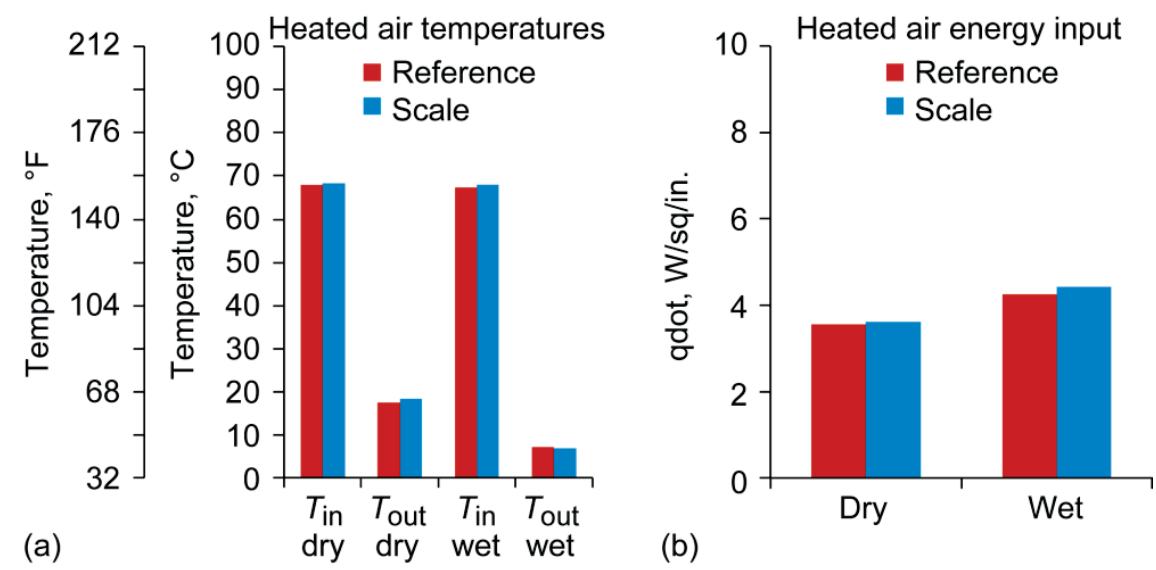

Figure 14.-Descent (a) heated air temperatures and (b) heated air energy input before and during exposure to icing cloud.

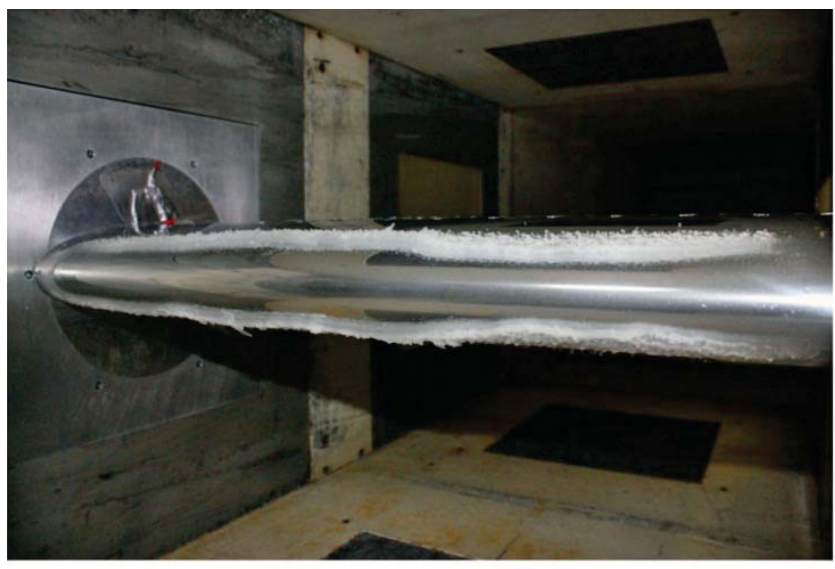

Figure 15.-Descent for scaled conditions with model surface temperature increased $2.8^{\circ} \mathrm{C}\left(5.0^{\circ} \mathrm{F}\right)$.

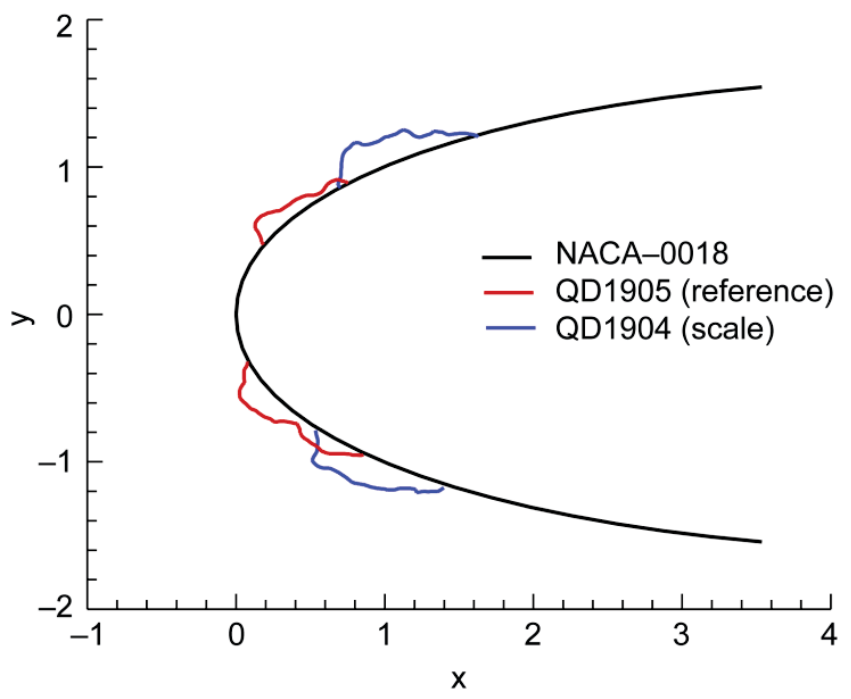

Figure 16.-Descent ice tracing for scaled conditions with increased surface temperature compared with reference ice tracing. 


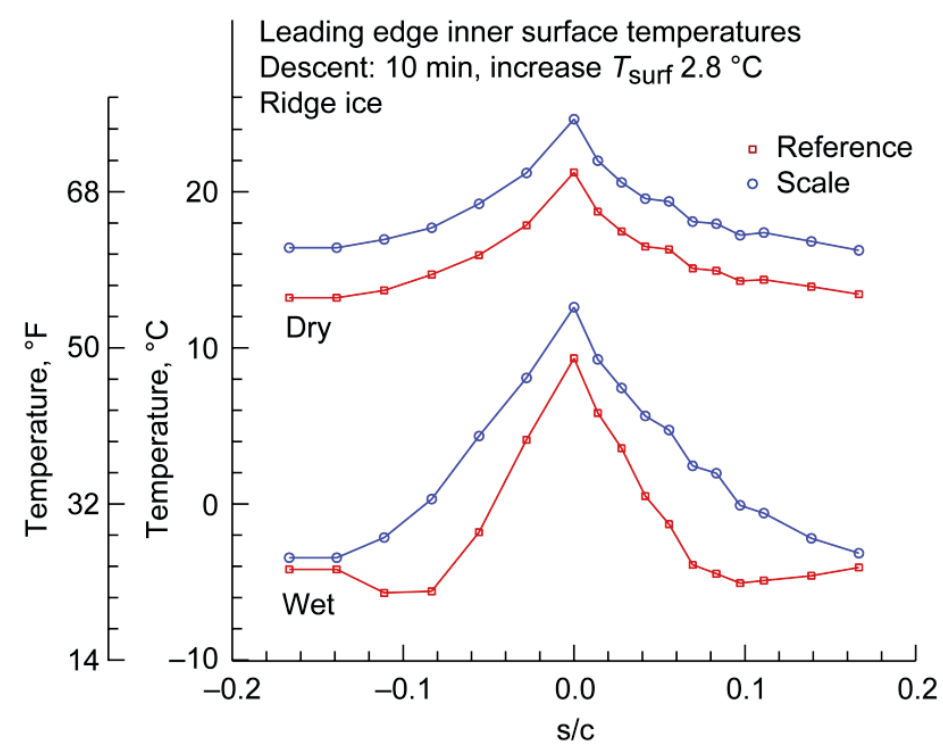

Figure 17.-Surface temperatures for Descent for scaled conditions with increased surface temperatures compare with reference surface temperatures.
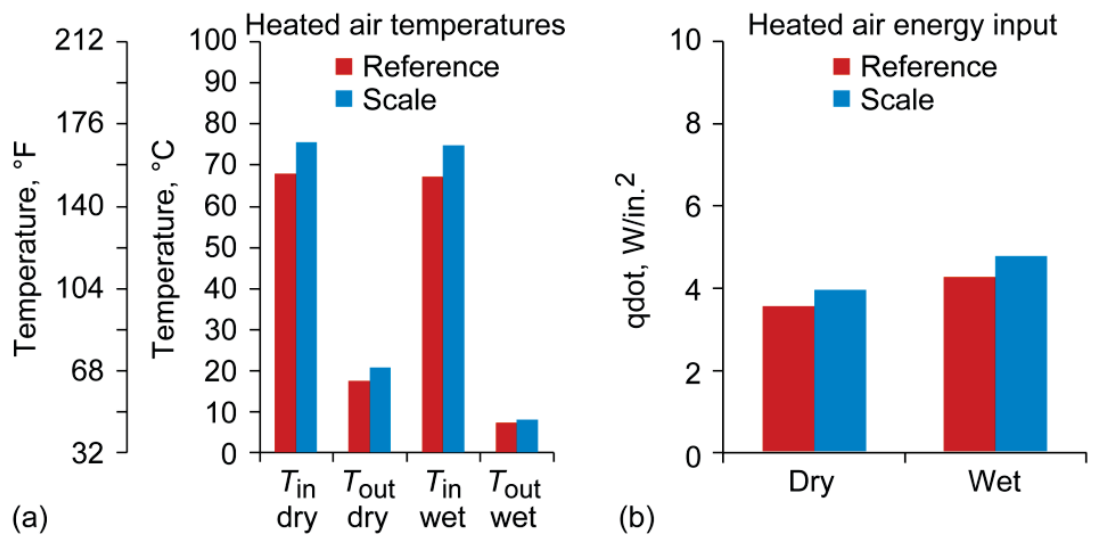

Figure 18.-(a) Heated air inlet and outlet temperatures and (b) heated air energy input for Descent at scale conditions with increased model surface temperatures compared with reference case.

\subsection{Cold Hold Case}

For tunnel operation purposes, the scale conditions were run first for this Cold Hold case only. No checkout run was performed for the reference conditions, therefore, the reference ice accretion was not the result of adjusting the IPS settings to obtain a more desirable accretion. The case was not repeated due to time and priority considerations.

Photographs of the ice accreted for the reference and scale conditions of the Cold Hold case are shown in Figure 19. The mid-span ice tracings are shown in Figure 20. Unfortunately, a relatively large piece of ice shed from the upper surface of the model during the run at reference conditions. The shed ice prevents a quantitative comparison of the upper surface ice thickness, and overall mass. The ice on the lower surface was fairly similar, however, and it is not unreasonable to assume the upper ice accretions would also have been similar had the piece of ice not been shed. It will be noted that the ice accretion formed more forward in these runs. The measured ice height and mass data for this case are given in Table 5. 

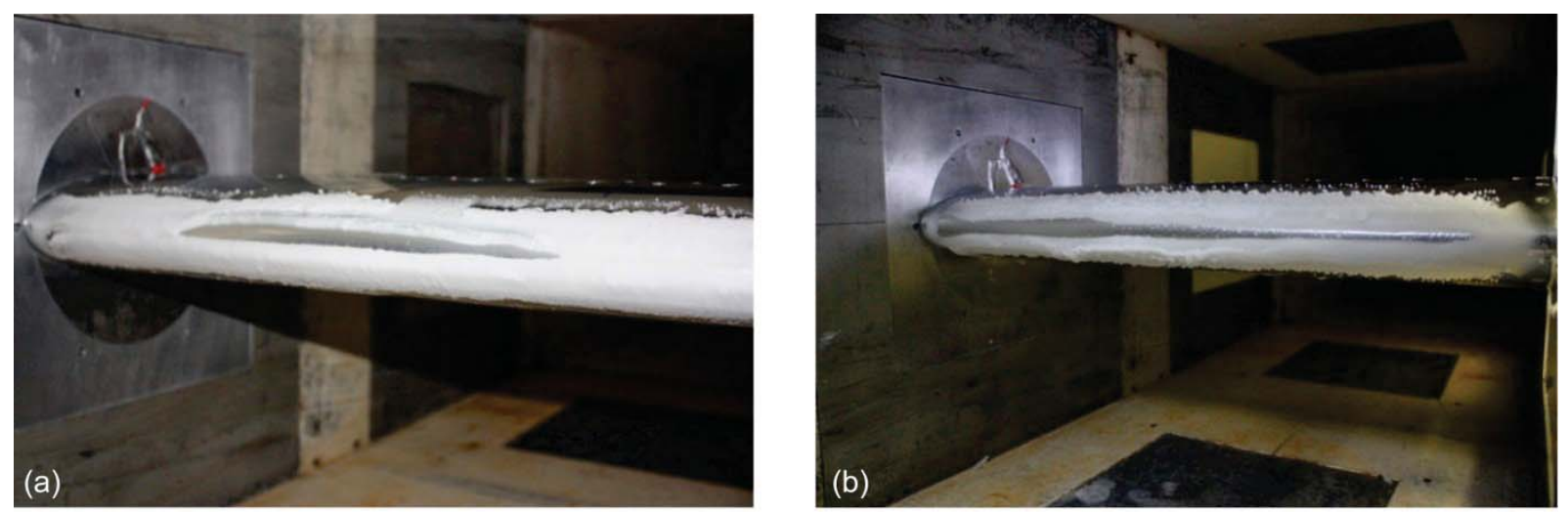

Figure 19.-Cold Hold ice accretions for (a) reference and (b) scale conditions.

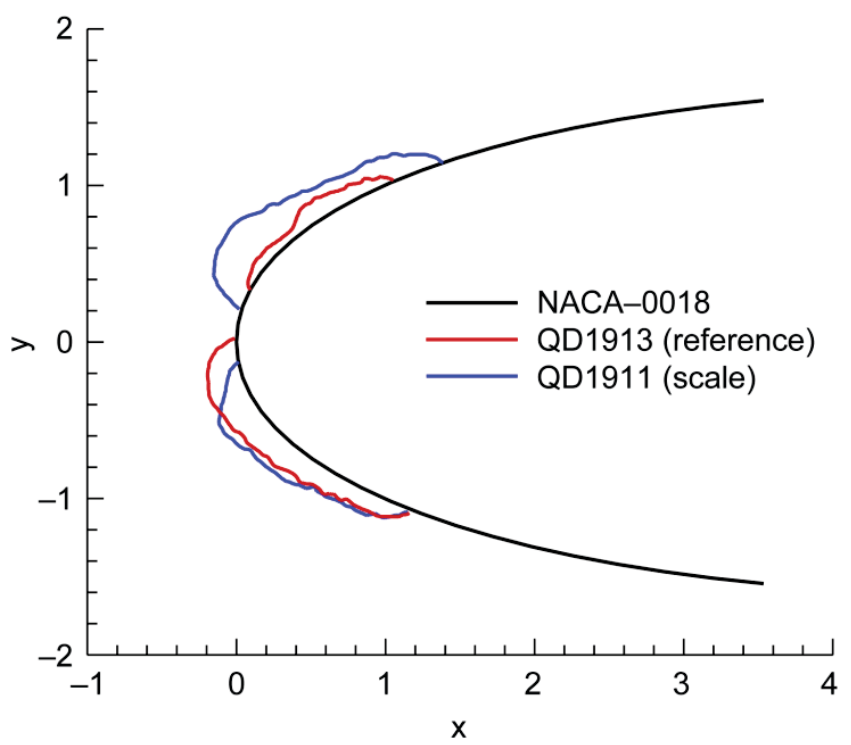

Figure 20.-Cold Hold ice tracings.

TABLE 5.-COLD HOLD CASE RESULTS

\begin{tabular}{|l|c|c|c|c|c|c|c|c|c|c|c|}
\hline \multicolumn{1}{|c|}{ Flight phase } & $\begin{array}{c}\text { Alt., } \\
\mathrm{ft}\end{array}$ & $\begin{array}{c}V_{\text {tas, }} \\
\mathrm{kn}\end{array}$ & $\begin{array}{c}\mathrm{AOA}, \\
\mathrm{deg}\end{array}$ & $\begin{array}{c}T_{\text {static, }} \\
{ }^{\circ} \mathrm{F}\end{array}$ & $\begin{array}{c}T_{\text {total, }}{ }^{\circ} \mathrm{F} \\
\mathrm{g} / \mathrm{m}^{3}\end{array}$ & $\begin{array}{c}\mathrm{LWC}, \\
\mu \mathrm{m},\end{array}$ & $\begin{array}{c}\tau, \\
\mathrm{s}\end{array}$ & $\begin{array}{c}\text { Up ice, } \\
\text { in. }\end{array}$ & $\begin{array}{c}\text { Lo ice, } \\
\text { in. }\end{array}$ & $\begin{array}{c}\text { Ice } \\
\text { mass, } \\
\mathrm{g}\end{array}$ \\
\hline Cld Hld(ref) & 15,000 & 180 & 0 & -22.0 & -14.3 & $\mathbf{0 . 1 5}$ & $\mathbf{1 6 . 2}$ & 600 & 0.12 & 0.20 & 25 \\
Cld Hld(sc) & & 106 & 0 & -17.8 & -15.1 & $\mathbf{0 . 2 6}$ & $\mathbf{3 2 . 6}$ & 600 & 0.20 & 0.23 & 56 \\
\hline
\end{tabular}

Model surface temperatures for this case are shown in Figure 21. The dry model temperature profiles are nearly the same for the reference and scale icing conditions, again indicating similarity in heat transfer. For icing cloud on, wet surface conditions, the reference surface temperature profile, as in the Descent case, is lower than the profile for the scale conditions. Here, $M_{w}$ is 23.4 percent higher and $K_{0}$ is 77.3 percent higher in the scale conditions. Figure 22 shows the heated air temperatures and heat energy used by the IPS. Once again, IPS operating parameters are not greatly affected by such deviations from the target icing condition parameters, $M_{w}$ and $K_{0}$. 


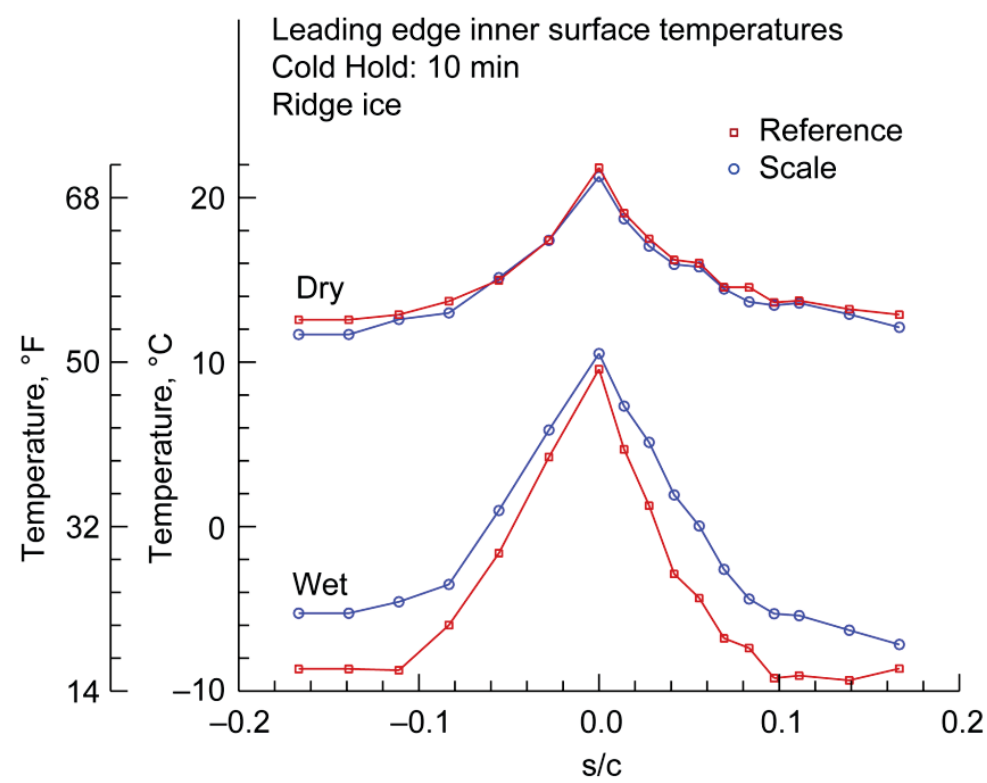

Figure 21.-Cold Hold surface temperatures before and during exposure to icing cloud.
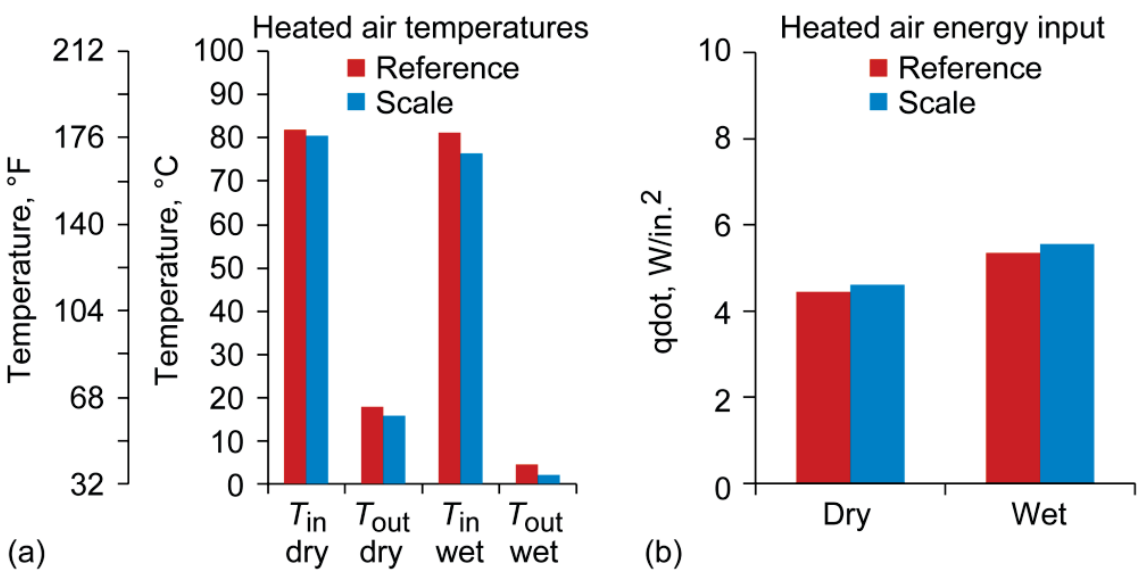

Figure 22.-Cold Hold (a) heated air temperatures and (b) heated air energy input before and during exposure to icing cloud.

\subsection{Warm Hold Case}

Warmer ambient air temperatures typically result in ice accretions of less structural strength while higher water loading conditions usually result in larger ice accretions. The combination of these two factors made the Warm Hold case the most challenging for which to obtain measurable runback ice. Several initial runs at the reference conditions were made during which large portions of ice were shed before reaching the end of the designated $10 \mathrm{~min}$ icing exposure period. The exposure time was then reduced to seven minutes and a run at reference conditions was completed without ice shedding. A photograph of the ice accreted at the reference conditions, along with the centerline ice tracing, are shown in Figures 23(a) and (b), respectively. When the scale conditions were run, however, the runback ice did not form a ridge. It instead froze in the form of rivulets further aft on the airfoil. Photographs of this ice are shown in Figure 24(a) and (b). This frozen rivulet ice did not lend itself to the tracing method used for the runback ridge ice. The tracing templates did not extend far enough aft in the chordwise direction to capture this ice. Moreover, frozen rivulet ice is oriented primarily in the chordwise direction, with 
relatively large spaces between the rivulets in the spanwise direction. Because the tracing templates were not designed to trace this type of ice, no tracings were made. The thickness of the frozen rivulets was, however, measured using a depth gage in the forward part of the rivulet. The ice was removed from the model and weighed, similar to the instances where ridge ice formed; however, all of the rivulet ice was removed and weighed, instead of weighing only the ice from the center section $10.5 \mathrm{in}$. section of the airfoil. The ice depth and mass data for this case are shown in Table 6.

For this case, the post-test tunnel cloud calibration yielded an $M_{w}$ that was 21.6 percent higher and a $\mathrm{K}_{0}$ that was 50.0 percent higher for the scale conditions. It appears likely that these deviations in cloud conditions resulted in dramatically different ice accretions. Although verification of this observation is warranted, it would illustrate the highly non-linear nature of icing at near-freezing temperatures.
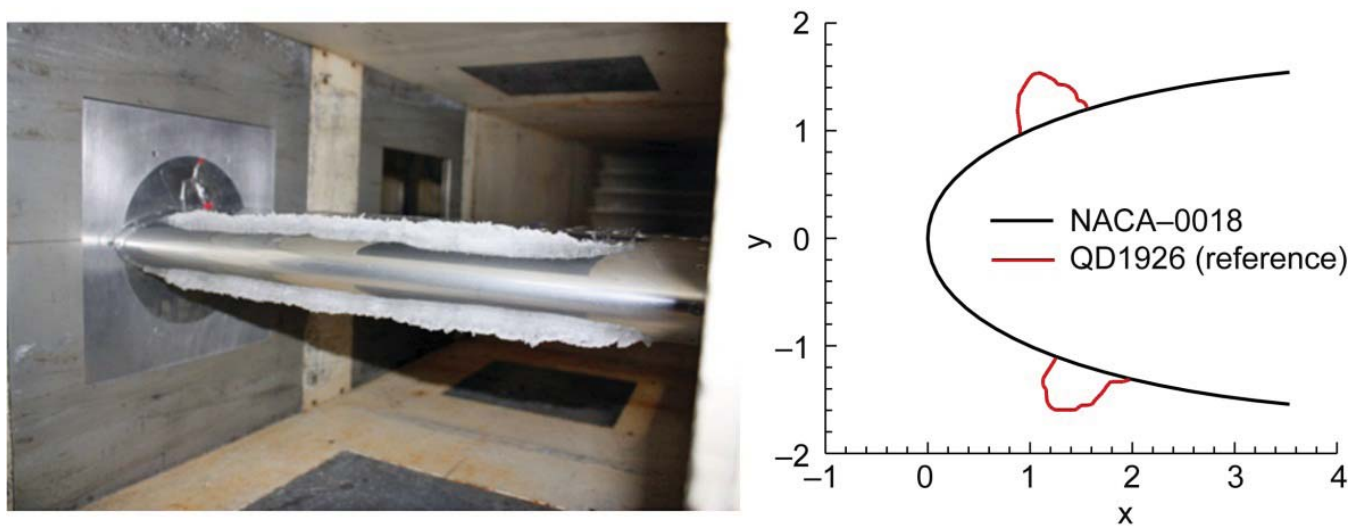

Figure 23.-(a) Warm Hold ice accretion and (b) mid-span ice tracing for reference conditions.
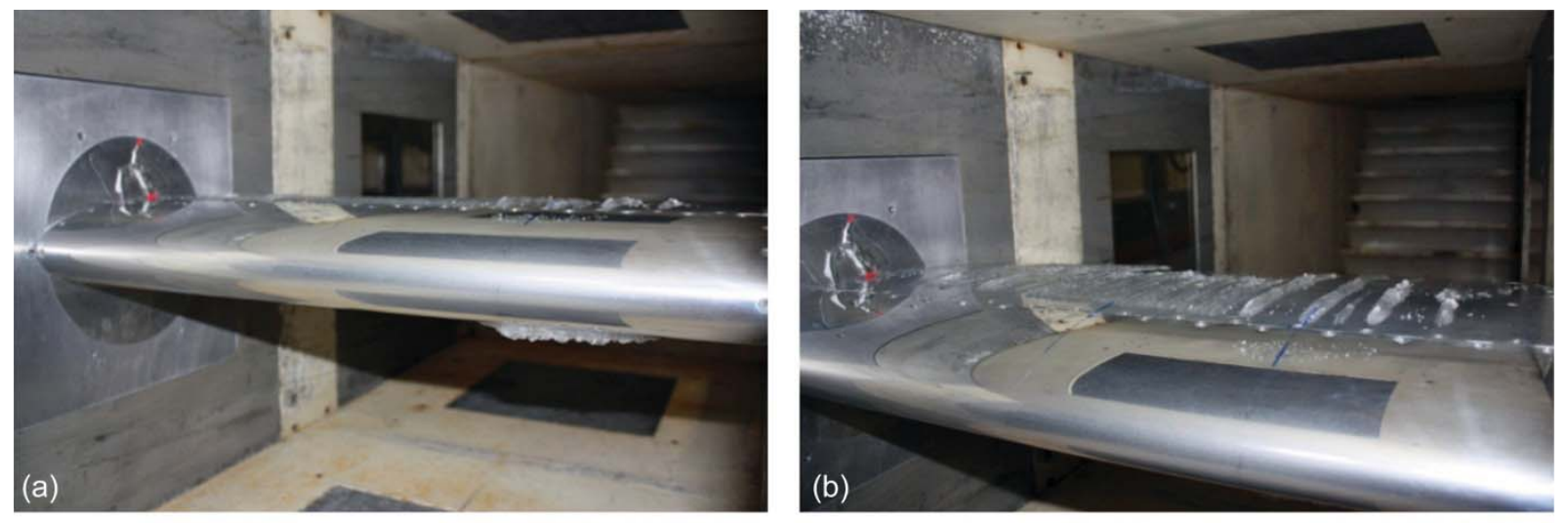

Figure 24.-(a) Warm Hold ice accretion for scale conditions and (b) view of frozen rivulets formed.

TABLE 6.-WARM HOLD CASE-RIDGE ICE RESULTS

\begin{tabular}{|l|c|c|c|c|c|c|c|c|c|c|c|}
\hline Flight phase & $\begin{array}{c}\text { Alt., } \\
\mathrm{ft}\end{array}$ & $\begin{array}{c}V_{\text {tas, }} \\
\mathrm{kn}\end{array}$ & $\begin{array}{c}\mathrm{AOA}, \\
\mathrm{deg}\end{array}$ & $\begin{array}{c}T_{\text {static, }}{ }^{\circ} \mathrm{F} \\
{ }^{\prime}\end{array}$ & $\begin{array}{c}T_{\text {total, }} \\
{ }^{\circ} \mathrm{F}\end{array}$ & $\begin{array}{c}\mathrm{LWC}, \\
\mathrm{g} / \mathrm{m}^{3}\end{array}$ & $\begin{array}{c}\mathrm{MVD}, \\
\mu \mathrm{m}\end{array}$ & $\begin{array}{c}\tau, \\
\mathrm{s}\end{array}$ & $\begin{array}{c}\text { Up ice, } \\
\text { in. }\end{array}$ & $\begin{array}{c}\text { Lo ice, } \\
\text { in. }\end{array}$ & $\begin{array}{c}\text { Ice } \\
\text { mass, } \\
\mathrm{g}\end{array}$ \\
\hline Wm Hld(ref) & 15,000 & 180 & 0 & 16.5 & 24.2 & $\mathbf{0 . 4 8}$ & $\mathbf{1 6 . 6}$ & 420 & 0.48 & 0.51 & 53 \\
Wm Hld(sc) & & 105 & 0 & 20.8 & 23.4 & $\mathbf{0 . 8 7}$ & $\mathbf{2 9 . 9}$ & 420 & ---- & --- & --- \\
\hline
\end{tabular}


The airfoil surface temperature data are given in Figure 25. As in the other cases, surface temperature profiles are the same for the dry conditions and close for the wet conditions with the reference-run temperatures slightly lower $\left(1^{\circ} \mathrm{C}\right.$ or less). Heated air inlet and outlet temperatures as well as the heat energy input for the reference and scale conditions are nearly identical, as shown in Figure 26.

The difficulties associated with successfully accreting and recording runback ridge ice accretions became a major obstacle to obtaining results for use in the study. Therefore, the test plan was changed to instead accrete and record runback rivulet ice accretions as the reference for the Warm Hold case. This was done by raising the heated air inlet temperature by $20^{\circ} \mathrm{F}\left(11.1^{\circ} \mathrm{C}\right)$. While this eliminated ice tracings as a means of recording and comparing test results, the height of the frozen rivulets could still be measured and the ice could still be removed and weighed for comparison purposes.

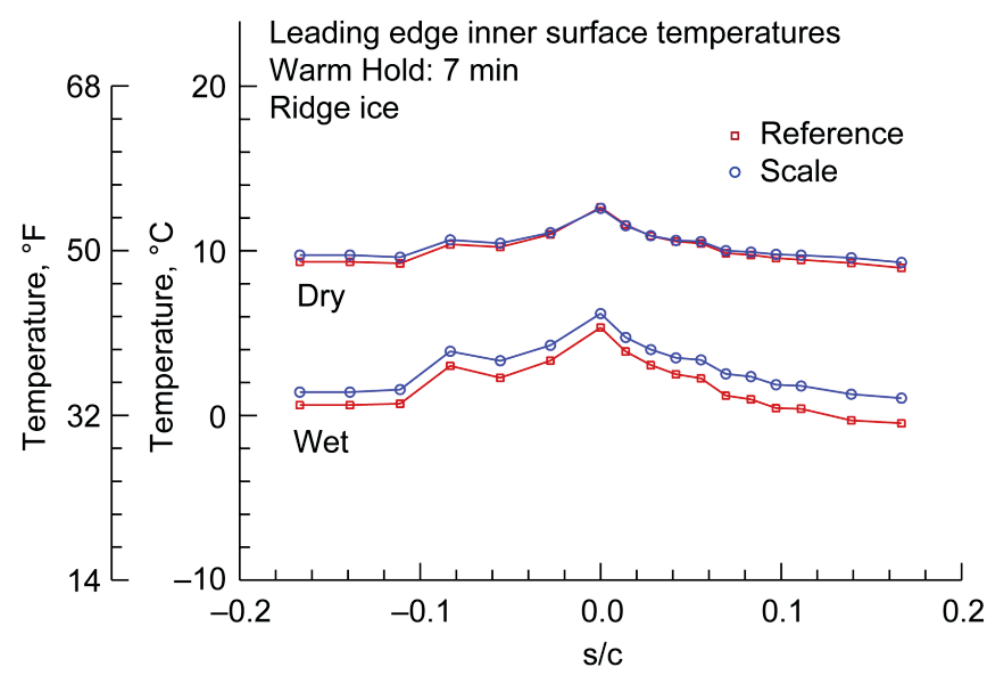

Figure 25.-Warm Hold surface temperatures before and during exposure to icing cloud.
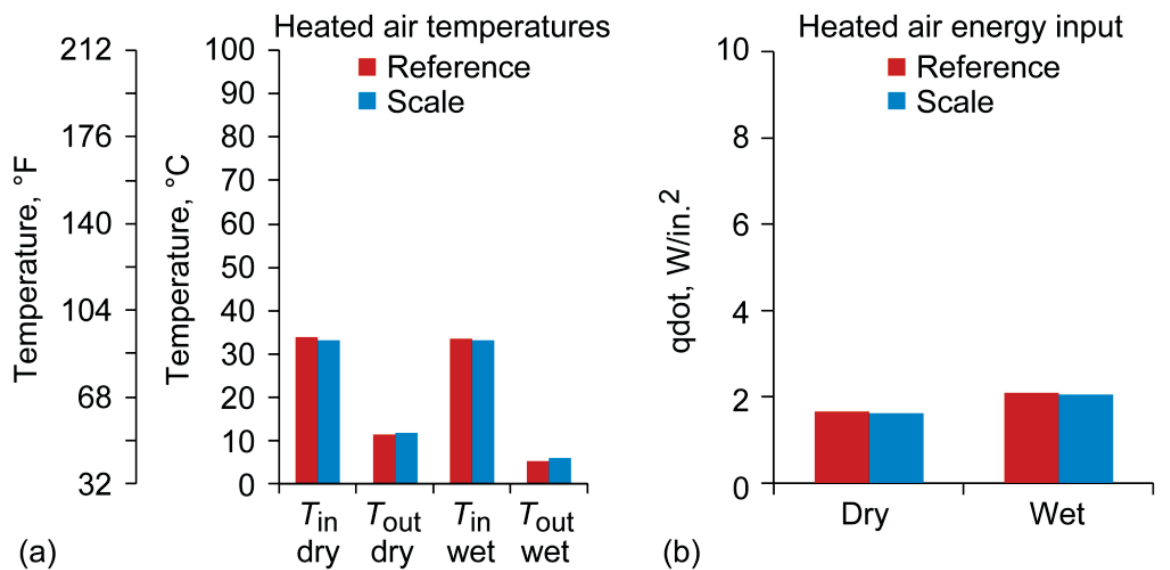

Figure 26.-Warm Hold (a) heated air temperatures and (b) heated air energy input before and during exposure to icing cloud. 
Photographs of the resulting ice from the test runs at the Warm Hold conditions with runback rivulet ice accretions are shown in Figure 27. An examination of the frozen rivulets formed shows that, similar to the cases run with runback ridge ice, more ice accreted at the scale conditions than at the reference conditions. This increase in accreted ice is reflected in the measured ice heights and masses given in Table 7. During close observation of the formation of the frozen rivulets, beads of water were seen running aft along the length of the rivulets and then disappearing. It is suspected that these relatively large beads of water were being re-entrained into the airstream, rather than freezing and adding to the ice mass on the airfoil.

Figure 28 shows the model surface temperatures for this case. They are again close between the reference and scale runs, indicating a close matching of heat transfer between the two. Figures 29(a) and (b) show the heated air data for this case. The close matching between reference and scale conditions also substantiate a matching of heat transfer as well as a reduced level of sensitivity of the IPS operation to deviations in cloud parameters.
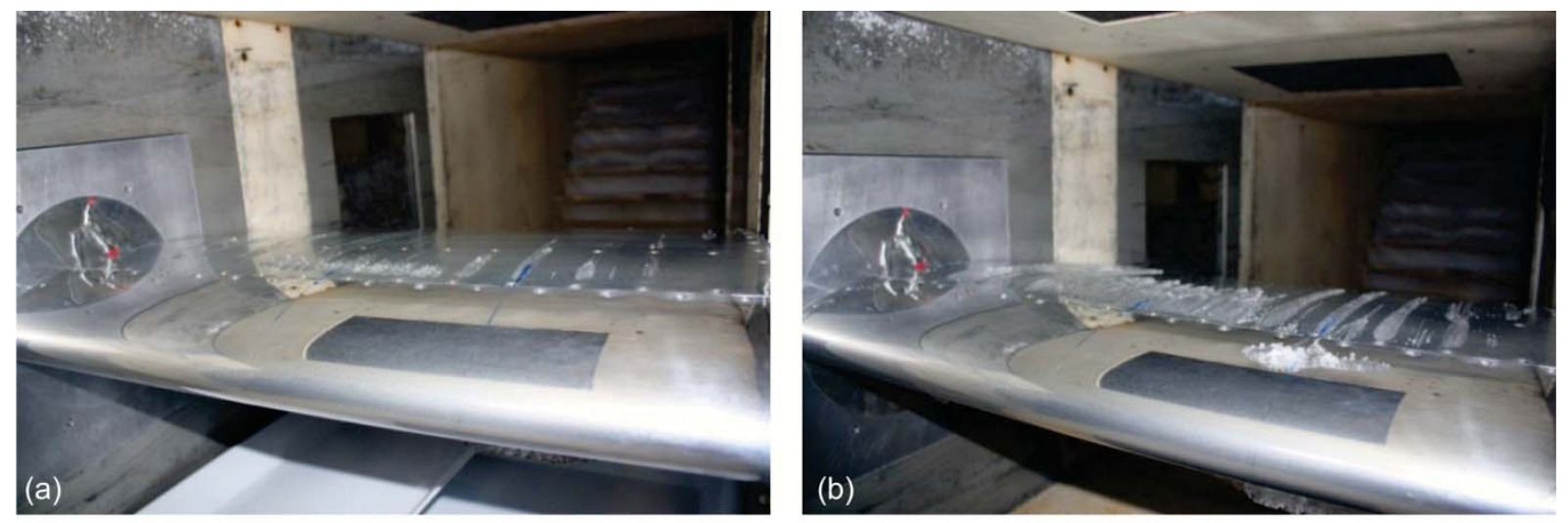

Figure 27.-Warm Hold frozen rivulets for (a) reference and (b) scale conditions.

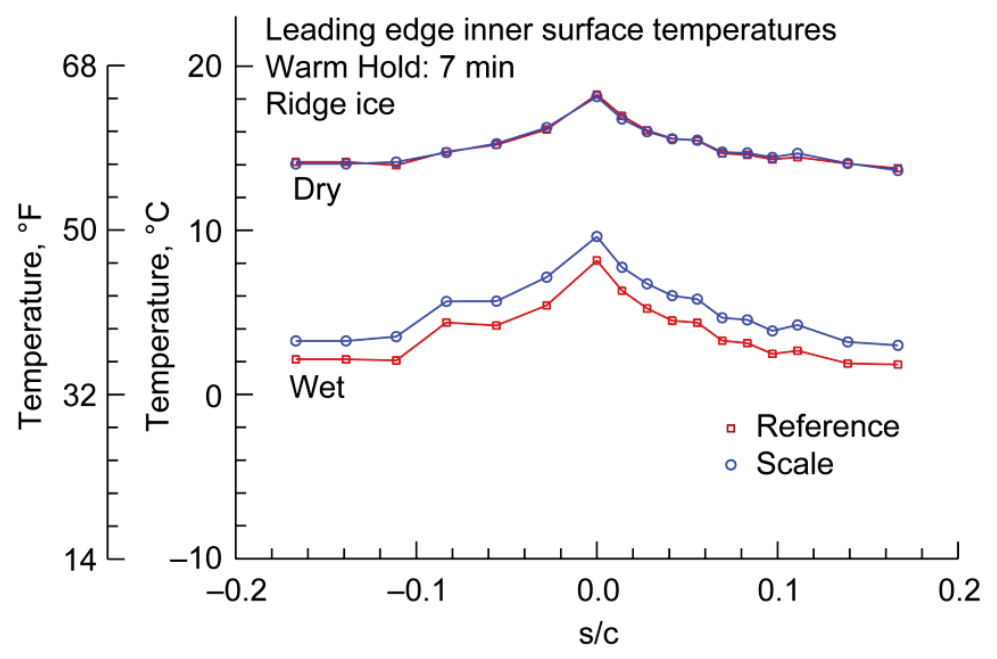

Figure 28.-Warm Hold surface temperatures before and during exposure to icing cloud; frozen rivulet ice. 

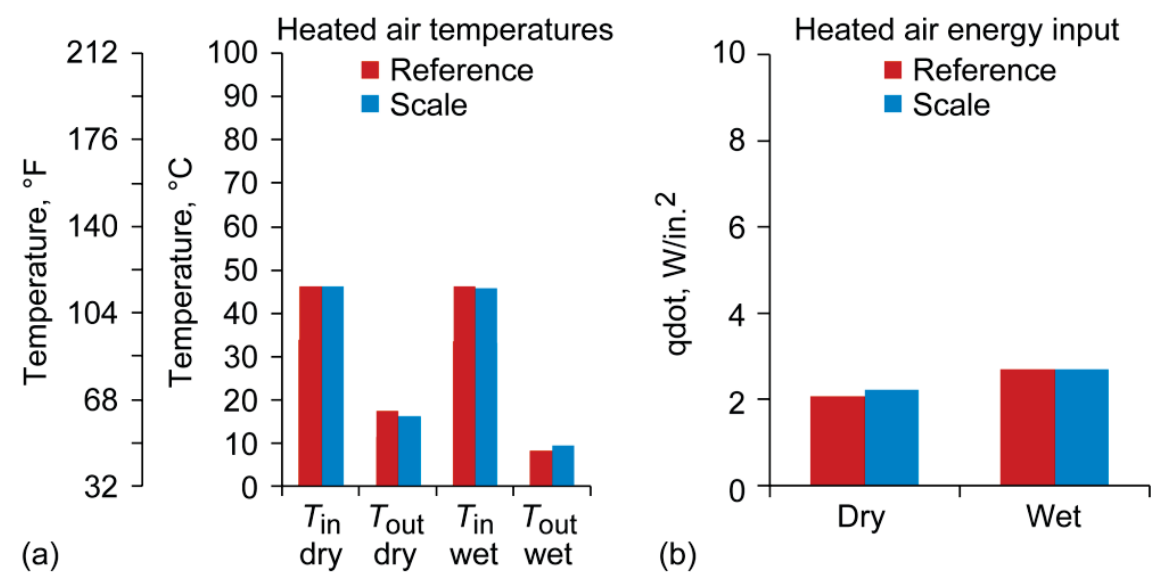

Figure 29.-Warm Hold (a) heated air temperatures and (b) heat energy used.

TABLE 7.-WARM HOLD CASE-FROZEN RIVULET ICE RESULTS

\begin{tabular}{|l|c|c|c|c|c|c|c|c|c|c|c|}
\hline Flight phase & $\begin{array}{c}\text { Alt., } \\
\mathrm{ft}\end{array}$ & $\begin{array}{c}V_{\text {tas, }} \\
\mathrm{kn}\end{array}$ & $\begin{array}{c}\text { AOA, } \\
\mathrm{deg}\end{array}$ & $\begin{array}{c}T_{\text {static, }}{ }^{\circ} \mathrm{F} \\
{ }^{\circ}\end{array}$ & $\begin{array}{c}T_{\text {total, }} \mathrm{F} \\
{ }^{\circ} \mathrm{F}\end{array}$ & $\begin{array}{c}\mathrm{LWC}, \\
\mathrm{g} / \mathrm{m}^{3}\end{array}$ & $\begin{array}{c}\mathrm{MVD}, \\
\mu \mathrm{m}\end{array}$ & $\begin{array}{c}\tau, \\
\mathrm{s}\end{array}$ & $\begin{array}{c}\text { Up ice, } \\
\text { in. }\end{array}$ & $\begin{array}{c}\text { Lo ice, } \\
\text { in. }\end{array}$ & $\begin{array}{c}\text { Ice } \\
\text { mass, } \\
\mathrm{g}\end{array}$ \\
\hline Wm Hld(ref) & 15,000 & 180 & 0 & 16.5 & 24.2 & $\mathbf{0 . 4 8}$ & $\mathbf{1 6 . 3}$ & 420 & 0.08 & 0.09 & 15 \\
Wm Hld(sc) & & 105 & 0 & 20.8 & 23.4 & $\mathbf{0 . 8 7}$ & $\mathbf{2 9 . 8}$ & 420 & 0.13 & 0.12 & 83 \\
\hline
\end{tabular}

\subsection{Discussion}

For all cases, the close matching of the surface temperatures and heated air temperatures and energy use rates between the reference and scale conditions showed that the scaling method works well in matching the heat transfer between altitude and ground level conditions. The fact that there was consistently less ice accreted for the reference conditions than for the corresponding scale conditions, however, suggested that the scaling method does not match mass transfer between altitude and scale conditions. Confounding this observation is the post-test calibration finding that $M_{w}$ was 21.6 to 28.9 percent higher for the scale conditions in each flight-scenario case. In general, the mass of the accreted ice was roughly 80 to 500 percent higher for the scale conditions in each case. The additional ice accreted in the scale conditions cannot be due to the increase in $M_{w}$ unless the ice accretion rate in each case was highly nonlinear, a distinct possibility.

The one exception to mass transfer scaling mismatch is the Cold Hold case. Here ice which shed from the upper surface of the reference conditions precluded a direct comparison of the ice masses between reference and scale. Inspection of the ice tracings, however, indicated that the masses may have been similar had the ice not shed. The additional ice accreted due to the increased $M_{w}$ in the scale conditions would still have placed the ice masses within the margin of error estimated for these measurements. It should further be noted that the ice accreted for this case nearly covered the entire leading edge, thereby reducing the area for evaporation as well as reducing the length of runback for the water. The case rightfully should have been rerun with a higher heated air energy input such that the IPS operated more effectively. As was mentioned earlier, tunnel test time and run priorities prevented a repeat run of this case. One should be cautioned against drawing conclusions from this single case.

All of the Descent and Warm Hold cases with the IPS operating resulted in less ice accreted during runs with the reference conditions than during the runs with scale conditions. This was evident even though ice shedding was a problem for the Descent cases and the Warm Hold cases where runback ridge ice was formed. To further illustrate the ice accretion differences between reference and scale conditions, normalized icing rates for the Descent and Warm Hold conditions are plotted in Figures 30 and 31, respectively. Icing rates, in terms of grams of ice per unit area per unit time, were calculated from the ice 


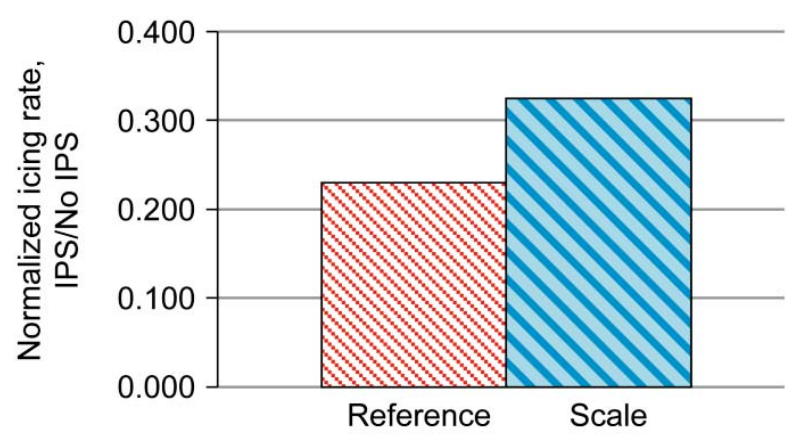

Figure 30.-Normalized icing rates for Descent.

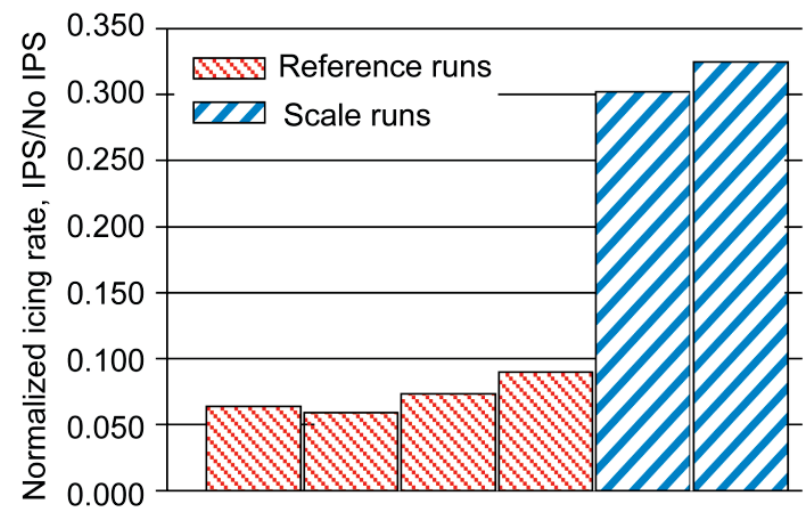

Figure 31.-Normalized icing rates for Warm Hold.

mass measurements, the pertinent impingement area of the airfoil, and the icing exposure time. The normalized values were obtained by dividing the icing rates for the runs with the IPS operating by the rates for the corresponding unprotected runs. Figure 31 shows multiple Warm Hold runs for both reference and scale conditions because the frozen rivulet results proved to be more repeatable than the runback ridge ice results where shedding ice was a frequent occurrence. For both cases, the increase in accreted ice for the scale conditions was greater than the unintended increase in $M_{w}$.

The difference between the reference and scale ice accretions is more pronounced for the Warm Hold case than for the Descent case. It is strongly suspected that a reason for at least part of difference between the Warm Hold and Descent cases is the observation of the runback water droplets on the frozen rivulets which appeared to be re-entrained into the airstream. This phenomenon was not readily noticeable during the Descent cases where only runback ridge ice was formed.

The unintended increase in $M_{w}$ and $K_{0}$ for the scale conditions tested in this study added uncertainty to the results. Those results, nonetheless, strongly suggested that, in order to faithfully simulate the amount of runback ice formed where a running wet IPS is being tested at ground level, another scaling parameter may well need to be considered or an appropriate correction method be employed. Methods used to calculate water evaporation rates should also be examined more closely. The evaporation rates used during prediction of ice accretion on unprotected surfaces are relatively low in comparison to the incoming water, so errors in the evaporation rate calculation are not critical. This is not the case for a thermal IPS that is operating effectively. Here a relatively large portion of the incoming water is evaporating, and thus accurate calculation is more important when determining the amount of runback ice that accumulates.

In cases of aircraft icing where flow of water is known to occur, such as during the accretion of glaze ice on an unprotected surface, the Weber number can be an important factor in scaling icing conditions to obtain ice shape similarity. The flow of water is obviously present in the instance of frozen rivulet icing. Therefore, the inclusion of the Weber number should be considered in future research. 


\subsection{Closing Remarks}

This study was the first documented effort directed specifically toward better understanding the effects of altitude on the heat and mass transfer processes occurring during operation of a thermal IPS. The tests described should be considered an initial step toward providing technology that is essential to the enhancement of aircraft thermal IPSs and, thereby, aviation safety. Further steps in the study of the effects of altitude on IPS performance should include testing in an altitude icing wind tunnel to:

1. Verify initial findings,

2. More firmly establish the existence of water droplet re-entrainment, and investigate methods to quantify it, and

3. Establish methods to determine water evaporation rates.

\section{References}

1. Anderson, D.N., "Manual of Scaling Methods," NASA/CR—2004-212875, 2004.

2. Kind, R.J. and Oleskiw, M.M., "Recent Developments in Scaling Methods for Icing Wind Tunnel Testing at Reduced Scale," ICAS 2002 Congress, 2002.

3. Bartlett, C.S., "An Analytical Study of Icing Similitude for Aircraft Engine Testing," DOT/FAA/CT-86/35; AEDC-TR-86-26, 1986.

4. Newton, J.E., VanFossen, G.J., Poinsatte, P.E., and DeWitt, K.J., "Measurement of Local Convective Heat Transfer Coefficients From a Smooth and Roughened NACA-0012 Airfoil; Flight Test Data," AIAA-88-0287, NASA TM-100284, 1988.

5. Poinsatte, P.E., VanFossen, G.J., and DeWitt, K.J., "Convective Heat Transfer Measurements From a NACA 0012 Airfoil in Flight and in the NASA Lewis Icing Research Tunnel," AIAA-90-0199, NASA TM-102448, 1990.

6. Bragg, M.B., Lee, S., and Henze, C.M., "Heat-Transfer and Freestream Turbulence Measurements for Improvement of the Ice Accretion Physical Model," AIAA-97-0053, 1997.

7. Miller, D., Bond, T., Sheldon, D., Wright, W., Langhals, T., Al-Khalil, K., and Broughton, H., "Validation of NASA Thermal Ice Protection Computer Codes Part 1-Program Overview," AIAA97-0049, NASA TM-107397, 1997.

8. Wright, W.B., Al-Khalil, K.M., and Miller, D.R., "Validation of NASA Thermal Ice Protection Computer Codes: Part 2 - The Validation of LEWICE/Thermal," AIAA-97-0050, 1997.

9. Al-Khalil, K.M., Horvath, C., Wright, and W.B., Miller, D.R., "Validation of NASA Thermal Ice Protection Computer Codes: Part 3 - The Validation of ANTICE," AIAA-97-0051, 1997.

10. Oleskiw, M.M., Hyde, F.H., and Penna, P.J., "In-Flight Icing Simulation Capabilities of NRC's Altitude Icing Wind Tunnel," AIAA-2001-0094, 2001.

11. Wright, W., "User's Manual for LEWICE Version 3.2," NASA/CR—2008-214255, 2008. 

